DENIS TANIGUCHI

\title{
APLICAÇÃO DE TÉCNICAS DE COMPUTAÇÃO PARALELA PARA SIMULAÇÃO DE FLUIDOS COM MÉTODOS DE PARTÍCULAS EXPLÍCITOS
}


DENIS TANIGUCHI

\section{APLICAÇÃO DE TÉCNICAS DE COMPUTAÇÃO PARALELA PARA SIMULAÇÃO DE FLUIDOS COM MÉTODOS DE PARTÍCULAS EXPLÍCITOS}

Tese apresentada à Escola Politécnica da Universidade de São Paulo para obtenção do título de Doutor em Ciências 
DENIS TANIGUCHI

\title{
APLICAÇÃO DE TÉCNICAS DE COMPUTAÇÃO PARALELA PARA SIMULAÇÃO DE FLUIDOS COM MÉTODOS DE PARTÍCULAS EXPLÍCITOS
}

\author{
Tese apresentada à Escola \\ Politécnica da Universidade de São \\ Paulo para obtenção do título de \\ Doutor em Ciências \\ Área de Concentração: \\ Engenharia de Computação e \\ Sistemas Digitais \\ Orientadora: Profa. Dra. Liria \\ Matsumoto Sato
}


Este exemplar foi revisado e corrigido em relação à versão original, sob responsabilidade única do autor e com a anuência de seu orientador.

São Paulo, 04 de abril de 2014.

Assinatura do autor

Assinatura do orientador

Catalogação-na-publicação

Taniguchi, Denis

Aplicação de técnicas de computação paralela para simulação de fluidos com métodos de partículas explícitos / D.

Taniguchi. -- versão corr. -- São Paulo, 2014.

$124 \mathrm{p}$.

Tese (Doutorado) - Escola Politécnica da Universidade de São Paulo. Departamento de Engenharia de Computação e Sistemas Digitais.

1.Programação paralela (Técnicas; Aplicações) 2.3GVC I.Universidade de São Paulo. Escola Politécnica. Departamento de Engenharia de Computação e Sistemas Digitais II.t. 


\section{DEDICATÓRIA}

Dedico este trabalho a meus pais e minha família 


\section{AGRADECIMENTOS}

À Profa. Dra. Liria Matsumoto Sato pela orientação e estímulo a começar e concluir este trabalho.

Aos meus pais por me guiar e preparar para a vida.

À minha esposa pelo estímulo e suporte para conclusão deste trabalho.

Ao meu filho por me fazer rir.

Ao Prof. Dr. Kazuo Nishimoto, Prof. Dr. Cheng Liang Yee e Dr. Márcio Michiharu Tsukamoto pela ajuda no desenvolvimento deste trabalho.

Ao Dr. Humberto Makiyama por cuidar da nossa empresa.

Aos amigos do Tanque de Provas Numérico por toda ajuda. 


\section{RESUMO}

O MPS é um método lagrangeano sem malha para simulação de fluidos, que teve origem para estudos de fluxo incompressíveis com superfície livre. Ele possui diversas vantagens se comparado a métodos convencionais baseados no uso de malha, podendo-se citar como principais a facilidade de representação de interfaces e geometrias complexas, assim como a ausência do termo de convecção nas equações algébricas.

Este trabalho foca na aplicação de métodos de computação paralela para simulações de escoamento utilizando a variante explícita do método MPS, denominado E-MPS. O objetivo é a diminuição do tempo de processamento das simulações, e o aumento da quantidade de partículas, que possibilita a simulação de casos cada vez mais complexos, e o real emprego do método para solução de problemas de engenharia.

O método proposto consiste de dois níveis de paralelismo: um através de uma decomposição de domínio espacial sobre uma arquitetura de memória distribuída, e outra pelo uso de processamento paralelo em uma arquitetura com memória compartilhada, podendo ser pelo uso de dispositivos Graphics Processing Unit (GPU), ou pelo uso de processadores multicore.

Os métodos de decomposição de domínio espacial tratados neste trabalho são o estático, ou não adaptativo, o Orthogonal Recursive Bisection (ORB), o ortogonal e uma nova proposta chamada cell transfer. Dentre os métodos já existentes, o ortogonal se mostrou mais atrativo devido à sua simplicidade, conseguindo manter um melhor nível de balanceamento do que o estático no caso estudado. O novo método cell transfer tenta superar as limitações geométricas dos outros métodos citados, ao levar em consideração a natureza do fluxo.

Uma das grandes contribuições deste trabalho é um novo método genérico de comunicação entre subdomínios, que evita a reordenação das partículas, e serve para todos os métodos de decomposição investigadas neste trabalho. 


\begin{abstract}
MPS is a meshless lagrangian method for computational fluid dynamics that was created to study incompressible free surface flows and has many advantages compared to traditional mesh based methods, such as the ability to represent complex geometries, interface problems, and the absence of the advection term in the algebraic equations.

This work focus on the use of parallel computing methods for fluid dynamic simulation, and more specifically, on the explicit variant of the MPS method, namely E-MPS, to decrease the amount of processing needed to perform a simulation and increase the number of particles, which enables the simulation of real and complex engineering problems.

The proposed method is composed of two levels of parallelism: a distributed memory parallelism based on spatial domain decomposition, and a shared memory parallelism, using either GPU or multicore CPUs, for fast computation of each subdomain.

Static non-adaptive, ORB, orthogonal, and cell transfer spatial decomposition methods are subject of investigations in this work, the latter being originally proposed by this work to overcome the drawbacks found in most of the methods found in the literature. Among the already proposed methods the more attractive was the orthogonal, due to its simplicity, and capability of maintaining a good load balance in the test case. The new cell transfer method was proposed to overcome the geometrical limitations found in all the above methods, by considering the flux while balancing the load among subdomains.

One of the main contributions of this work is a new method for the communication of subdomains, which avoids additional sorting steps, and proved to be generic for all the decomposition methods investigated.
\end{abstract}




\section{GLOSSÁRIO}

\begin{tabular}{|c|c|}
\hline Vetor & $\begin{array}{l}\text { Área contínua de memória utilizada para armazenagem de } \\
\text { dados. É escrito em itálico para diferenciar do vetor } \\
\text { matemático. }\end{array}$ \\
\hline $\begin{array}{l}\text { Decomposição } \\
\text { de domínio }\end{array}$ & $\begin{array}{l}\text { Divisão do domínio de simulação em um número finito de } \\
\text { subdomínios para permitir a computação paralela de cada um } \\
\text { deles. Neste trabalho tem significado apenas espacial não } \\
\text { afetando as equações algébricas. }\end{array}$ \\
\hline $\begin{array}{l}\text { Padrão de } \\
\text { acesso }\end{array}$ & $\begin{array}{l}\text { Dada uma partícula, refere-se ao critério utilizando na } \\
\text { determinação do conjunto de partículas que influenciam no } \\
\text { cálculo das suas grandezas. }\end{array}$ \\
\hline $\begin{array}{l}\text { Comunicação } \\
\text { all-to-all }\end{array}$ & $\begin{array}{l}\text { Padrão de comunicação onde cada processo se comunica } \\
\text { com todos os outros processos participantes. }\end{array}$ \\
\hline
\end{tabular}




\section{LISTA DE FIGURAS}

Figura 1 - Sequência de imagens de uma simulação utilizando-se um método de partículas.

Figura 2 - Exemplo de divisão do domínio utilizando-se o método ORB (extraído

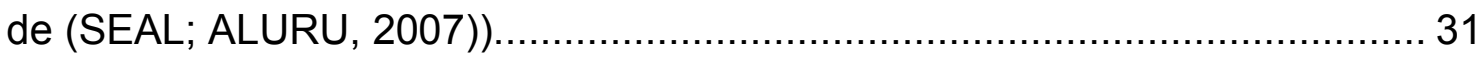

Figura 3 - Dois tipos de curvas utilizadas no método SFC: Curva Z e Curva de Hilbert (extraído de (SEAL; ALURU, 2007)) ……........................................... 32

Figura 4 - Exemplo de ordenação dos pontos utilizando-se uma Curva Z....... 33

Figura 5 - Exemplo de uma Octree (extraído de (SEAL; ALURU, 2007))......... 34

Figura 6 - Fluxograma do método E-MPS................................................ 42

Figura 7 - Malha estruturada auxiliar com células de tamanho $h=1$................ 44

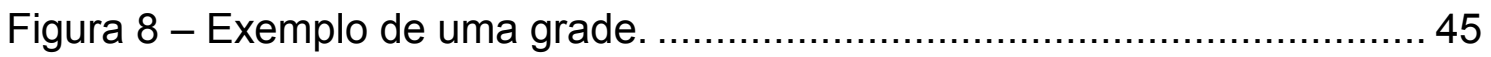

Figura 9 - Processo de ordenação das partículas na subgrade. .................... 48

Figura 10 - Exemplo de um processo de busca de vizinhos. ........................ 50

Figura 11 - Caso em que o tamanho da célula é exatamente o raio de influência (as células vizinhas de $A$ são destacadas em cinza)..................................... 52

Figura 12 - Tamanho de célula maior que o raio de influência........................ 53

Figura 13 - Fluxograma do método E-MPS com controle de ordenação.......... 53

Figura 14 - Dois subdomínios vizinhos com partículas não ordenadas............ 58

Figura 15 - Processo de ordenação utilizando o AABB estendido de cada

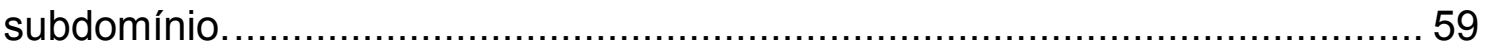

Figura 16 - Determinação das células receptoras do subdomínio A, destacadas em laranja, e transmissoras, destacadas em verde. ..................................... 60

Figura 17 - Processo de transmissão das partículas de borda. ...................... 61

Figura 18 - Fluxograma do método E-MPS com comunicação entre subdomínios.

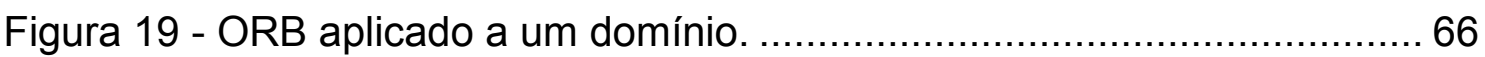

Figura 20 - Representação da bisseção do domínio em forma de árvore binária.

Figura 21 - Determinação do subdomínio de cada processo. ........................ 69

Figura 22 - Comunicação necessária ao se recalcular a mediana do nó raiz. . 70 Figura 23 - Fluxograma do método E-MPS paralelo para o método ORB. ...... 71

Figura 24 - Fluxograma da métrica de balanceamento do método ORB. ........ 72

Figura 25 - Fluxograma do balanceamento de carga do método ORB. ........... 72

Figura 26 - Divisão dos subdomínios em dois instantes de simulação utilizando-

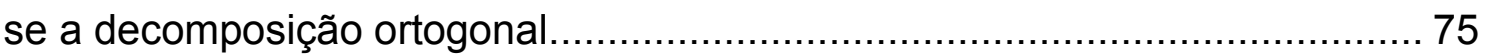

Figura 27 - Subprocesso de balanceamento de carga do método ortogonal. .. 76 Figura 28 - Fluxograma da busca de vizinhos para o método Cell Transfer. ... 81 Figura 29 - Exemplo de um caso de dam break tridimensional....................... 97

Figura 30 - Caso de dam break tridimensional utilizando decomposição de domínio estático com 8 subdomínios. O volume do fluido é representado em cinza, e as linhas tracejadas são o planos que dividem os subdomínios....... 100 
Figura 31 - Porcentagem de tempo gasto em um passo temporal em ordenação, cálculo e comunicação com a variação do número de processos.................. 100 Figura 32 - Escalabilidade ao se aumentar a quantidade de processos MPI. 101 Figura 33 - Caso de dam break 3D utilizado para comparação de desempenho entre os métodos estático e ortogonal. 102 Figura 34 - Comparação do tempo de processamento de um passo temporal.

Figura 35 - Gráfico do ganho de desempenho do método ortogonal frente ao estático. 103

Figura 36 - Gráfico do nível de desbalanceamento entre os subdomínios para os casos em que se utilizou o método de decomposição estático. 104 Figura 37 - Gráfico do nível de desbalanceamento entre os subdomínios para os casos em que se utilizou o método de decomposição ortogonal. 104 Figura 38 - Tempo de processamento em CUDA de um passo temporal, variando-se o tamanho das células .................................................... 106 Figura 39 - Ganho de desempenho em CUDA com diferentes tamanhos de célula. 107

Figura 40 - Ganho de desempenho em CUDA na ordenação com diferentes tamanhos de célula. 107

Figura 41 - Perda de desempenho em CUDA no cálculo das variáveis ponderadas pela função peso com diferentes tamanhos de célula. 108 Figura 42 - Proporção entre os custos computacionais de ordenação e cálculo das variáveis ponderadas pela função peso para o caso CUDA.................... 108 Figura 43 - Tempo de processamento em OpenMP de um passo temporal, variando-se o tamanho das células. 109 Figura 44 - Ganho de desempenho em OpenMP com diferentes tamanhos de célula. 109

Figura 45 - Ganho de desempenho em OpenMP na ordenação com diferentes tamanhos de célula. 110 Figura 46 - Perda de desempenho em OpenMP no cálculo das variáveis ponderadas pela função peso com diferentes tamanhos de célula. 110 Figura 47 - Proporção entre os custos computacionais de ordenação e cálculo das variáveis ponderadas pela função peso para o caso OpenMP...............111

Figura 48 - Geometria do caso com 500 mil partículas. 123

Figura 49 - Geometria do caso com 700 mil partículas. 123

Figura 50 - Geometria do caso com 1 milhão de partículas. 124 


\section{LISTA DE TABELAS}

Tabela 1 - Posição e índice linearizado da célula das partículas ordenadas. . 48 Tabela 2 - Posição e índice linearizado da célula das partículas não ordenadas.

Tabela 3 - Índices de início e fim de cada célula no vetor de partículas

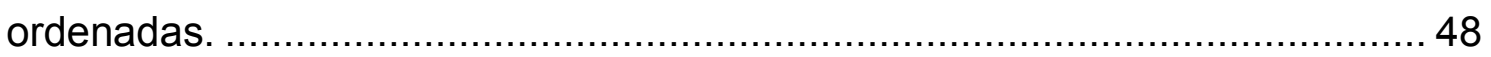

Tabela 4 - Células não vazias que contêm partículas vizinhas da partícula 9. 50 Tabela 5 - Posição e índice linearizado da célula das partículas vizinhas da partícula 9 ..... 50

Tabela 6 - Posição e índice linearizado da célula das partículas não ordenadas do subdomínio $A$. 59

Tabela 7 - Posição e índice linearizado da célula das partículas ordenadas do subdomínio $A$. 59

Tabela 8 - Índices de início e fim de cada célula no vetor de partículas ordenadas do subdomínio $A$.

Tabela 9 - Posição e índice linearizado da célula das partículas não ordenadas do subdomínio $B$.

Tabela 10 - Posição e índice linearizado da célula das partículas ordenadas do subdomínio $\mathrm{B}$. 59

Tabela 11 - Índices de início e fim de cada célula no vetor de partículas ordenadas do subdomínio $B$

Tabela 12 - Índice de início e fim da célula do vetor de partículas do subdomínio A, com destaque às células receptoras com seus valores já atualizados.

Tabela 13 - Índice de início e fim do vetor de partículas de borda a serem transmitidas de B para A.

Tabela 14 - Posição e índice linearizado da célula das partículas do subdomínio $A$, com destaque às partículas recebidas de $B$.

Tabela 15 - Posição das partículas de borda a serem transmitidas de B para A.

Tabela 16 - Índices de início e fim do vetor de partículas do subdomínio B, com células transmissoras em destaque.

Tabela 17 - Posição e índice linearizado da célula das partículas do subdomínio $\mathrm{B}$, com partículas residentes nas células transmissoras em destaque. ...........61 61

Tabela 18 - Semântica de cada tag do arquivo de descrição de caso. ............. 85

Tabela 19 - Configuração do cluster GPU..................................................... 98

Tabela 20 - Configuração do cluster CPU.................................................. 98

Tabela 21 - Tempo médio para computação de um passo temporal (em segundos).... 


\section{SUMÁRIO}

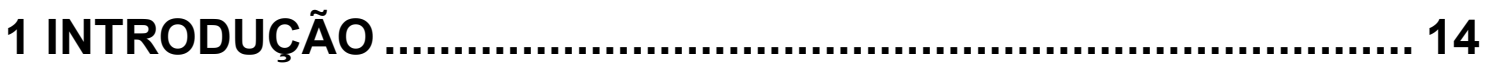

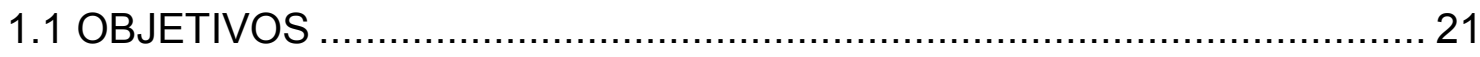

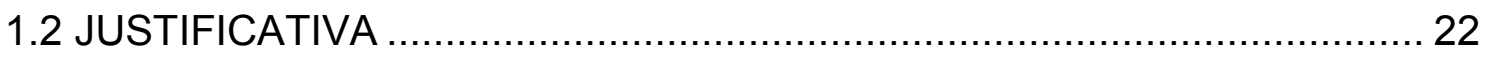

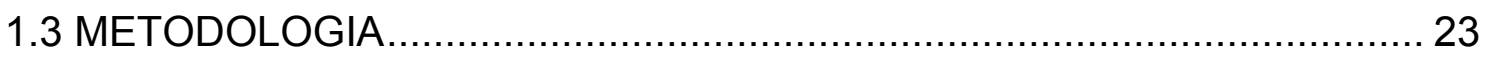

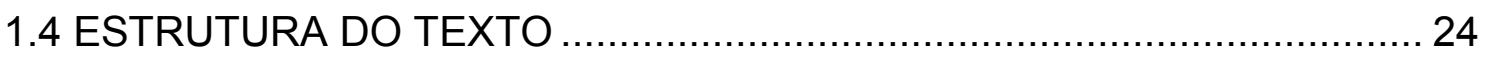

2 CONCEITOS, MÉTODOS EM CFD, E APLICAÇÃO DE

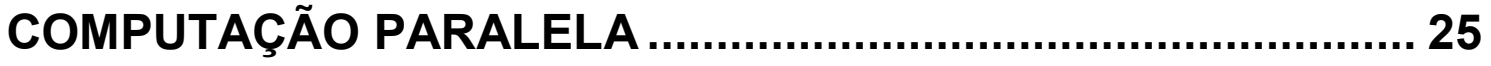

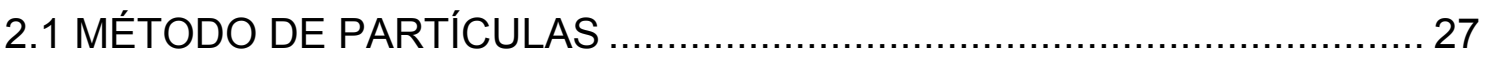

2.1.1 Smoothed Particle Hydrodynamics (SPH) ........................................ 27

2.1.2 Moving Particle Simulation (MPS)..................................................... 28

2.2 COMPUTAÇÃO PARALELA APLICADA AOS MÉTODOS DE PARTÍCULAS 28

2.2.1 Decomposição de Domínio ................................................................ 30

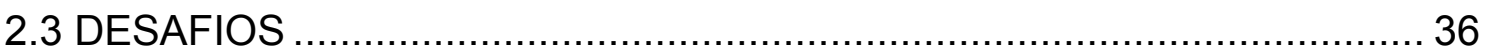

3 MÉTODO DE PARTÍCULAS E-MPS ..................................... 40

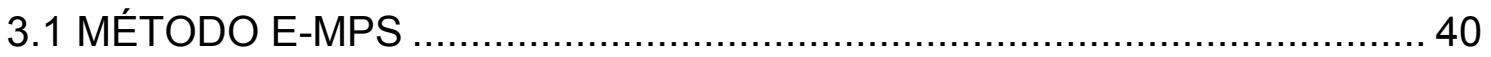

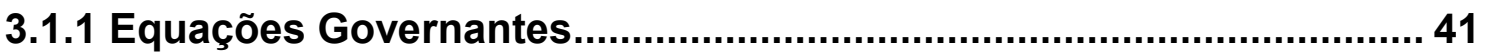

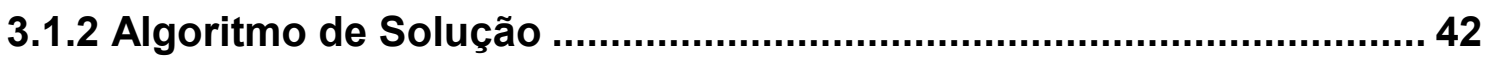

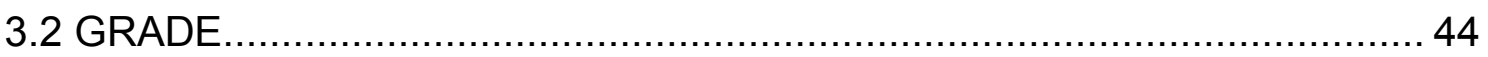

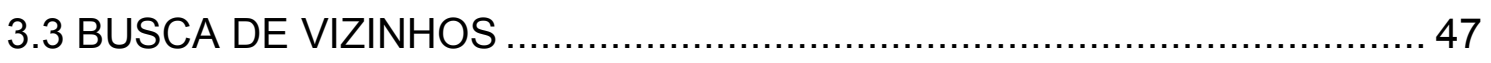

3.3.1 Minimização do Número de Buscas .................................................. 51

4 COMPUTAÇÃO PARALELA DO MÉTODO E-MPS .................. 55

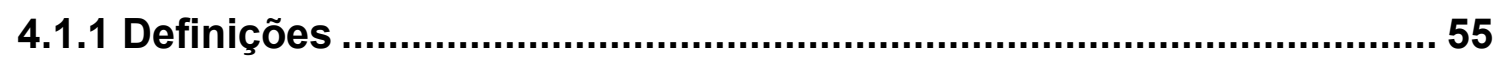

4.1.2 Axis Aligned Bounding Box (AABB) ……...................................... 56

4.1.3 Comunicação entre Subdomínios.................................................. 57

4.1.4 Método de Decomposição Estático ………….................................... 65

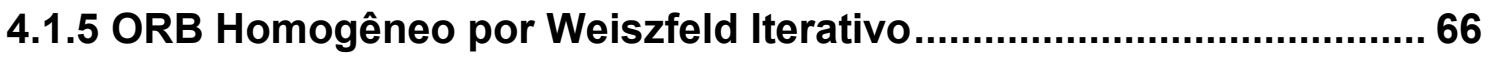

4.1.6 Método de Decomposição Ortogonal ............................................... 74

4.1.7 Método de Decomposição Cell Transfer ............................................. 78

5 IMPLEMENTAÇÃO ............................................................ 82 
5.1 AMBIENTE DE DESENVOLVIMENTO ........................................... 83

5.2 ARQUIVO DE DESCRIÇÃO DO CASO ............................................ 84

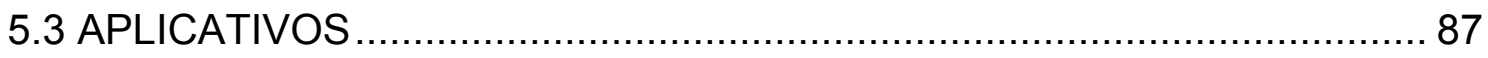

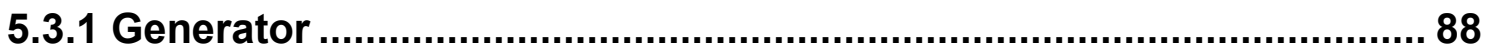

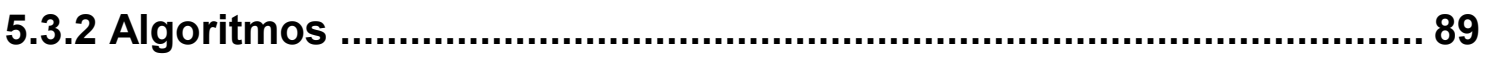

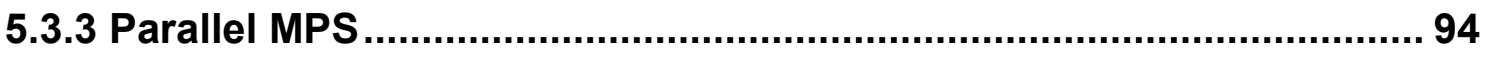

6 APLICAÇÃO E RESULTADOS ........................................... 96

6.1 MÉTODO DE DECOMPOSIÇÃO DE DOMÍNIO ESTÁTICO.................... 97

6.2 MÉTODO DE DECOMPOSIÇÃO DE DOMÍNIO ORTOGONAL................ 102

6.3 MINIMIZAÇÃO DO NÚMERO DE BUSCAS DE VIZINHOS ..................... 105

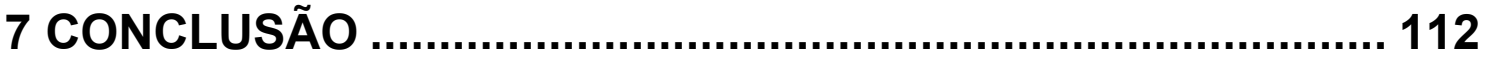

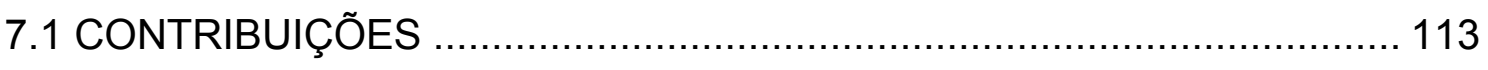

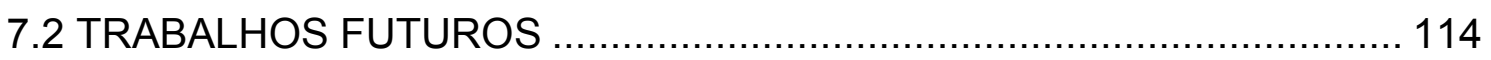

REFERÊNCIAS ............................................................... 116

APÊNDICE A - EXEMPLO DE UM ARQUIVO DE DESCRIÇÃO DE CASO (DAM BREAK BIDIMENSIONAL) ............................... 119 APÊNDICE B - GEOMETRIA DOS CASOS PARA AVERIGUAÇÃO DO IMPACTO DO TAMANHO DAS CÉLULAS ......................... 123 


\section{INTRODUÇÃO}

Simuladores são ferramentas que reproduzem alguma situação de interesse do mundo real em um ambiente controlado. A sua utilização é justificada nos casos em que a reprodução da situação no mundo real envolve altos custos ou riscos. Por exemplo, a alocação de um maquinário para treinamento de um operador pode muitas vezes comprometer o fluxo da produção, além de gerar riscos de quebra do mesmo ou de falha de segurança devido à falta de experiência do operador. Estudos de vários tipos de fenômenos físicos são feitos através de simuladores, o que muitas vezes dispensa a execução de experimentos físicos que podem incorrer em altos custos.

Computadores são amplamente utilizados em simuladores, e pode-se dizer que o rápido desenvolvimento do primeiro foi, em grande parte, impulsionado pelas necessidades computacionais do segundo. Atualmente, os sistemas de simulação inevitavelmente incluem algum sistema computacional que é responsável por reproduzir a situação de interesse baseado em algum modelo numérico. Este deve ser capaz de captar as principais idiossincrasias do fenômeno estudado a partir de cálculos matemáticos que são efetuados utilizando-se o computador. Ele inclui dessa maneira o equacionamento do fenômeno em termos de parâmetros e funções matemáticas, assim como os métodos numéricos que permitem que os cálculos sejam efetuados no computador.

A simulação da dinâmica de fluidos, conhecida como Computational Fluid Dynamics (CFD), é um ramo extremamente ativo da área de simulação que tem como objetivo estudar fenômenos relacionados aos mais diversos tipos de escoamentos. Resgata o embasamento matemático para representação de diversos tipos de fenômenos da área da dinâmica dos fluidos, e a teoria que possibilita o uso do computador para realização dos cálculos da área de métodos numéricos. Vários métodos foram desenvolvidos nessa área, sendo de particular interesse desse trabalho os métodos de partículas ${ }^{1}$, nos quais o contínuo do fluido é representado por um número finito de partículas móveis, cada uma representanda um ponto de interpolação para cálculo das propriedades do fluido.

\footnotetext{
${ }^{1}$ particle methods
} 
Um exemplo de simulação utilizando um método de partículas é mostrado na Figura 1.

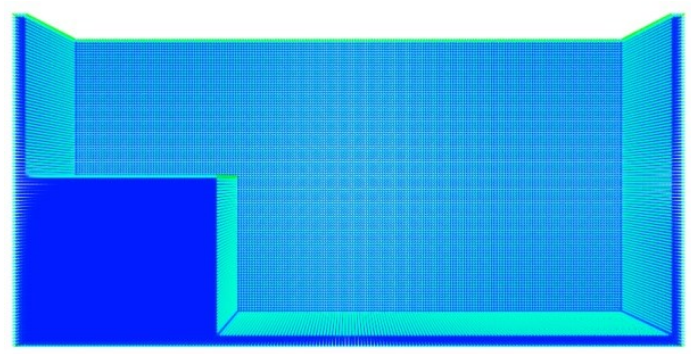

1

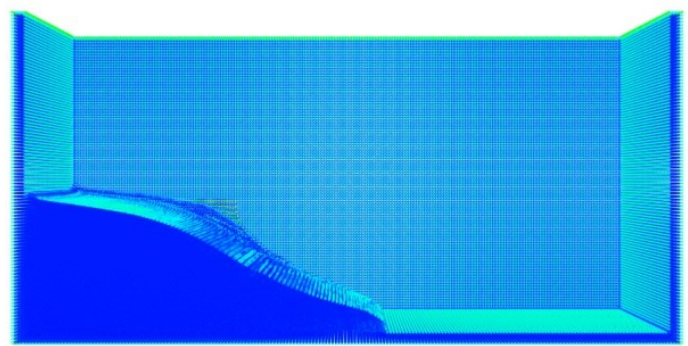

3

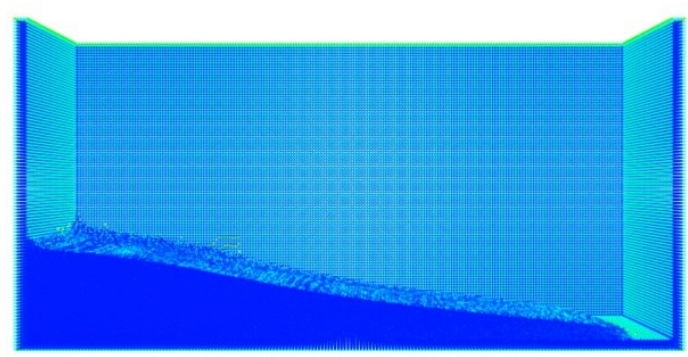

5

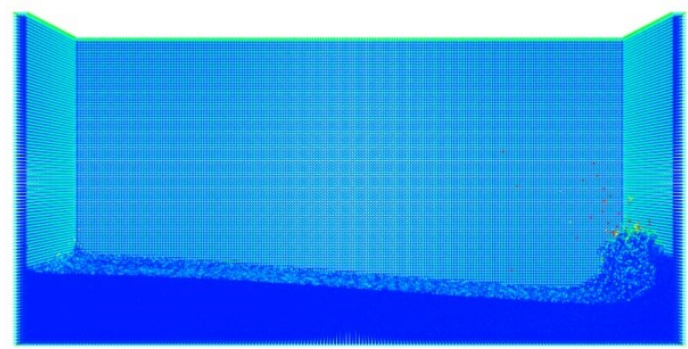

7

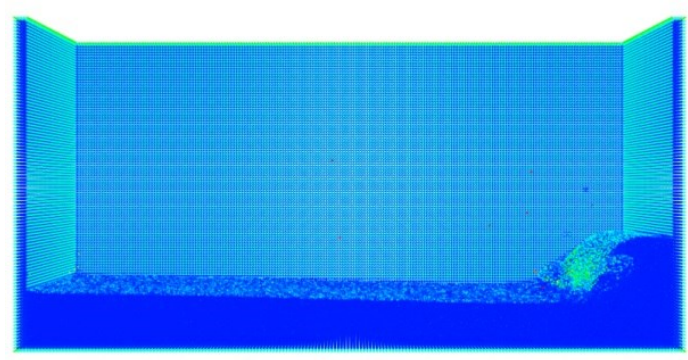

9

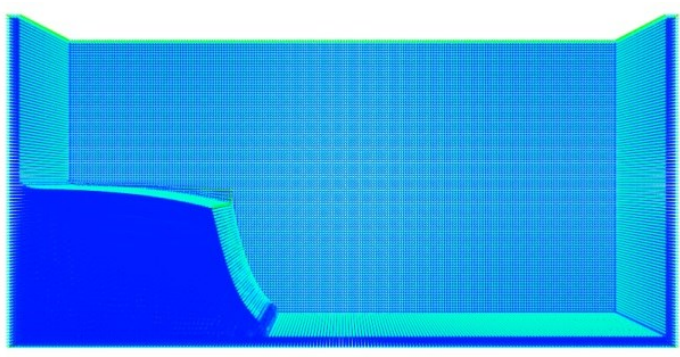

2

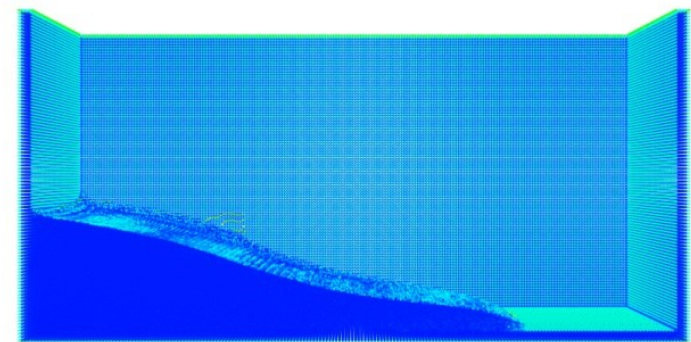

4

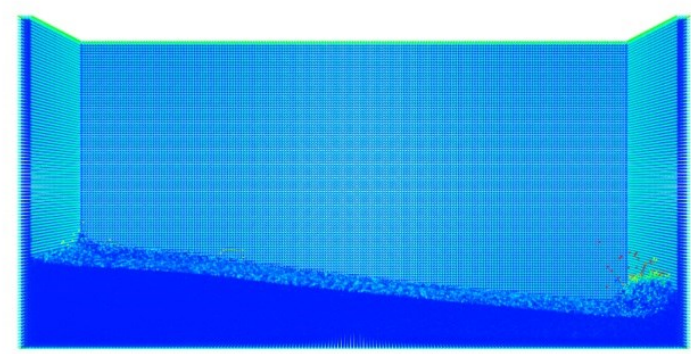

6

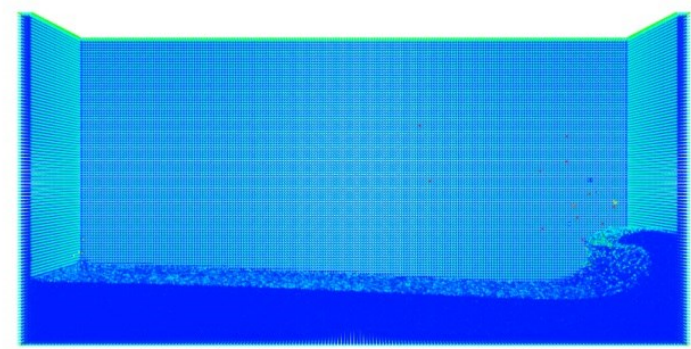

8

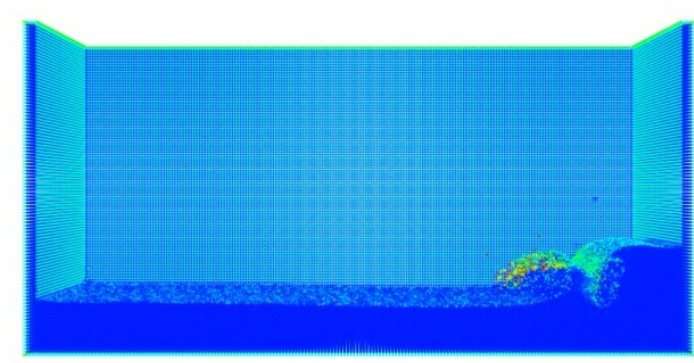

10

Figura 1 - Sequência de imagens de uma simulação utilizando-se um método de partículas. 
Vários métodos foram desenvolvidos aplicando-se essa metodologia, como o Smoothed Particle Hydrodynamics (SPH) e o Moving Particle SemiImplicit (MPS). Uma característica comum desses métodos é o fato dos cálculos das propriedades dos fluidos de uma partícula serem baseados na interpolação das propriedades das partículas vizinhas. Considerando que em casos de estudos tridimensionais alcançam-se facilmente simulações com dezenas de milhões de partículas com cada partícula possuindo 200 partículas vizinhas em média, pode-se dizer que os métodos possuem uma alta demanda computacional.

Uma variação existente tanto no método SPH como no MPS é a garantia da incompressibilidade do fluxo. Essa garantia incorre no aparecimento de um passo implícito nos cálculos, que consiste em solucionar um sistema linear. Métodos puramente explícitos não garantem a incompressibilidade do fluxo. Em contrapartida parâmetros são ajustados de modo que o fluido adquira uma característica pouco compressível.

Esta tese foca as questões computacionais, mais especificamente na aplicação de técnicas de computação paralela, dos métodos de partículas lagrangeanos sem malhas e explícitos, tendo como caso de estudo o método Explicit Moving Particle Simulation (E-MPS). Métodos puramente explícitos se adequam melhor à computação paralela pois não incorrem na solução de sistemas lineares.

Com o desenvolvimento desse trabalho espera-se que o domínio de aplicações para os métodos de partículas lagrangeanos explícitos sejam ampliados em decorrência do aumento do número de partículas capazes de compor uma simulação. Isso causaria uma maior demanda de processamento que poderia ser provida pela aplicação da computação paralela.

Diversas áreas da ciência possuem problemas que, devido à complexidade, não possuem solução analítica. A dinâmica dos fluidos é uma dessas áreas que conta com uma forte atuação da comunidade de computação paralela científica para propor novos métodos que possam melhorar a qualidade dos resultados e estender os campos de aplicação. A computação paralela é essencial neste caso para garantir que os tempos de computação estejam em níveis praticáveis. 
Dado um determinado fenômeno físico de interesse, como por exemplo o fluxo incompressível de um fluido com superfície livre, define-se as suas equações governantes, que são compostas de equações diferenciais parciais, e nelas se aplica um determinado esquema de discretização.

O termo "decomposição de domínio" é comumente utilizado para se referir ao artifício de se dividir o domínio do problema em um número finito de subdomínios. Isso pode se dar tanto no nível contínuo, aplicando-se diferentes modelos matemáticos em cada subdomínio, no nível discreto, através de diferentes métodos de aproximação, ou no nível da solução dos sistemas lineares das equações algébricas advindos da discretização das equações governantes. Neste último, os métodos de decomposição de domínio servem como um precondicionador que diminui o número de iterações necessárias para solução do sistema linear.

Neste trabalho, o termo "decomposição de domínio" é utilizado para se referir ao artifício de se dividir espacialmente o domínio de simulação em subdomínios com objetivo de se paralelizar o processamento da simulação, o que significa que não há impacto nas equações governantes ou no método de discretização.

A utilização de técnicas de decomposição de domínio exige cuidados especiais com relação a dois aspectos: comunicação e balanceamento de carga. A divisão do domínio invariavelmente incorre na troca de informações entre processos, mas é importante que ela seja minimizada de modo que o paralelismo não seja prejudicado, e consiga ter uma boa escalabilidade frente ao aumento da granularidade da divisão e do número de processos participantes.

O balanceamento de carga é essencial para manter o nível de carga computacional entre os processos equilibrados mantendo assim todos os recursos de processamento ocupados durante a maior parte do tempo. É importante, no entanto, que as operações envolvidas no balanceamento sejam de custo computacional baixo em relação ao custo de processamento de um passo temporal, sendo que o mesmo princípio se aplica para os custos de comunicação. Vale salientar que existe uma forte interdependência entre balanceamento de carga e decomposição de domínio, de modo que o algoritmo do primeiro depende inteiramente do método escolhido para o segundo. 
Um computador paralelo é aquele que contém diversos processadores que são capazes de trabalhar em conjunto na solução de um problema computacional. A computação paralela é a área de estudo que foca 0 desenvolvimento de computadores paralelos e seu uso efetivo, de modo que se maximize a execução paralela, o qual pode ser alcançado por meio da adequação do software à arquitetura de hardware.

$\mathrm{Na}$ história da computação, diversos computadores paralelos foram desenvolvidos apresentando diferentes arquiteturas. Uma classificação comumente utilizada para classificar as diferentes arquiteturas paralelas é a taxonomia de Flynn. Considerando-se um conjunto de unidades de processamento capazes de executar instruções de maneira concorrente, a classificação enumera as possíveis maneiras de distribuição dos dados e instruções para cada uma delas da seguinte forma:

- Single Instruction, Multiple Data (SIMD) - é capaz de executar a mesma instrução em um grupo de dados distintos.

- Multiple Instruction, Multiple Data (MIMD) - são aquelas capazes de executar diferentes instruções em diferentes conjuntos de dados concorrentemente.

- Single Instruction, Single Data (SISD) - caracteriza um computador puramente sequencial.

- Multiple Instruction, Single Data (MISD) - possui poucas aplicações práticas em termos de computação de alto desempenho, e é geralmente utilizada para se obter redundâncias em sistemas intolerantes a falhas.

São exemplos da arquitetura SIMD as instruções Streaming SIMD Extensions (SSE) da arquitetura x86, assim como os Graphics Processing Units (GPU). Clusters, conjunto de computadores interligados por uma infraestrutura de comunicação e que possui memórias independentes (sistema de memória distribuída), são exemplos da arquitetura MIMD, sendo esta a mais utilizada na área de computação científica atualmente. $O$ advento dos clusters pode ser visto como um processo natural de evolução dentro da computação paralela, no qual perduram aqueles sistemas que provêm a melhor relação entre desempenho computacional e custo. 
Com o desenvolvimento de tecnologias de comunicação de dados mais rápidas e baratas, e com a redução de custo dos computadores graças ao mercado de computadores pessoais, clusters foram tomando rapidamente 0 lugar dos supercomputadores. A sua popularização foi também acompanhada pelo desenvolvimento de infraestruturas de software, como o Message Passing Interface (MPI) e Parallel Virtual Machine (PVM), capazes de lidar com sistemas de memória distribuída.

O MPI é uma especificação de biblioteca para passagem de mensagens entre processos que forma um padrão, permitindo que diferentes implementações sejam criadas, e tornando a infraestrutura de comunicação transparente para o usuário. Assim, um software paralelo que adota o MPI pode se beneficiar de diferentes camadas físicas de comunicação, como por exemplo, Gigabit Ethernet ou Infiniband, sem a necessidade de se alterar o código fonte.

Outro advento importante da computação paralela foi o surgimento de processadores multicore que possuem mais de um núcleo de processamento, e caracterizam uma arquitetura MIMD com memória compartilhada. Cada núcleo pode executar processos com instruções diferentes em espaços distintos da memória compartilhada.

Uma ferramenta muito utilizada para se aproveitar os múltiplos núcleos é - OpenMP, que através de diretivas especiais de compilação, consegue paralelizar trechos específicos do código sem a necessidade do programador lidar com detalhes relacionados à criação de novos processos pelo sistema operacional.

Embora seja predominante o uso de clusters em computação de alto desempenho, atualmente a utilização de processadores GPU se tornou bastante comum, fato decorrente do seu alto grau de paralelismo, da sua melhor relação GFLOPS/dólar frente aos processadores convencionais, e do desenvolvimento de frameworks que possibilitam a programação nessa arquitetura.

A GPU é a unidade central de processamento das placas gráficas, especializadas na geração de imagens. O seu desenvolvimento foi impulsionado pela demanda do mercado de $\mathrm{CAD} / \mathrm{CAM}^{2}$ e de jogos eletrônicos, que necessitavam de dispositivos capazes de gerar imagens de maneira rápida.

\footnotetext{
${ }^{2}$ Computer-Aided Design e Computer-Aided Manufacturing
} 
Projetistas queriam observar cada vez mais detalhes da planta de produção que geravam mais polígonos que deveriam ser mostrados na tela do monitor.

O mercado de jogos eletrônicos exigia cada vez mais detalhes do personagem e do ambiente em sua volta, com efeitos de luz, sombra e materiais cada vez mais rebuscados, que demandava mais processamento para geração de cada pixel. A frequência de geração de imagens para que uma sequência de imagens seja percebida de modo contínuo para o olho humano é de aproximadamente $30 \mathrm{hz}$. Portanto, a GPU deve ser capaz de gerar ao menos uma imagem completa a cada $30 \mathrm{~ms}$, e para tanto a arquitetura dos dispositivos gráficos recorreu ao paralelismo.

Inicialmente dividiu-se o problema em duas partes: a primeira responsável por fazer a projeção dos vértices dos triângulos no plano da tela, e a segunda por definir a coloração de cada pixel resultante da determinação da área preenchida da tela por cada triângulo. Nos dois casos a escolha de uma arquitetura SIMD é natural pois tanto a transformação de vértices como a definição das cores podem ser feitas de maneira paralela, aplicando-se a mesma operação em um conjunto de vértices ou pixel (arquitetura SIMD).

Com o amadurecimento dos dispositivos gráficos o hardware evoluiu dispondo um alto nível de paralelismo e unificando a sua arquitetura de modo que processos genéricos, tanto de vértice como de pixel, pudessem ser executados em um conjunto de processadores de propósito geral. Essa alteração visou maximizar o uso dos recursos de processamento que ficavam ociosos devido ao desbalanceamento de carga entre os dois tipos de computação.

O alto poder de processamento dos dispositivos gráficos chamou a atenção dos desenvolvedores de softwares de alto desempenho para utilizá-los para fins fora do âmbito gráfico. Embora isso fosse possível dentro da nova arquitetura, a interface de programação era voltada para aplicações gráficas. Isso mudou com a criação de frameworks de programação para GeneralPurpose Computation on Graphics Processing Units (GPGPU), eliminando o último fator restante que distanciava o uso da GPU para computação científica de alto desempenho. Atualmente é comum a existência de clusters que possuam em seus nós dispositivos capazes de processamento GPU, caracterizando uma 
coexistência de duas arquiteturas paralelas em um único recurso de processamento.

\subsection{OBJETIVOS}

A utilização de métodos de partículas para análise de engenharia tem como grande barreira o limitado número de partículas que podem ser processados em um tempo factível de projeto.

O objetivo principal deste trabalho é viabilizar o processamento de dezenas a centenas de milhões de partículas de maneira rápida utilizando-se clusters que dispõem de dispositivos capazes de processamento GPU e processadores multicore. De uma forma mais específica, o objetivo desta tese é apresentar soluções paralelas para os métodos de partículas explícitos que viabilizem o processamento dessa grande quantidade de partículas.

Vale enfatizar que tais soluções são genéricas a ponto de abranger a maioria dos métodos de partículas explícitos. Neste trabalho, em particular, as soluções são aplicadas ao método E-MPS, devido à existência de um grupo de estudos do método MPS no laboratório onde este foi desenvolvido.

Visando aproveitar a totalidade dos recursos computacionais disponíveis no cluster, é necessário existir dois níveis distintos de paralelismo: um pelo uso do MPI e outro por meio da computação em GPU ou multicore.

O primeiro nível, por utilizar memória distribuída, exige a divisão espacial do domínio de simulação em subdomínios distintos (decomposição de domínio), os quais são processados por processos MPI distintos. O emprego dessa subdivisão ocasiona um problema de balanceamento de carga computacional entre subdomínios. Isso deve ser resolvido por algum processo de balanceamento dinâmico entre os processos, que devem abdicar ou tomar posse das partículas de subdomínios vizinhos.

A comunicação entre processos responsáveis por cada subdomínio se dará por conta das partículas das interfaces entre eles. O tempo de comunicação, assim como a carga de processamento necessário para que ocorra essa comunicação, devem sempre ser minimizados para garantir a 
escalabilidade do paralelismo. Essa minimização é garantida graças a um novo método de comunicação entre subdomínios, aqui proposto, que pode ser empregado em qualquer um dos métodos de decomposição discutidos neste trabalho

O segundo nível de paralelismo ocorrerá na computação do método EMPS, aproveitando os diversos núcleos presentes na CPU ou GPU, em cada nó de processamento.

\subsection{JUSTIFICATIVA}

Baseada na revisão bibliográfica realizada neste trabalho, poucos trabalhos na área de métodos de partículas conseguiram chegar no nível de paralelismo aqui alcançado. Para o método MPS, destacou-se apenas o trabalho de Ovaysi (OVAYSI; PIRI, 2012), mas que é semi-implícito e não apresenta balanceamento dinâmico. Para o método $\mathrm{SPH}$, o trabalho de Valdez-Balderas e Domínguez (DOMíNGUEZ et al., 2013; VALDEZ-BALDERAS et al., 2013) apresenta o mesmo nível de paralelismo deste trabalho, com diferenças no esquema de comunicação entre subdomínios, e por empregarem apenas o método de decomposição ortogonal.

Embora ainda haja várias questões a serem resolvidas com relação à estabilidade numérica do método E-MPS, principalmente com relação ao campo de pressão, acredita-se que existam várias aplicações nas quais a pressão não representa o foco principal da análise, sendo de maior importância o comportamento espacial das partículas. Isso é verdade, por exemplo, para estudos de vazamento de óleo em tubulações ou reservatórios submersos, que representam análises de extrema importância do ponto de vista ambiental.

O fato da incompressibilidade do fluxo não ser garantida nos métodos puramente explícitos também não é um fator que impossibilite a sua aplicabilidade em estudos nos quais um comportamento quase incompressível já seja suficiente para garantir resultados satisfatórios.

Outro ponto importante a se destacar é que embora o E-MPS seja o caso de estudo desse trabalho, este propõe uma arquitetura genérica de computação 
paralela para solução de métodos de partículas explícitos, o que possibilitaria a aplicação em outros métodos.

Embora seja importante detalhar as particularidades do método E-MPS, não é foco principal desta tese a solução dos seus problemas quanto à estabilidade numérica e completude do modelo físico, ou a comparação dos resultados obtidos por outros métodos.

\subsection{METODOLOGIA}

Primeiramente um estudo detalhado do método MPS foi conduzido, seguido pela assimilação da sua variante explícita. Além de se atentar para o modelo matemático adotado, especial atenção foi tomada com relação aos métodos numéricos envolvidos e como eles se adequam às arquiteturas computacionais.

Paralelamente a esses estudos, investigou-se os métodos para paralelização do processamento em memória distribuída aplicada à problemática das partículas. O mesmo foi feito para o processamento em GPU, aliado à familiarização com o framework CUDA de programação para GPGPU.

Terminado esses estudos, um sistema capaz de processar o método EMPS utilizando tanto a CPU como a GPU foi confeccionado, seguido de uma verificação do seu funcionamento a partir da simulação de casos de validação. Ele foi então aprimorado para que diversos processos, cada um responsável por uma parte do domínio, fossem capazes de trabalhar em conjunto através de trocas de mensagens via MPI. Para que isso fosse possível, um novo método de comunicação entre subdomínios foi desenvolvido. Por último, mediu-se o ganho de desempenho alcançado e a escalabilidade do sistema em termos de velocidade de processamento e número de partículas.

Verificado os ganhos de desempenho e os gargalos de processamento, notou-se que era importante prover métodos de decomposição de domínio completos, que fornecessem mecanismos de balanceamento de carga. Para isso foram estudados os métodos já propostos e mais utilizados na área de simulação de fluidos que proviam tais mecanismos. Em seguida implementou- 
se dois desse métodos analisando-se os ganhos de desempenho que cada um oferecia, sendo eles o método ortogonal e o ORB.

Verificando-se o alto grau de dependência geométrica que todos os métodos já propostos incorriam, foi proposto um novo método, chamado de cell transfer, no sentido de se reduzir essa dependência.

\subsection{ESTRUTURA DO TEXTO}

A seção 2 apresenta brevemente os conceitos e métodos em CFD, detalhando-se de maneira mais aprofundada os métodos SPH e MPS, assim como da variante explícita E-MPS. Trabalhos relativos à paralelização desses métodos também são apresentadas, assim como os recentes avanços no uso da GPU para computação de propósito geral.

O método de partículas E-MPS é fundamentado na seção 3, que inclui uma descrição do método de busca de vizinhos utilizada neste trabalho. São descritas também as ferramentas que possibilitam o emprego da busca, e uma técnica que minimiza a necessidade de se efetuá-la, melhorando o desempenho computacional do sistema.

A seção 4 detalha a proposta de computação paralela aplicado ao método E-MPS, que engloba o esquema de comunicação entre subdomínios e os métodos de decomposição de domínio estático, ORB, ortogonal e cell transfer.

A implementação dessa metodologia é descrita na seção 5 , seguida da apresentação dos casos de estudo na seção 6 , juntamente com os resultados numéricos e de desempenho.

A discussão dos resultados alcançados é feita na seção 7 em conjunto com as propostas de trabalhos futuros. 


\section{CONCEITOS, MÉTODOS EM CFD, E APLICAÇÃO DE COMPUTAÇÃO PARALELA}

Nesta seção apresenta-se primeiramente os conceitos e métodos em CFD, com foco no processo de surgimento dos métodos de partículas. São brevemente analisadas as vantagens dos métodos de partículas, e a seguir apresentada uma revisão dos métodos SPH e MPS. A aplicação de técnicas de computação paralela aos métodos de partículas é apresentada em seguida, incluindo uma revisão bibliográfica dos trabalhos mais significativos na área. Analisa-se também os métodos de decomposição de domínio mais utilizados na literatura com foco na sua aplicabilidade nos métodos de partículas.

As equações diferenciais parciais que regem um escoamento de fluido são conhecidas como Equações de Navier-Stokes (ANDREA COLAGROSSI, 2004). Quando se trata de um método em CFD, elas também são denominadas equações governantes, sendo que o conjunto de equações pode variar de método para método.

$\mathrm{Na}$ maior parte dos problemas de engenharia, essas equações, juntamente com as condições de contorno, formam um problema de valor de contorno que não possui solução analítica (ANDREA COLAGROSSI, 2004). Dessa forma, para se obter uma solução numérica, emprega-se algum esquema de discretização do domínio, obtendo-se assim o conjunto de equações algébricas.

Dentro dos diversos métodos já propostos em CFD esse trabalho foca nos métodos de partículas. Essa classe de métodos possui a característica de não apresentar conectividades fixas entre os pontos de discretização, também chamados de partículas ou nós. Consequentemente, métodos com malhas possuem um número limitado de nós vizinhos, enquanto métodos de partículas possuem um número variável.

Os métodos de partículas possuem as seguintes vantagens sobre os métodos com malhas:

- não há necessidade de pré-processamento para geração de malhas como ocorre nos métodos de diferenças finitas, e por isso a representação de geometrias complexas é facilitada; 
- como a descrição é feita em termos lagrangeanos ${ }^{3}$, o termo de convecção das equações de Navier-Stokes, que é altamente sensível à descontinuidades, é eliminado;

- a simulação de problemas que possuem interfaces entre tipos diferentes de fluidos, superfície livre, fragmentação do continuum e paredes móveis são mais facilmente realizáveis.

$\mathrm{Na}$ realidade, antes de ser proposto um método totalmente baseado em partículas, o método Particle-In-Cell, proposto por Harlow (HARLOW, 1964), foi o primeiro a resolver a parte convectiva utilizando partículas com referência lagrangeana e o tradicional esquema de diferenças finitas para resolver a parte da pressão.

O primeiro método totalmente baseado em partículas foi o Smoothed Particle Hydrodynamics (SPH), apresentado simultaneamente por Lucy (LUCY, 1977) e Gingold (GINGOLD; MONAGHAN, 1977), sendo o método de partículas lagrangeano mais difundido e alvo de inúmeros estudos, tendo como origem aplicações na área de astrofísica, e, em trabalhos subsequentes, no escoamento com superfície livre (MONAGHAN, 1994).

Anos depois da apresentação do SPH, o Moving Particle Semi-Implicit (MPS) foi proposto por Koshizuka (KOSHIZUKA; OKA, 1996) como um método de partículas, também lagrangeano, que teve como objetivo em sua concepção, a aplicação em estudos de escoamento com superfície livre. Como o nome revela, ele é originalmente semi-implícito, ou seja, possui uma etapa explícita e outra implícita, sendo esta última responsável por garantir que o fluxo seja incompressivel.

Os primeiros trabalhos aplicados a escoamentos com superfície livre do SPH foram totalmente explícitos sem a garantia de incompressibilidade do fluxo.

A principal diferença entre os dois métodos jaz no modelo matemático dos operadores diferenciais advindos da discretização do fluído e da interpolação de suas propriedades.

A incompressibilidade do fluxo pode ser garantida tanto em um método como em outro, através de uma etapa implícita para solução de uma equação

\footnotetext{
${ }^{3}$ Realizado com referência lagrangeana, de modo que as propriedades do fluido definidas nas partículas se movimentam com ela. A referência euleriana adota os pontos de discretização fixos no espaço.
} 
advinda da equação de continuidade. Existem também trabalhos com estratégias totalmente explícitas para ambos.

\subsection{MÉTODO DE PARTÍCULAS}

A seguir, é apresentada uma revisão mais detalhada dos métodos SPH e MPS. O primeiro é o método de partículas mais utilizado em aplicações e alvo de um grande número de trabalhos. O segundo é o método escolhido neste trabalho para aplicação das soluções paralelas.

\subsubsection{Smoothed Particle Hydrodynamics (SPH)}

O emprego do SPH para simulação de fluidos foi primeiramente realizado por Monaghan (MONAGHAN, 1994), que além de testar o fluxo de uma gota elíptica com campo de velocidade inicial, caso que possui solução analítica, inclui testes de dam break, e gerador de ondas, todas bidimensionais.

Colagrossi, em sua tese (ANDREA COLAGROSSI, 2004), faz uma profunda investigação de vários aspectos do método SPH, incluindo análises quanto à precisão, convergência e diferentes aplicações do método. São feitos importantes estudos de sloshing ${ }^{4}$, incluindo a validação do campo de pressão, e ondas geradas pela proa de cascos com deslocamento avante.

Para maiores detalhes quanto à convergência do método recomenda-se a leitura dos trabalhos de Moussa (MOUSSA; VILA, 2000), Belytschko (BELYTSCHKO et al., 1998) e Ferrari (FERRARI et al., 2009).

\footnotetext{
${ }^{4}$ Sloshing é o fenômeno de deslocamento dos fluídos nos tanques do navio, que pode ocasionar diferentes comportamentos hidrodinâmicos e tensões estruturais.
} 


\subsubsection{Moving Particle Simulation (MPS)}

O método MPS foi introduzido por Koshizuka (KOSHIZUKA; OKA, 1996) com bons resultados de validação, na qual se utilizou resultados experimentais de um caso de dam break, fruto de aprimoramentos de trabalhos anteriores em simulação de escoamento incompressível com superfície livre de fluídos viscosos.

Modificações no método foram feitas por Gotoh (GOTOH et al., 2009) visando a conservação de momento linear e angular, e por Kondo (KONDO; KOSHIZUKA, 2011) buscando a melhoria das oscilações no campo de pressão. Uma análise matemática dos operadores diferenciais utilizados no método foi realizada por Isshiki (ISSHIKI, 2011).

Shakibaeinia, em (SHAKIBAEINIA; JIN, 2010), introduziu a variante explícita do método MPS, utilizando a equação de estado (COLE, 1948) para cálculo da pressão comumente utilizada no método SPH.

No mesmo ano, Oochi (OOCHI; KOSHIZUKA; SAKAI, 2010) propôs um método semelhante, que foi denominado E-MPS, e modificou o significado do acrônimo MPS, originalmente Moving Particle Semi-Implicit, para Moving Particle Simulation, pois a permanência do termo "semi-implícito" não faria sentido.

O método semi-implícito foi então rebatizado de SI-MPS (Semi-Implicit Moving Particle Simulation). O E-MPS foi posteriormente alvo de melhorias no trabalho de Yamada (YAMADA et al., 2011) para simulações tridimensionais.

\subsection{COMPUTAÇÃO PARALELA APLICADA AOS MÉTODOS DE PARTÍCULAS}

Trabalhos na área de computação paralela utilizando-se a GPU aplicada ao método SI-MPS podem ser vistos em diversos trabalhos (HORI et al., 2011; OVAYSI; PIRI, 2012; ZHU et al., 2011). Os dois primeiros são capazes de utilizar apenas um único dispositivo GPU, enquanto o último possibilita a utilização de múltiplos dispositivos distribuídos em diferentes nós de um cluster. 
No trabalho de Ovaysi não é detalhada qual é a estrutura de dados utilizada no algoritmo de busca de vizinhos. Menciona-se apenas o uso de uma lista ligada, sem detalhar como essa estrutura é adaptada para utilização no processamento em GPU. O método empregado para solução do sistema linear é o gradiente biconjugado estabilizado, que requer a troca de informação entre subdomínios a cada iteração. Como a aplicação visa o estudo de casos de fluxo em meios porosos, não há balanceamento dinâmico entre subdomínios, pois na maioria dos casos o domínio apresenta uma distribuição uniforme de partículas.

O paralelismo dos dispositivos GPU também foi explorado em trabalhos que utilizam o método SPH.

A computação desse método de modo paralelo é o foco de vários trabalhos (CRESPO et al., 2011; GAO et al., 2010; HARADA; KOSHIZUKA; KAWAGUCHI, 2007; RUSTICO et al., 2012), sendo que nenhum deles é compatível com clusters GPU, pois não possuem esquema de decomposição de domínio como proposto neste trabalho.

$\mathrm{O}$ único trabalho que utilizou o $\mathrm{SPH}$ e possui o mesmo nível de paralelismo alcançado neste trabalho é o apresentado por Valdez-Balderas, (VALDEZ-BALDERAS et al., 2013), seguido de um trabalho, do mesmo grupo, apresentado por Domínguez (DOMÍNGUEZ et al., 2013). O esquema empregado para a procura de vizinhos é o mesmo utilizado neste trabalho e apresentado por Le Grand (LE GRAND, 2008). Já a estratégia de comunicação entre subdomínios é diferente da empregada neste trabalho. A entrada e saída de partículas de um subdomínio é tratada separadamente, aplicando-se uma ordenação de acordo com o subdomínio no qual a partícula se encontra. No presente trabalho, isso é realizado conjuntamente com a ordenação necessária para a busca de vizinhos.

No trabalho de Valdez-Balderas, a recepção das partículas de borda de um subdomínio vizinho é seguida de outro processo de ordenação, o que possibilita tratá-las corretamente durante a fase de interação entre partículas. No presente trabalho, essa nova ordenação é evitada pela comunicação de dados adicionais.

Infelizmente a comparação de desempenho entre o presente trabalho e o de Valdez-Balderas e Domínguez é dificultada pelo fato de serem métodos de partículas distintos. Além disso, o gargalo de processamento nos dois trabalhos 
se dá na fase de interação entre as partículas, e portanto, nos dois trabalhos, os resultados de escalabilidade são satisfatórios.

O método de decomposição de domínio utilizado por Valdez-Balderas e Domínguez é o ortogonal, também investigado neste trabalho, mas nenhum outro método é proposto ou investigado, diferentemente do presente trabalho, em que se investiga os métodos estático e ORB, além de ser proposto o método cell transfer.

Uma grande vantagem do trabalho de Valdez-Balderas e Domínguez em relação a este é a otimização realizada para processamento utilizando-se CPUs multicore, que, dentre outras técnicas, utiliza lista ligadas na busca de vizinhos (DOMÍNGUEZ; CRESPO; GÓMEZ-GESTEIRA, 2013). No presente trabalho, não se empregou nenhum tipo de otimização especificamente para essa arquitetura, pois o foco foi a análise dos métodos de decomposição de domínio, e o algoritmo geral de comunicação. Cabe salientar que as otimizações propostas por Valdez-Balderas e Domínguez são compatíveis com as técnicas propostas no presente trabalho.

\subsubsection{Decomposição de Domínio}

Em (SEAL; ALURU, 2007) é realizada uma revisão bibliográfica dos métodos de decomposição de domínio paralelo e suas aplicações. Nela, o termo "padrão de acesso" é utilizado para se referir ao modo como cada ponto ${ }^{5}$ do domínio discretizado se relaciona com os pontos vizinhos.

De modo geral, nos métodos de diferenças finitas, por exemplo, cada célula necessita de informações de pressão e velocidade das células adjacentes. Isso caracteriza um padrão de acesso no qual cada ponto consulta um número limitado e baixo de pontos vizinhos.

No mesmo trabalho, Seal e Aluru classificam os padrões de acesso em três tipos principais:

\footnotetext{
${ }^{5}$ No caso dos métodos de partículas, cada partícula representa um ponto.
} 
- Consulta de região esférica: cada ponto requer a informação de todos os pontos que se encontram a uma distância menor que um raio $r$.

- Consulta de vizinho mais próximo: cada ponto necessita da informação do(s) ponto(s) mais próximo(s).

- Consulta de região anelar: cada ponto necessita da informação de todos os pontos que se encontram a uma distância $d$, no intervalo $d_{1} \leq d \leq d_{2}$.

Tanto no método MPS quanto no SPH verifica-se que o padrão de acesso é caracterizado por consultas de região esférica.

Ainda no mesmo trabalho, discute-se a respeito de três métodos de decomposição de domínio: Orthogonal Recursive Bisection (ORB), Space Filling Curves (SFC) e Octrees. Muitos deles são capazes de se adaptar para diferentes padrões de acesso aos dados. Analisa-se também como é realizado o balanceamento de carga em cada um desses métodos.
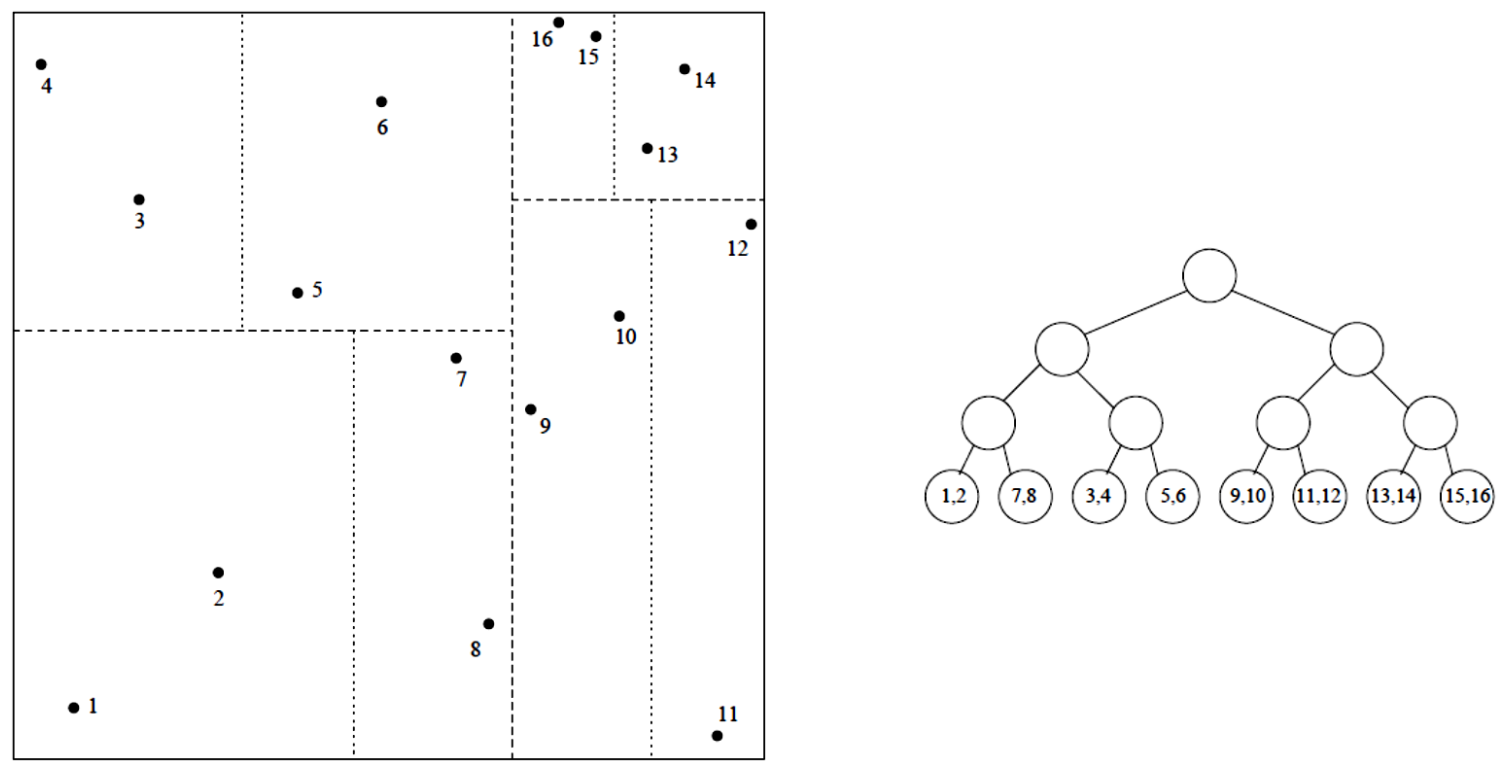

Figura 2 - Exemplo de divisão do domínio utilizando-se o método ORB (extraído de (SEAL; ALURU, 2007)).

O método ORB consiste na divisão recursiva do domínio utilizando-se hiperplanos ortogonais aos eixos cartesianos, como mostra a Figura 2, sendo usualmente representado por uma árvore binária, com os nós internos representando os hiperplanos, e os nós folha os pontos. 
Quando o objetivo é a divisão uniforme da carga computacional entre os processos, o hiperplano tem a sua posição definida pela mediana da posição dos pontos.

Quando a carga computacional não é uniforme entre os pontos, é possível definir um peso que influencia na posição da mediana para cada um deles. Artifícios similares podem ser adotados para o caso de uso de recursos computacionais heterogêneos.

Uma clara desvantagem do método ORB é a restrição geométrica introduzida pelo uso dos hiperplanos de bisseção ortogonais. Caso não seja feita uma escolha cuidadosa do eixo de bisseção pode-se incorrer em um alto custo de comunicação. Outro ponto negativo é o fato das divisões se darem de forma recursiva, fazendo que qualquer mudança de hiperplano nos níveis superiores force o recálculo nos níveis inferiores, considerando a representação em árvore binária, como mostra a Figura 2.

O método SFC 6 , que utiliza as curvas de mesmo nome, também chamadas de Curvas de Peano, são definidas em (SEAL; ALURU, 2007) como segue: dado um hipercubo de dimensão $d$, recursivamente bisecionando-o $k$ vezes em cada dimensão, obtém-se uma matriz com $2^{k} \times 2^{k} \times \ldots \times 2^{k}=2^{d k}$ células não sobrepostas e de igual tamanho.
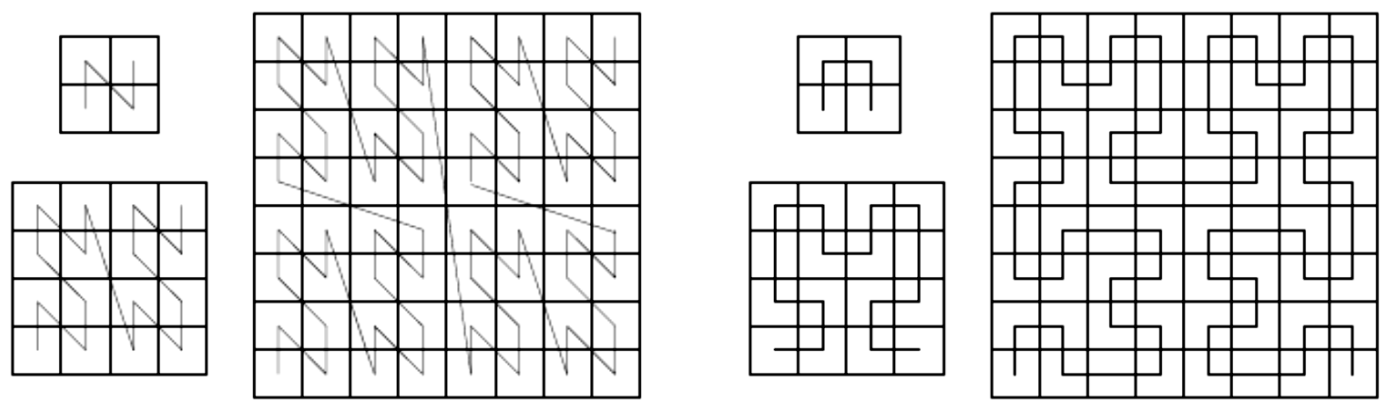

Figura 3 - Dois tipos de curvas utilizadas no método SFC: Curva Z e Curva de Hilbert (extraído de (SEAL; ALURU, 2007)).

Considerando-se que cada célula possui uma coordenada de dimensão $d$, o SFC faz um mapeamento de modo a ordená-las linearmente. A Figura 3 mostra a linearização utilizando dois tipos de curvas distintas.

Fazendo-se a ordenação dos pontos baseado na sequência de linearização das células que os contêm, o balanceamento é feito dividindo-se os

\footnotetext{
${ }^{6}$ Neste trabalho Space Filling Curve sempre se refere ao seu caso discreto.
} 
pontos em $p$ partes iguais, sendo $p$ o número total de processos. Dessa maneira, dependendo do tipo de curva que é utilizado, o agrupamento se dá de forma diferente.

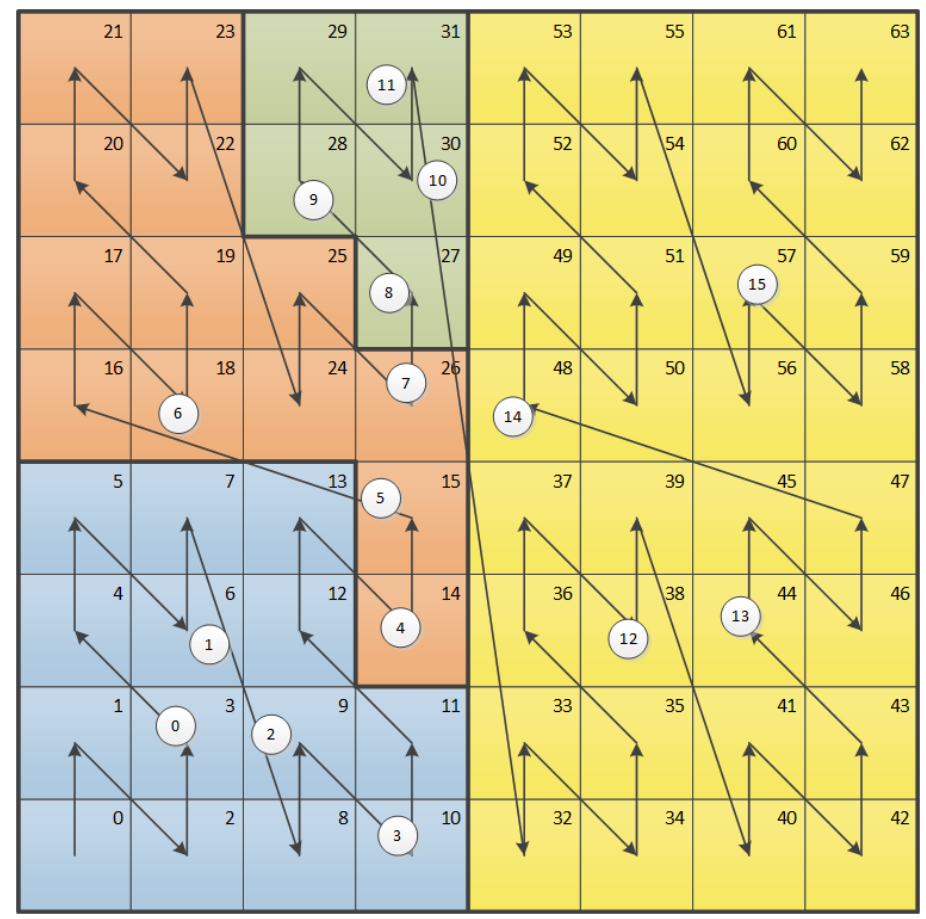

Figura 4 - Exemplo de ordenação dos pontos utilizando-se uma Curva Z.

A Figura 4 retrata um exemplo de uma matriz com 64 células com seus índices linearizados por uma Curva Z, com os 16 pontos já ordenados com base neles. Fazendo-se a decomposição do domínio com $p=4$, tem-se 4 pontos em cada subdomínio, resultando nas regiões retratadas por cores distintas.

Pontos com cargas computacionais heterogêneas podem ser tratados fazendo-se uma divisão não uniforme dos pontos.

A grande desvantagem do método SFC é a necessidade de se realizar uma ordenação global dos pontos. Neste trabalho, isso significa a realização de uma ordenação em uma arquitetura com memória distribuída, que incorre na realização de pelo menos um passo de comunicação all-to-all de uma quantidade de dados que cresce proporcionalmente ao número de pontos, afetando a escalabilidade do método com relação ao número de processos (HOFMANN; RUNGER, 2011).

Outra desvantagem é a maior dificuldade de se determinar o conjunto de partículas próximas às fronteiras dos subdomínios que devem ser comunicadas 
entre os processos, devido à fronteira apresentar geometrias irregulares, como evidenciado na Figura 4.

Contudo, a qualidade do particionamento é um ponto positivo do método SFC, graças à simplicidade do esquema adotado.

Octrees são compostos de um conjunto de hipercubos organizados de forma hierárquica, que dá nome ao método de decomposição. Uma estrutura de dados de árvore é capaz de captar essa organização hierárquica dos hipercubos perfeitamente, e por isso é comum que se diga que uma octree é uma estrutura de dados em árvore.

Os hipercubos são representados pelos nós da árvore, os quais respeitam a propriedade de que todos os nós filhos são hipercubos totalmente contidos no hipercubo do nó pai e todos os nós contêm ao menos um ponto. A construção pode ser feita partindo-se do hipercubo que contém todo o domínio de simulação e subdividindo-o recursivamente em $2^{d}$ hipercubos iguais.
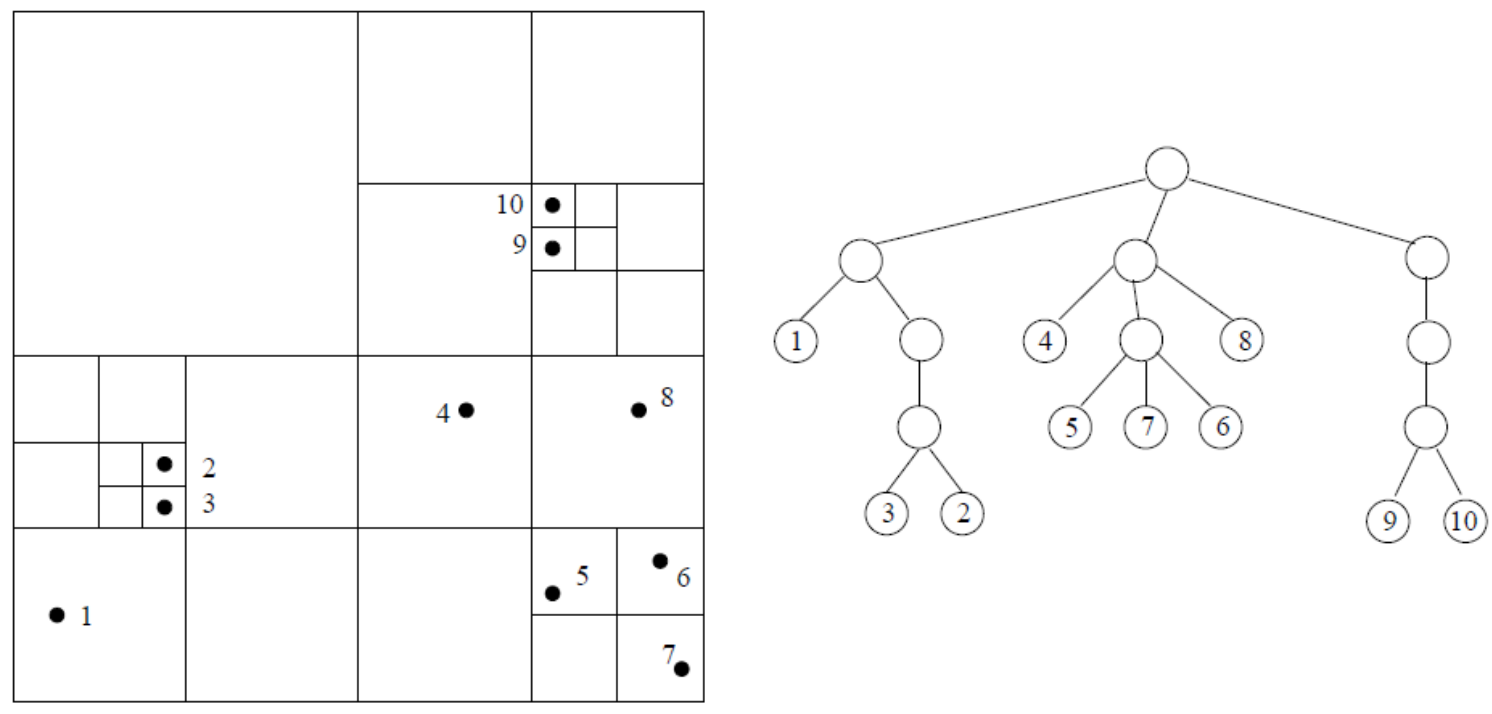

Figura 5 - Exemplo de uma Octree (extraído de (SEAL; ALURU, 2007)).

A recursão é interrompida quando se chega a uma resolução limite do tamanho do hipercubo, ou a um hipercubo vazio. A Figura 5 mostra uma octree subdividindo 10 pontos e a sua representação em árvore.

Octrees são muito utilizados para problemas dos n-corpos, mais especificamente em (BARNES; HUT, 1986) para problemas gravitacionais, mas a estrutura hierárquica dos subdomínios pouco colabora nos métodos em que o padrão de acesso é a consulta a região esférica. 
Para que o emprego de octrees fosse devidamente justificado, deveriam ser propostos métodos nos quais fosse possível a criação de partículas que sintetizassem o efeito de um conjunto de partículas espacialmente próximas. Dessa maneira se reduz o número de iterações de pares de partículas que são calculadas. Além disso, o método deveria incluir um mecanismo claro de se medir o erro introduzido por essa aproximação.

Neste trabalho, investigam-se três métodos de decomposição:

- Estático, ou não adaptativo - método no qual não há balanceamento dinâmico entre os subdomínios, que pode ser empregado em casos em que a natureza do fluxo não gera desbalanceamentos entre eles.

- ORB - propõem-se o emprego do Método de Weiszfeld Iterativo para cálculo da mediana para determinação dos planos de bisseção, que, dentro do que se foi levantado na revisão bibliográfica, nunca foi utilizada para decomposição de domínio. A estrutura hierárquica e rigidez geométrica do método ORB são suas grandes desvantagens.

- Ortogonal - segue o esquema apresentado no trabalho de ValdezBalderas (VALDEZ-BALDERAS et al., 2013).

Foi proposto também um novo método de comunicação entre subdomínios que possibilita o correto tratamento das partículas de borda dos subdomínios sem incorrer em processos de ordenação adicionais. Esse esquema foi utilizado em todos os três métodos de decomposição estudados, o que mostra que a proposta é suficientemente genérica.

O método estático consiste de subdomínios que não sofrem alterações no decorrer da simulação. O balanceamento de carga, nesse caso, deve ser garantido pelo correto casamento entre a geometria do problema e dos subdomínios.

Um exemplo simples para o qual esse método é efetivo é no estudo de fluxos incompressíveis em tubulações sem superfície livre, onde se pode delimitar cada subdomínio em seções sucessivas da tubulação, de modo que cada subdomínio contenha um número próximo de partículas. Como não há superfície livre e o fluxo é incompressível, não ocorrem grandes alterações na contagem de partículas em cada subdomínio, garantindo-se assim o bom balanceamento em todo o decorrer da simulação. 
O método ORB foi escolhido como um caso de estudo de algum método consagrado no campo de aplicação desse trabalho. Foi escolhido também pelo fato de ser um método conceitualmente intuitivo, e de implementação razoavelmente fácil.

O SFC, por outro lado, envolveria a complexa tarefa de se desenvolver um algoritmo eficiente de ordenação em memória distribuída, e portanto não foi considerado neste trabalho.

Outro método consagrado e de mais comum aplicação no campo dos métodos de partículas estudados neste trabalho é o ortogonal. Esse método também é investigado e pode ser visto como um caso particular do método ORB, mas com grandes simplificações na implementação e representação de dados.

Além desses métodos, um novo método é proposto neste trabalho, chamado de cell transfer, tendo como objetivo principal não incorrer em limitações geométricas impostas em métodos como o ORB ou SFC.

\subsection{DESAFIOS}

Os desafios na área de simulação por método de partículas podem ser divididos em duas categorias bem distintas, uma com relação aos seus modelos matemáticos e outra do ponto de vista da sua computação. O aumento do campo de aplicação dos métodos de partículas, com o seu real uso para solução de problemas de engenharia, depende do desenvolvimento conjunto dessas duas frentes.

O SPH possui um maior número de estudos com relação à convergência do método (BELYTSCHKO et al., 1998; MONAGHAN, 2000; MOUSSA; VILA, 2000; MOUSSA, 2006) se comparado ao MPS (KONDO; KOSHIZUKA, 2011) e (TANAKA; MASUNAGA, 2010).

Um ponto crítico para ambos os métodos nos resultados de validação é o campo de pressão, e pode-se dizer que ambos possuem trabalhos nos quais são apresentados resultados satisfatórios, em (ANDREA COLAGROSSI, 2004) e (FERRARI et al., 2009) para o SPH e em (KONDO; KOSHIZUKA, 2011) para o SI-MPS. 
O E-MPS, utilizado neste trabalho, ainda possui problemas de estabilidade do campo de pressão, mas mostra-se adequado para aplicação em estudos nos quais o foco é o comportamento espacial do fluido, e em que a taxa de compressibilidade introduzida não seja limitante ao estudo.

O emprego dos métodos de partículas em problemas de engenharia depende também das suas possibilidades de modelagem dos fenômenos físicos, que são impactantes para um determinado campo de aplicação. Para citar um exemplo, ao se estudar fluxos multifásicos, é importante a modelagem da tensão superficial que age na interface dos dois fluidos (KONDO et al., 2007). Com a inclusão de novos fenômenos físicos, a computação das suas diversas propriedades necessita uma força computacional cada vez maior.

Para o caso do método MPS, cada novo fenômeno significa a inclusão no cálculo de um ou mais operadores diferenciais discretos aplicados a alguma variável do fluido (posição, velocidade, pressão, etc.), sendo estes os que respondem pela maior parte da carga computacional. A implementação desses operadores de forma paralela e otimizada para as diversas arquiteturas paralelas disponíveis é um desafio que deve ser vencido, tendo em vista que a confecção de um hardware com arquitetura paralela especializada nesse problema seria de difícil sustentação econômica. Outra característica desses operadores é que para que se sintetize um resultado para uma partícula são necessárias as informações das partículas vizinhas. Esse caráter espacial (vizinhos) das operações mais custosas computacionalmente torna ainda mais natural o uso da decomposição de domínio, que é uma forma de paralelizar o problema tendo como base a sua espacialidade.

Dentro do que se pode averiguar não existe na literatura um trabalho dedicado a investigar qual método de decomposição de domínio espacial é o mais adequado para o problema de consultas de regiões esféricas, e mais especificamente para aplicações no método MPS ou SPH. Talvez isso possa ser justificado pelo fato da eficácia do método ser, na maioria das vezes, muito dependente da aplicação, sendo difícil propor um método eficiente e genérico.

Atualmente a realização de simulações complexas, que incluem paredes móveis, corpos rígidos livres, escoamentos multifásicos, entre outros fenômenos, já é uma realidade. Isso configura uma heterogeneidade na carga computacional de cada partícula, dependendo se ela faz parte de uma parede 
móvel com movimento forçado, ou se pertence a um fluido para o qual desejase que o efeito de tensão superficial seja considerada nos cálculos, por exemplo. Portanto, o balanceamento de carga, idealmente, deve ser capaz de se adequar a heterogeneidade de carga computacional das partículas.

Já é comum em instituições que utilizam clusters, seja para uso em projetos comerciais ou de pesquisa, possuírem não apenas um, mas um conjunto deles. A tendência é que isso se intensifique, pois atualmente um cluster tem a sua obsolescência por volta de dois a três anos após a sua aquisição, mas só é descartado depois de cinco a seis anos ${ }^{7}$.

Métodos de balanceamento de carga adaptativos, que possam se adequar à heterogeneidade de hardware, são essenciais para que se possa explorar a totalidade dos recursos computacionais.

Outro desafio que não tange o modelo matemático nem o computacional é o de engenharia de software. Como exposto anteriormente, esse trabalho inclui a existência de dois níveis de paralelismo. O primeiro, através da decomposição de domínio em uma arquitetura de memória distribuída, utiliza a interface MPI como solução para a comunicação entre processos. $O$ segundo, pela computação paralela em cada subdomínio, usa os recursos de processamento paralelo em arquitetura de memória compartilhada para computação do método E-MPS.

Devido ao rápido aparecimento de diferentes arquiteturas para paralelismo em memória compartilhada ${ }^{8}$, é vital que o software de simulação seja capaz de se adequar a cada uma delas.

Boas práticas de engenharia de software são necessárias para que se proveja uma arquitetura que garanta a contínua extensibilidade, manutenibilidade e reusabilidade do código, mesmo frente ao aparecimento de novas arquiteturas de hardware. A decisão de se utilizar um novo tipo de processador e/ou framework de computação paralela, não deve impactar o simulador a ponto de ser necessária uma profunda mudança em seu código

\footnotetext{
7 Com base nos ciclos de renovação dos clusters do laboratório Tanque de Provas Numérico da Universidade de São Paulo.

${ }^{8}$ Neste trabalho considera-se o uso de processadores multicore, dispositivos GPU, e Intel Xeon Phi, mas outras possibilidades podem surgir no futuro.
} 
fonte. Isso também se aplica a diferentes métodos que podem ser utilizados em pontos distintos do programa.

A confecção de programas de computação científica deve sempre considerar o surgimento de novos algoritmos e métodos que vão impactar o código de alguma forma. Isso foi considerado neste trabalho, aplicando-se técnicas de programação que permitem a extensão das funcionalidades minimizando-se o impacto no código já existente. 


\section{MÉTODO DE PARTÍCULAS E-MPS}

É fundamentada, aqui, o método de partículas E-MPS proposto em (SHAKIBAEINIA; JIN, 2009). A escolha pelo método MPS se deu principalmente pelo fato dele apresentar uma menor quantidade de parâmetros que necessitam de calibração se comparado ao SPH, embora recentes trabalhos (FERRARI et al., 2009) tenham conseguido dirimir esse problema. Outro fator determinante na escolha desse método foi o maior conhecimento prévio do grupo de pesquisa envolvido neste trabalho, além da maior facilidade de se tratar os efeitos de paredes sólidas.

A variante explícita do método MPS foi escolhida porque não recai na solução de um sistema linear, o que permite empregar a decomposição de domínio puramente espacial.

O método proposto neste trabalho consiste de dois níveis de paralelismo: um através de uma decomposição de domínio espacial sobre uma arquitetura de memória distribuída, e outra em cada nó dessa última, pelo uso de processamento paralelo em arquitetura de memória compartilhada, podendo ser pelo uso de dispositivos GPU, ou pelo uso de processadores multicore.

As subseções 3.1, 3.2 e 3.3 formam a base metodológica para que seja possível realizar a computação do método E-MPS de maneira eficiente em uma arquitetura de memória compartilhada, apresentada na seção 4.

\subsection{MÉTODO E-MPS}

Aqui é apresentado, em detalhes, o método E-MPS (SHAKIBAEINIA; JIN, 2010), partindo das suas equações governantes até a formulação de suas equações algébricas.

Apresenta-se o conceito de variável ponderada pela função peso que mais adiante desempenha um papel central na questão do paralelismo tanto no nível do processamento em memória compartilhada, quanto na comunicação em memória distribuída. 


\subsubsection{Equações Governantes}

Considerando-se um fenômeno de escoamento de fluxo incompressível, as equações de conservação de massa e de momento podem ser dadas por:

$$
\begin{gathered}
\frac{1}{\rho} \frac{D \rho}{D t}+\nabla \cdot \boldsymbol{u}=0 \\
\frac{D \boldsymbol{u}}{D t}=-\frac{1}{\rho} \nabla p+v \nabla^{2} \boldsymbol{u}+\boldsymbol{g}
\end{gathered}
$$

sendo $\rho$ a densidade do fluido, $\boldsymbol{u}$ a velocidade, $p$ a pressão, $v$ a viscosidade cinemática, e $\boldsymbol{g}$ a gravidade.

O método MPS se baseia na discretização do fluido em um número finito de partículas. A influência que uma partícula $i$ exerce em outra partícula $j$ é definida por uma função peso que pode ser definida como:

$$
w\left(r_{i j}, r_{e}\right)=\left\{\begin{array}{c}
\frac{r_{e}}{r_{i j}}-1, r_{i j}<r_{e} \\
0, r_{i j} \geq r_{e}
\end{array}\right.
$$

onde $r_{i j}$ é a distância entre as partículas $i$ e $j$, e $r_{e}$ é o raio de influência.

Uma grandeza adimensional chamada de densidade número de partícula é escrita como:

$$
\langle n\rangle_{i}=\sum_{i \neq j} w\left(r_{i j}, r_{e}\right)
$$

e está diretamente relacionada à densidade local do fluido.

O sinal tipográfico〈 > simboliza que a variável é ponderada pela função peso, ou seja, dada uma partícula $i$ e seu conjunto de partículas vizinhas $\mathcal{V}_{i}=$ $\left\{j: r_{i j}<r_{e}\right\}$, a variável é dada pela seguinte fórmula geral:

$$
\langle x\rangle_{i}=k \sum_{i \neq j}\left(f\left(a_{i j}^{1}, a_{i j}^{2}, \ldots, a_{i j}^{n}\right) w\left(r_{i j}, r_{e}\right)\right)
$$

onde $x$ é uma variável ponderada pela função peso, $k$ é uma constante, $a$ é uma variável qualquer da partícula (ex: velocidade, pressão, etc.), $a_{i j}=a_{j}-a_{i}$, $f\left(a_{i j}^{0}, a_{i j}^{1}, \ldots, a_{i j}^{n-1}\right)$ é uma função que depende de $n$ variáveis (escalares ou vetores) da partícula $i$ e de uma partícula vizinha $j$, e $w\left(r_{i j}, r_{e}\right)$ é a função peso.

O gradiente é definido como: 


$$
\langle\nabla \cdot \phi\rangle_{i}=\frac{d}{n_{0}} \sum_{i \neq j}\left(\frac{\phi_{j}-\phi_{i}}{r_{i j}^{2}}\left(\boldsymbol{r}_{j}-\boldsymbol{r}_{i}\right) w\left(r_{i j}, r_{e}\right)\right)
$$

e o Laplaciano:

$$
\left\langle\nabla^{2} \phi\right\rangle_{i}=\frac{2 d}{\lambda n_{0}} \sum_{i \neq j}\left(\left(\phi_{j}-\phi_{i}\right) w\left(r_{i j}, r_{e}\right)\right)
$$

sendo $d$ a dimensionalidade do problema, $n_{0}$ a densidade número de partículas de referência, $\phi$ uma variável escalar, e $\lambda$ um fator de correção dado por:

$$
\lambda=\frac{\sum_{i \neq j}\left|\boldsymbol{r}_{i j}\right|^{2} w\left(r_{i j}, r_{e}\right)}{\sum_{i \neq j} w\left(r_{i j}, r_{e}\right)}
$$

\subsubsection{Algoritmo de Solução}

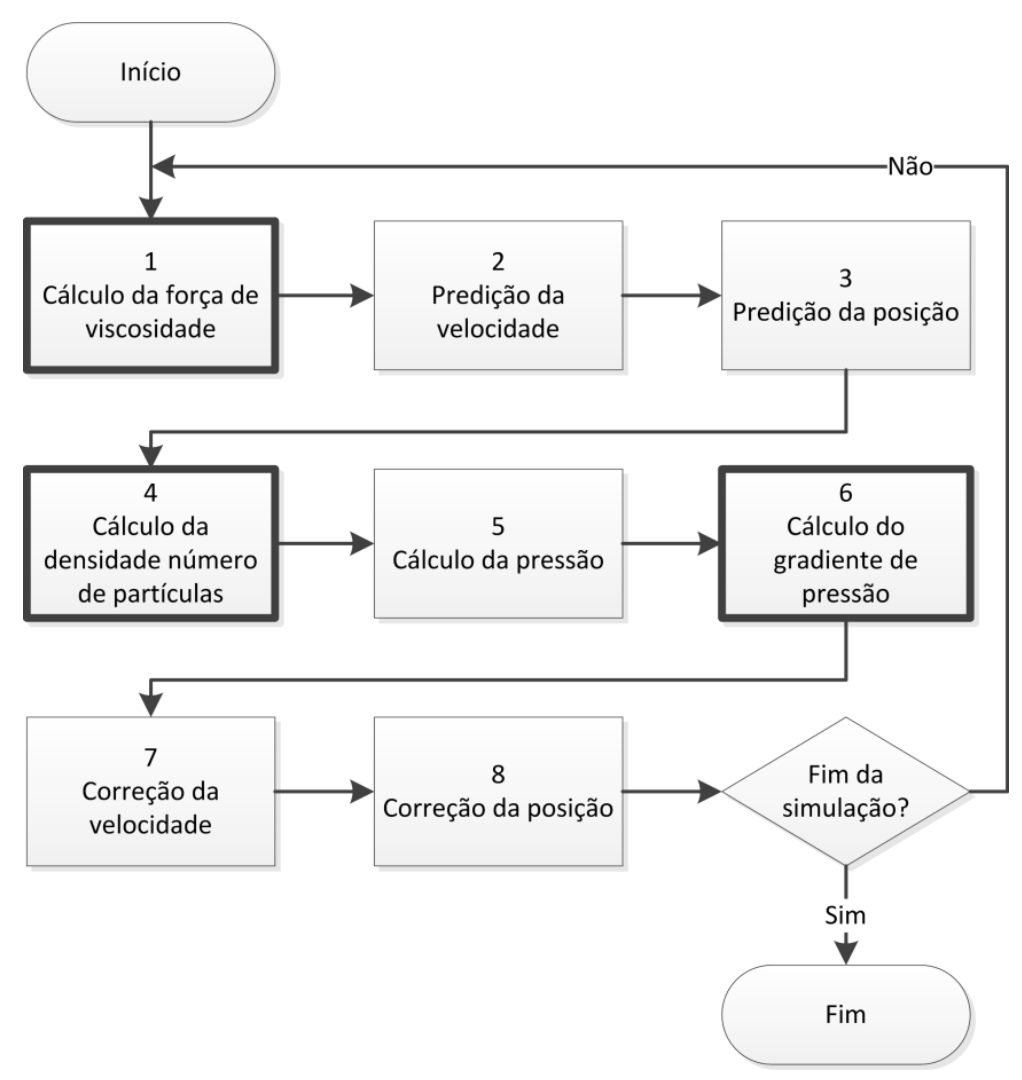

Figura 6 - Fluxograma do método E-MPS.

A Figura 6 apresenta o fluxograma do método E-MPS na qual estão destacados os passos que envolvem grandezas ponderadas pela função peso. 
Pode-se notar que é utilizado o método de predição-correção para integração numérica da equação de movimento.

Seguindo a sequência numérica da Figura 6, detalham-se, a seguir, os cálculos envolvidos em cada passo.

O primeiro passo calcula a força de viscosidade com base no laplaciano da velocidade aplicando-se o operador laplaciano (Equação 7) como segue:

$$
\boldsymbol{v}_{i}=\mu\left\langle\nabla^{2} \boldsymbol{u}\right\rangle_{i}=\mu \frac{2 d}{\lambda n_{0}} \sum_{i \neq j}\left(\left(\boldsymbol{u}_{j}-\boldsymbol{u}_{i}\right) w\left(r_{i j}, r_{e}\right)\right)
$$

sendo $\mu$ o coeficiente de viscosidade dinâmica.

A predição da velocidade e posição são feitas nos passos 2 e 3 , respectivamente, de acordo com as seguintes equações:

$$
\begin{gathered}
\boldsymbol{u}_{i}{ }^{*}=\boldsymbol{u}_{i}{ }^{n}+\Delta t \boldsymbol{f}_{i} \\
\boldsymbol{r}_{i}{ }^{*}=\boldsymbol{r}_{i}{ }^{n}+\Delta t \boldsymbol{u}_{i}{ }^{*}
\end{gathered}
$$

onde $\boldsymbol{u}_{i}{ }^{*}, \boldsymbol{u}_{i}{ }^{n}, \Delta t, \boldsymbol{f}_{i}, \boldsymbol{r}_{i}{ }^{*}$, e $\boldsymbol{r}_{i}{ }^{n}$ são a velocidade predita, velocidade no instante $n$, passo temporal, força, posição predita e posição no passo $n$, respectivamente. A densidade número de partículas é calculada a partir da Equação 4 no passo 4.

A pressão, seguindo a equação de estado proposta por Cole (COLE, 1948), é definida no passo 5 como:

$$
p_{i}=c_{0}^{2} \frac{\rho_{0}}{n_{0}}\left(n_{i}-n_{0}\right)
$$

na qual $c_{0}$ é a velocidade do som na densidade de referência $\rho_{0}$.

No sexto passo, o gradiente de pressão é calculado de acordo com a Equação 6. A correção da velocidade e posição é feita nos passos 7 e 8 de acordo com as seguintes equações:

$$
\begin{gathered}
\boldsymbol{u}_{i}{ }^{\prime}=-\frac{\Delta t}{\rho_{0}} \nabla p^{n+1} \\
\boldsymbol{r}_{i}{ }^{\prime}=\Delta t \boldsymbol{u}_{i}{ }^{\prime}
\end{gathered}
$$

A velocidade e posição do passo seguinte são definidas como:

$$
\begin{gathered}
\boldsymbol{u}_{i}{ }^{n+1}=\boldsymbol{u}_{i}{ }^{*}+\boldsymbol{u}_{i}{ }^{\prime} \\
\boldsymbol{r}_{i}{ }^{n+1}=\boldsymbol{r}_{i}{ }^{*}+\boldsymbol{r}_{i}{ }^{\prime}
\end{gathered}
$$




\subsection{GRADE}

A grade é uma malha estruturada auxiliar que faz a tesselação do espaço cartesiano por meio de hipercubos uniformes. Estes últimos são denominados células e são alinhados aos eixos cartesianos, auxiliando diretamente na procura de partículas vizinhas e na decomposição de domínio.

Ao se ordenar as partículas com base na grade, é possível diminuir a ordem de complexidade computacional da busca de vizinhos necessária em todos os operadores diferenciais do método MPS, assim como no cálculo do número densidade de partícula.

Uma célula de tamanho $h$ identificada pelo seu índice $\boldsymbol{i}=\left(i_{1}, i_{2}, i_{3}\right) \in \mathbb{Z}^{3}$ ocupa a região $\left[i_{1} h,\left(i_{1}+1\right) h\left[\times\left[i_{2} h,\left(i_{2}+1\right) h\left[\times\left[i_{3} h,\left(i_{3}+1\right) h\left[\right.\right.\right.\right.\right.\right.$ do espaço $\mathbb{R}^{3}$. Dessa forma, dada a posição $\boldsymbol{r}$ de uma partícula, é possível calcular a célula $\boldsymbol{i}$ que ela ocupa da seguinte maneira:

$$
\boldsymbol{i}=\left\lfloor\frac{\boldsymbol{r}}{h}\right\rfloor
$$

onde l 」 é a função de arredondamento para o menor inteiro.

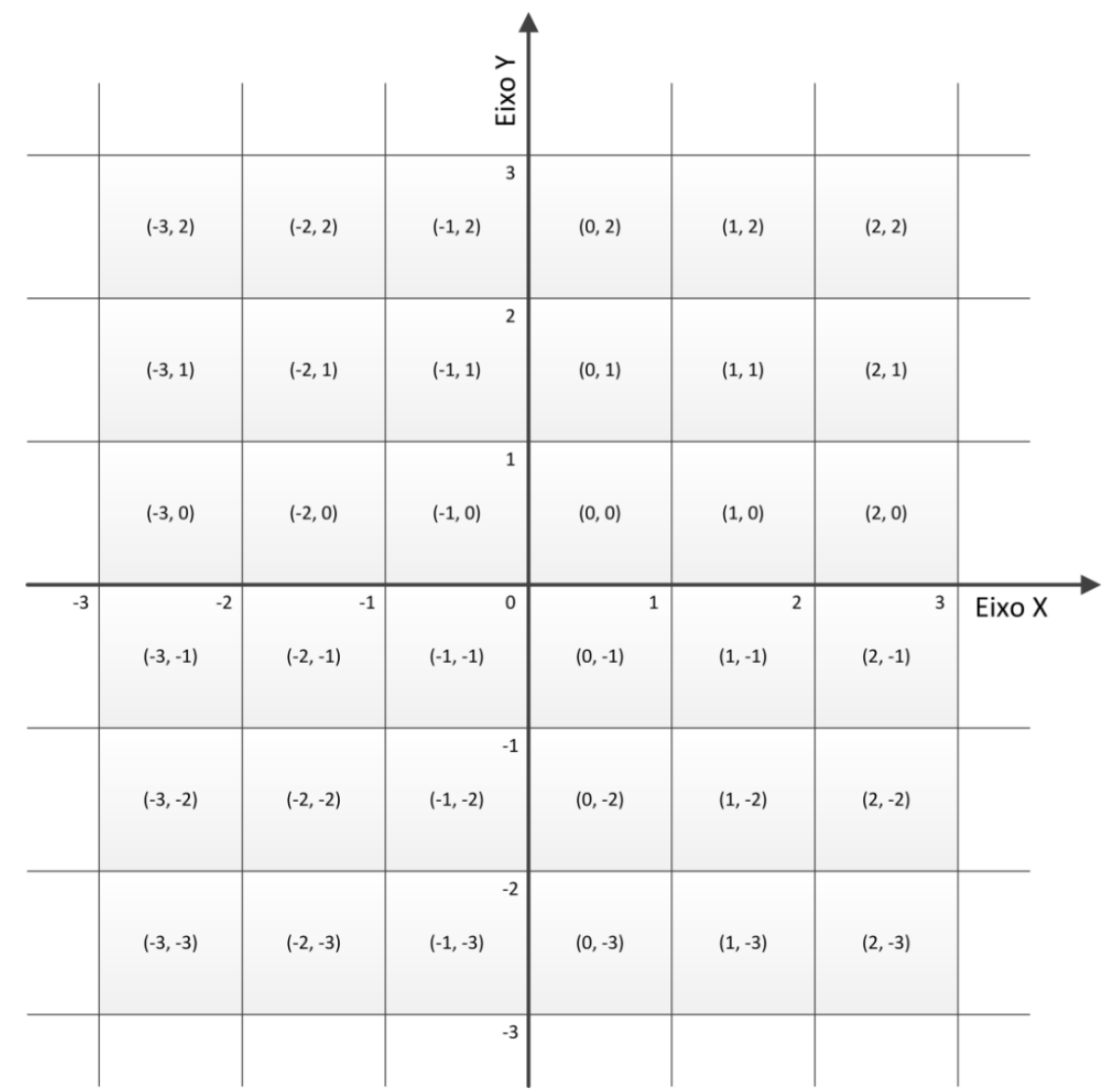

Figura 7 - Malha estruturada auxiliar com células de tamanho $\mathrm{h}=1$. 
A Figura 7 representa uma grade em $\mathbb{R}^{2}$ com células de tamanho $h=1 \mathrm{e}$ seus respectivos índices.

O sistema de coordenadas de grade é um sistema de coordenadas cartesianas em $\mathbb{Z}^{3}$ onde cada ponto $\boldsymbol{a}=\left(a_{1}, a_{2}, a_{3}\right)$ corresponde ao ponto $\boldsymbol{x}=$ $\left(a_{1} h, a_{2} h, a_{3} h\right)$ do sistema de coordenadas cartesianas em $\mathbb{R}^{3}$.

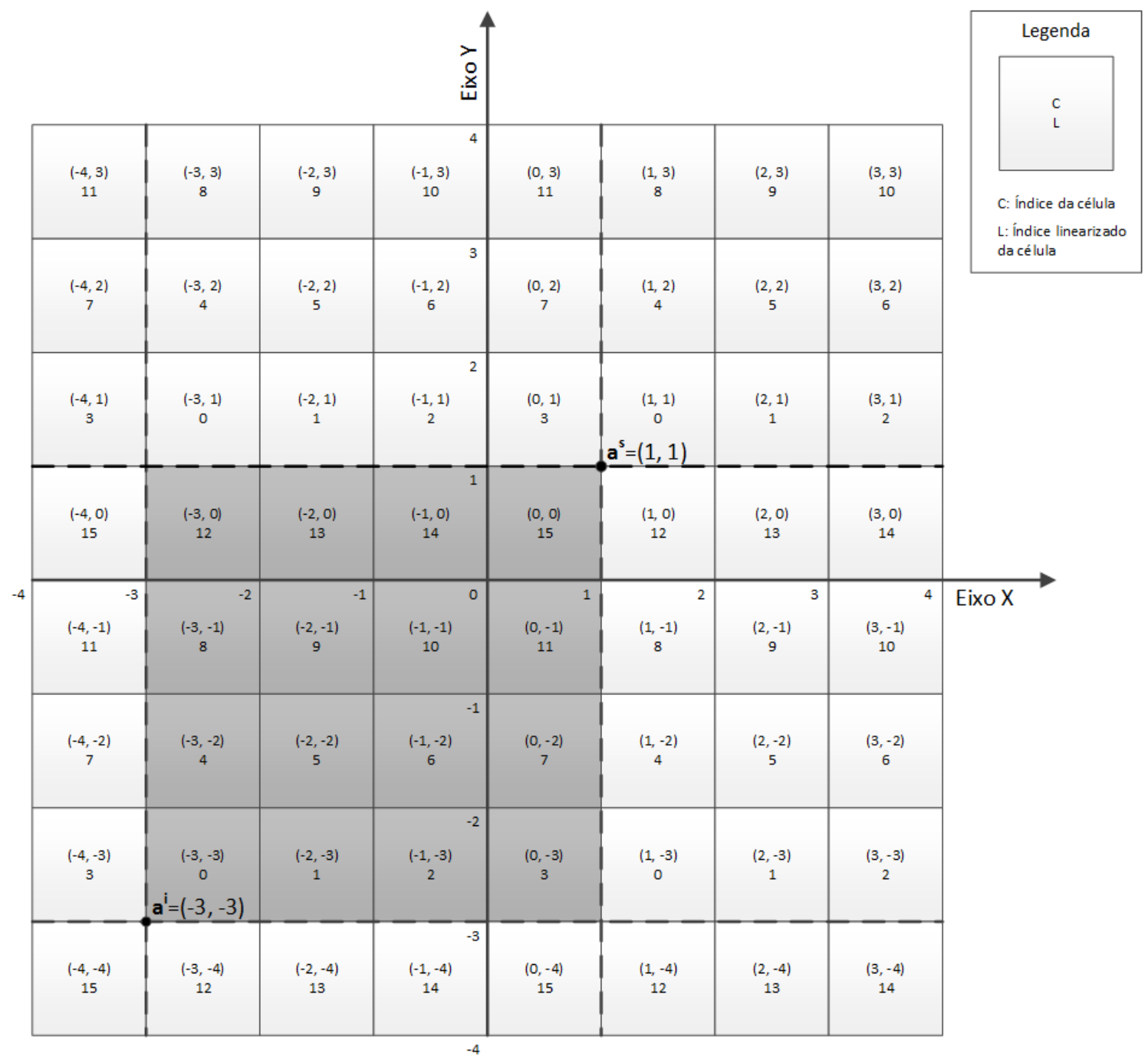

Figura 8 - Exemplo de uma grade.

É possível definir-se uma função de linearização $f: \mathbb{Z}^{3} \rightarrow \mathbb{N}$ que relaciona cada índice da célula $\boldsymbol{i}$ a um número $k$ denominado índice linearizado da célula, como é mostrado a seguir:

$$
\begin{gathered}
k=f(\boldsymbol{i})=\llbracket x_{1}^{f} s_{1} \rrbracket+\llbracket x_{2}^{f} s_{1} s_{2} \rrbracket+\llbracket x_{3}^{f} s_{1} s_{2} s_{3} \rrbracket \\
\boldsymbol{s}=\boldsymbol{a}^{s}-\boldsymbol{a}^{i} \\
\boldsymbol{x}=\frac{\left(\boldsymbol{i}-\boldsymbol{a}^{i}\right)}{\boldsymbol{s}}
\end{gathered}
$$




$$
x^{f}=x-\lfloor x\rfloor
$$

sendo $\boldsymbol{a}^{i}$ e $\boldsymbol{a}^{s}$ o limite inferior e superior da subgrade, em coordenadas de grade, 【 』a função de arredondamento para o inteiro mais próximo, e $x^{f}$ a parte fracionária de $\boldsymbol{x}$.

A Figura 8 apresenta uma subgrade no espaço $\mathbb{R}^{2}$ com os índices linearizados de cada célula aplicando-se a função de linearização $18, \operatorname{com} \boldsymbol{a}^{i}=$ $(-3,-3)$ e $\boldsymbol{a}^{s}=(1,1)$. Observe na mesma Figura que é possível calcular os índices linearizados das células que não pertencem à subgrade, ou seja, que se encontram fora da região delimitada por $\boldsymbol{a}^{i}$ e $\boldsymbol{a}^{s}$, ocorrendo uma repetição dos índices linearizados das células que pertencem à subgrade. Isso é uma caraterística desejada da função de linearização, pois dispensa tratamento especial das células de borda da subgrade ao se calcular os índices linearizados das suas células vizinhas.

Para subgrades $n \times m$, onde $n$ e $m$ são inteiros potência de dois, a seguinte função de linearização poderia ser empregada:

$$
i=i_{1} \wedge\left(s_{1}-1\right)+\left[i_{2} \wedge\left(s_{2}-1\right)\right] s_{1}+\left[i_{3} \wedge\left(s_{3}-1\right)\right] s_{1} s_{2}
$$

onde $\wedge$ é o operador binário "e", e $s$ é o vetor definido na Equação 19. Esta formulação exige um número menor de ciclos do processador para ser computada se comparada à Equação 18. No entanto, a limitação do tamanho da subgrade ser obrigatoriamente potência de dois, torna o balanceamento de carga entre os subdomínios mais difícil de ser realizada. Isso porque, caso exista a necessidade de se expandir um subdomínio, deve-se no mínimo dobrá-lo de tamanho, e no caso de uma redução, dividi-lo pela metade. Dependendo do método de decomposição de domínio a ser empregado, esses saltos de tamanho da subgrade podem ser muito grandes, fazendo com que a carga de comunicação aumente consideravelmente.

A subgrade desempenha um papel fundamental na determinação dos subdomínios quando se emprega os métodos de decomposição de domínio discutidos neste trabalho. 


\subsection{BUSCA DE VIZINHOS}

O cálculo de todas as variáveis ponderadas pela função peso, das quais fazem parte todas as variáveis dependentes dos operadores diferenciais do método MPS, necessita saber o conjunto de partículas vizinhas associado a cada partícula. Além disso, durante o processo de computação dos seus valores, segue-se um padrão de acesso do tipo consulta de região esférica.

Uma possível abordagem seria considerar como vizinhas de cada partícula a totalidade $N$ de partículas, que faria com que a computação dessas grandezas tivesse uma complexidade computacional $O\left(N^{2}\right)$, tornando essa abordagem impraticável computacionalmente. Para se diminuir essa complexidade, seguindo o método proposto por Le Grand (LE GRAND, 2008), utiliza-se uma subgrade para ordenar as partículas de modo que a busca por vizinhos de uma delas seja $O(k)$, onde $k \ll N$ é o número máximo de partículas vizinhas, fazendo com que a complexidade seja $O(k N)$.

A Figura 9 apresenta um processo de ordenação sendo realizado em uma subgrade $4 \times 4$ com células de tamanho $h=2$. A Tabela 1 contém a posição e o índice linearizado da célula das partículas não ordenadas, que corresponde ao estado retratado na subgrade superior da Figura 9. A Tabela 2 contém os mesmos dados das partículas ordenadas, correspondente à subgrade inferior.

A seguir são apresentados em mais detalhes cada passo do algoritmo de ordenação das partículas na subgrade:

1. cálculo do índice linearizado da célula para cada partícula, apresentados na última linha da Tabela 2;

2. ordenação das partículas com base no índice linearizado, com a permutação dos dados de posição (e outros intrínsecos à partícula) durante o processo, representada pelas setas entre a Tabela 2 e 1;

3. computação do índice inicial e final (um após o fim) de cada célula e o número de partículas existentes em cada uma, representado na Tabela 3.

Como ficará claro mais adiante, a Tabela 3 contém os dados que possibilitam a rápida busca dos vizinhos de uma partícula. 


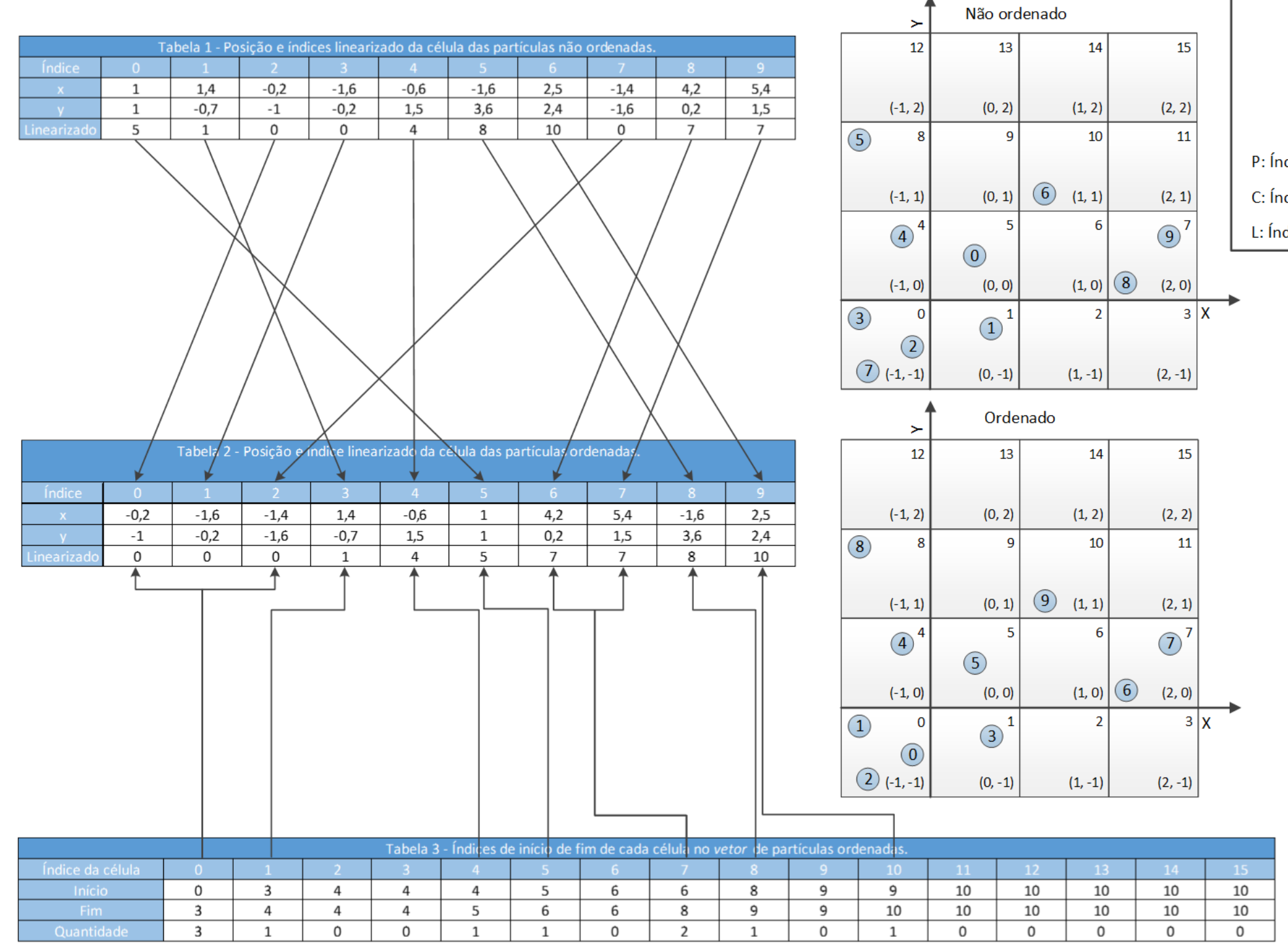

Figura 9 - Processo de ordenação das partículas na subgrade. 
Para cada célula, ela possui os seguintes dados:

1. Índice de início da célula: contém o índice da primeira partícula pertencente à célula no vetor de dados das partículas.

2. Índice de fim da célula: contém o índice posterior à útlima partícula pertencente à célula no vetor de dados das partículas.

3. Quantidade de partículas: contém a quantidade de partículas residente na célula.

Note que embora no exemplo tenha se empregado uma ordenação estável ${ }^{9}$, a estabilidade não é requisito do algoritmo.

A Figura 10 ilustra a procura dos vizinhos da partícula 9, e contém as Tabelas 4 e 5, além do estado da subgrade, mostrando quais são as suas partículas vizinhas.

A procura dos vizinhos de partícula é efetuada pelos seguintes passos:

1. cálculo do índice da célula baseado na posição da partícula, seguindo a Equação 17;

2. para esse índice, e para cada uma das células vizinhas, calcular o seu índice linearizado;

3. para cada índice linearizado, visitar a Tabela 4 para determinar o intervalo de partículas de cada célula vizinha na Tabela 5.

Para exemplificar esse algoritmo, considere a procura dos vizinhos da partícula 9 da Figura 10.

Primeiramente, baseado na sua posição, calcula-se o índice da célula na qual ela se encontra utilizando as Equações 17.

Nesse caso, $\boldsymbol{r}=(2,5 ; 2,4)$ e $h=2$, e portanto $\boldsymbol{i}=\left\lfloor\frac{r}{h}\right\rfloor=\left\lfloor\frac{(2,5 ; 2,4)}{2}\right\rfloor=(1,1)$. Seguindo as Equações 18 a 21, com $\boldsymbol{a}^{i}=(-1,-1), \boldsymbol{a}^{s}=(3,3), \boldsymbol{s}=\boldsymbol{a}^{s}-\boldsymbol{a}^{i}=(4,4)$, $\boldsymbol{x}=\frac{\left(\boldsymbol{i}-\boldsymbol{a}^{i}\right)}{\boldsymbol{s}}=\frac{((1,1)-(-1,-1))}{(4,4)}=(0,5 ; 0,5), \boldsymbol{x}^{f}=\boldsymbol{x}-\lfloor\boldsymbol{x}\rfloor=(0,5 ; 0,5)$, o valor do seu índice linearizado é $k=\llbracket x_{1}^{f} s_{1} \rrbracket+\llbracket x_{2}^{f} s_{1} s_{2} \rrbracket=\llbracket 0,5 \cdot 4 \rrbracket+\llbracket 0,5 \cdot 4 \cdot 4 \rrbracket=10$, e das suas células vizinhas $(0,0),(1,0),(2,0),(0,1),(2,1),(0,2),(1,2)$ e $(2,2)$, é $5,6,7,9,11,13,14$ e 15 , respectivamente, como mostra a Figura 10.

\footnotetext{
${ }^{9}$ Algoritmos de ordenação estáveis são aqueles que matem a ordem relativa entre os elementos. Isso significa que caso $a=b$, e $a$ preceder $b$ antes da ordenação, a precedência é mantida após a ordenação.
} 


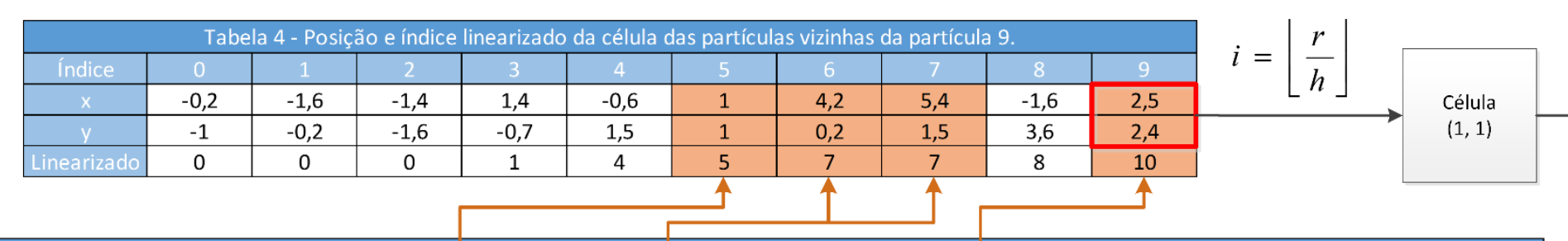

Tabela 5 - Células não vazias que contêm partículas vizinhas da partícula 9.

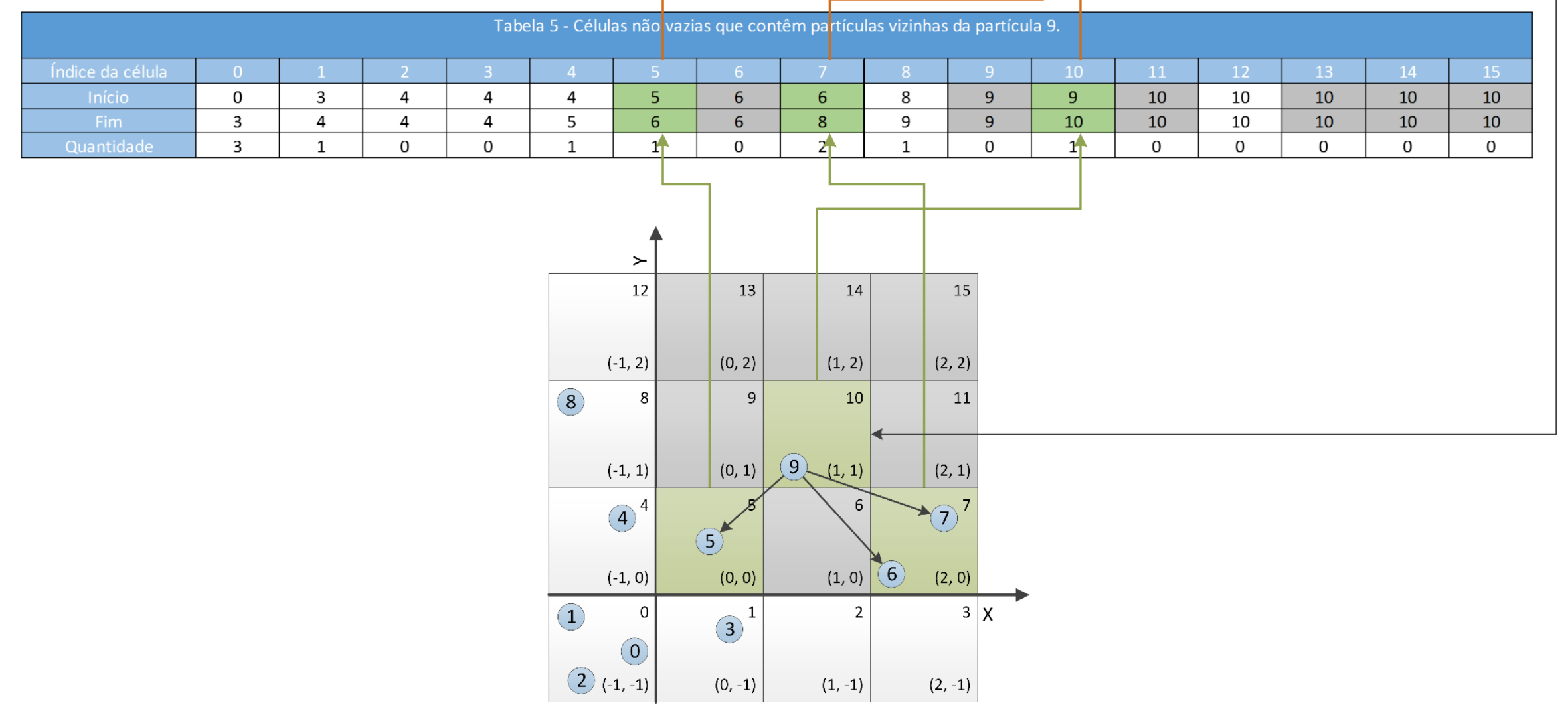

Figura 10 - Exemplo de um processo de busca de vizinhos. 
A partir desse conjunto de índices linearizados procuram-se os intervalos não vazios de início e fim das células, como destacado na Tabela 4. Enfim, conclui-se que as partículas vizinhas se encontram nos intervalos [5, 6[ e [6, 8[ da Tabela 5, conforme destacado na mesma.

Fazendo-se esse mesmo procedimento para a partícula de índice 2, por exemplo, conclui-se que as partículas de índice 6 e 7 são seus vizinhos. Isso porque o índice da célula que contém a partícula de índice 2 é $(-1,-1)$ e o índice linearizado da sua célula vizinha $(-2,0)$ é 7 , exatamente o índice linearizado da célula $(2,0)$.

Como se afirmou na subseção anterior, a repetição dos índices linearizados para células que não pertencem à subgrade é uma característica desejada da função de linearização, para se evitar o tratamento especial das células de borda da subgrade. A identificação das partículas 6 e 7 como vizinhas da partícula 2, no entanto, não ocasiona inconsistências no cálculo, pois naturalmente as suas contribuições serão nulas devido à ponderação da função peso.

Outros métodos foram propostos para se baixar a complexidade computacional da busca de vizinhos, como por exemplo, através da utilização de listas ligadas (LIU; LIU, 2003). No entanto o uso de estruturas de dados complexas não se adequa à arquitetura GPU. Portanto, optou-se pelo emprego de um método rápido e ao mesmo tempo com estrutura de dados simples e compatível com várias arquiteturas de processamento paralelo.

\subsubsection{Minimização do Número de Buscas}

Esta subseção discorre a respeito da possibilidade de se minimizar a quantidade de vezes que a busca de vizinhos é realizada durante uma simulação. Isso é possível adotando-se um tamanho de célula maior que o raio de influência, no entanto, surge a necessidade de se determinar qual o instante que uma nova busca é obrigatória, para se garantir a consistência no cálculo do método E-MPS. Essa garantia é imprescindível para que sejam consideradas no cálculo das variáveis ponderadas pela função peso de uma determinada partícula, todas as suas partículas vizinhas dentro do raio de influência. 
Pelo algoritmo de busca de vizinhos apresentado na subseção 3.3, o conjunto de partículas vizinhas $V$ de uma partícula pertencente a uma célula $C$, são aquelas que residem nas células vizinhas de $C$. Dessa forma, o tamanho das células $h$ da subgrade não deve ser menor que o raio de influência $r_{e}$ adotado nos cálculos.

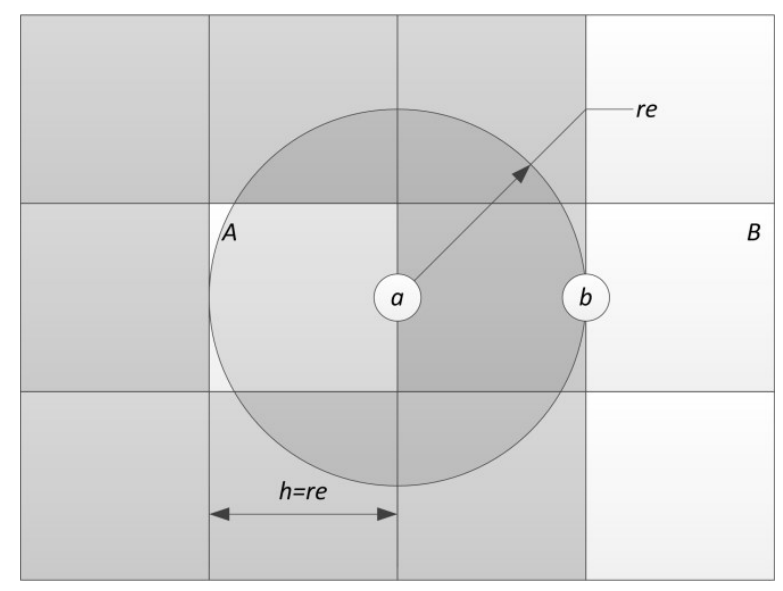

Figura 11 - Caso em que o tamanho da célula é exatamente o raio de influência (as células vizinhas de $A$ são destacadas em cinza).

Note que para o caso em que $h=r_{e}$, deve-se fazer uma nova busca de vizinhos após qualquer deslocamento das partículas, o que ocorre nos passos de predição e correção das suas posições. Um exemplo desse caso é mostrado na Figura 11, na qual a partícula $a$ se encontra no limite direito da célula $A$ e a partícula $b$ no limite esquerdo da célula $B$. Portanto, neste cenário, ao se realizar a busca de vizinhos, a partícula $b$ não constaria na lista de vizinhos de $a$. No entanto, o menor deslocamento relativo entre $a$ e $b$ pode fazer com que $b$ entre no raio de influência de $a$, exigindo-se a atualização da lista de vizinhos de $a$.

Já quando $h>r_{e}$, é possível manter a mesma lista de vizinhos durante um determinado número de passos de simulação sem incorrer em inconsistências. Contudo deve-se prover uma forma de detectar quando uma nova busca de vizinhos de ser feita.

Em (DOMÍNGUEZ; CRESPO; MARONGIU, 2011) é proposto um esquema estável de detecção do instante em que a nova busca de vizinhos se torna necessária, através do controle do deslocamento de cada partícula desde a última atualização da lista de vizinhos.

Sendo $\Delta h=h-r_{e}$, uma partícula qualquer e seus vizinhos podem se deslocar no máximo $\Delta h / 2$ para se garantir que a lista de vizinhos continue válida, considerandose o pior caso, como mostra a Figura 12. 

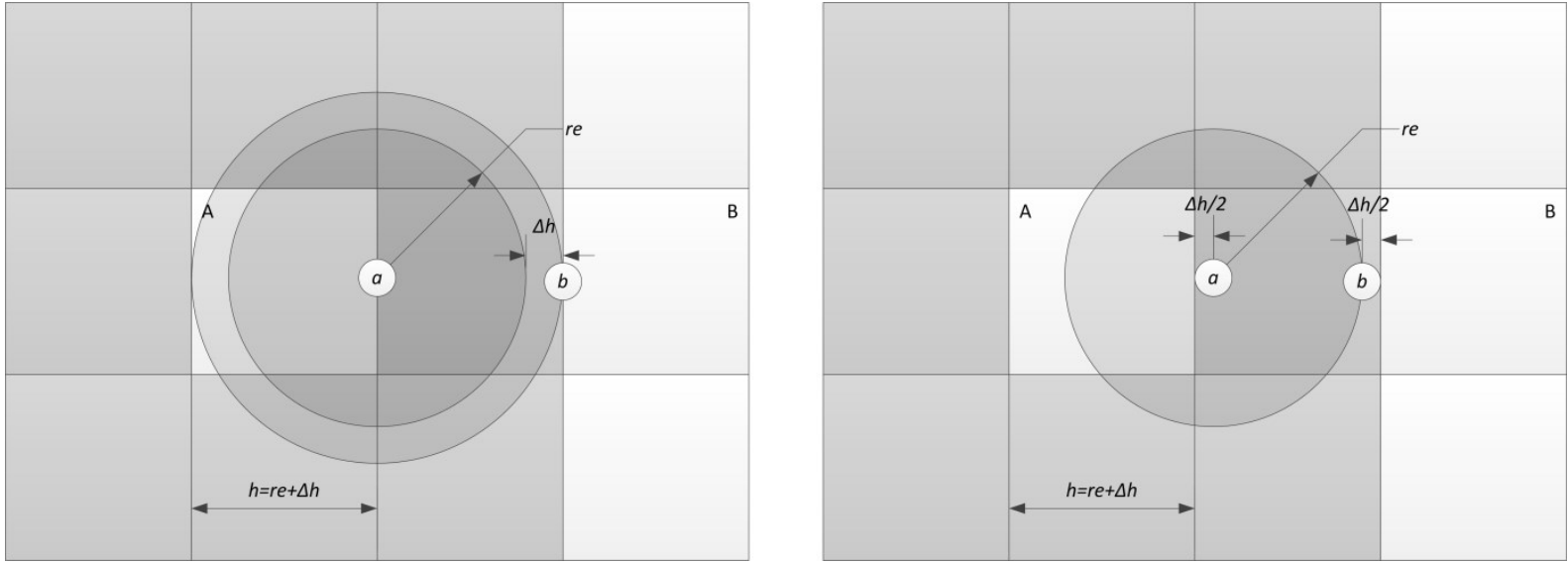

Figura 12 - Tamanho de célula maior que o raio de influência.

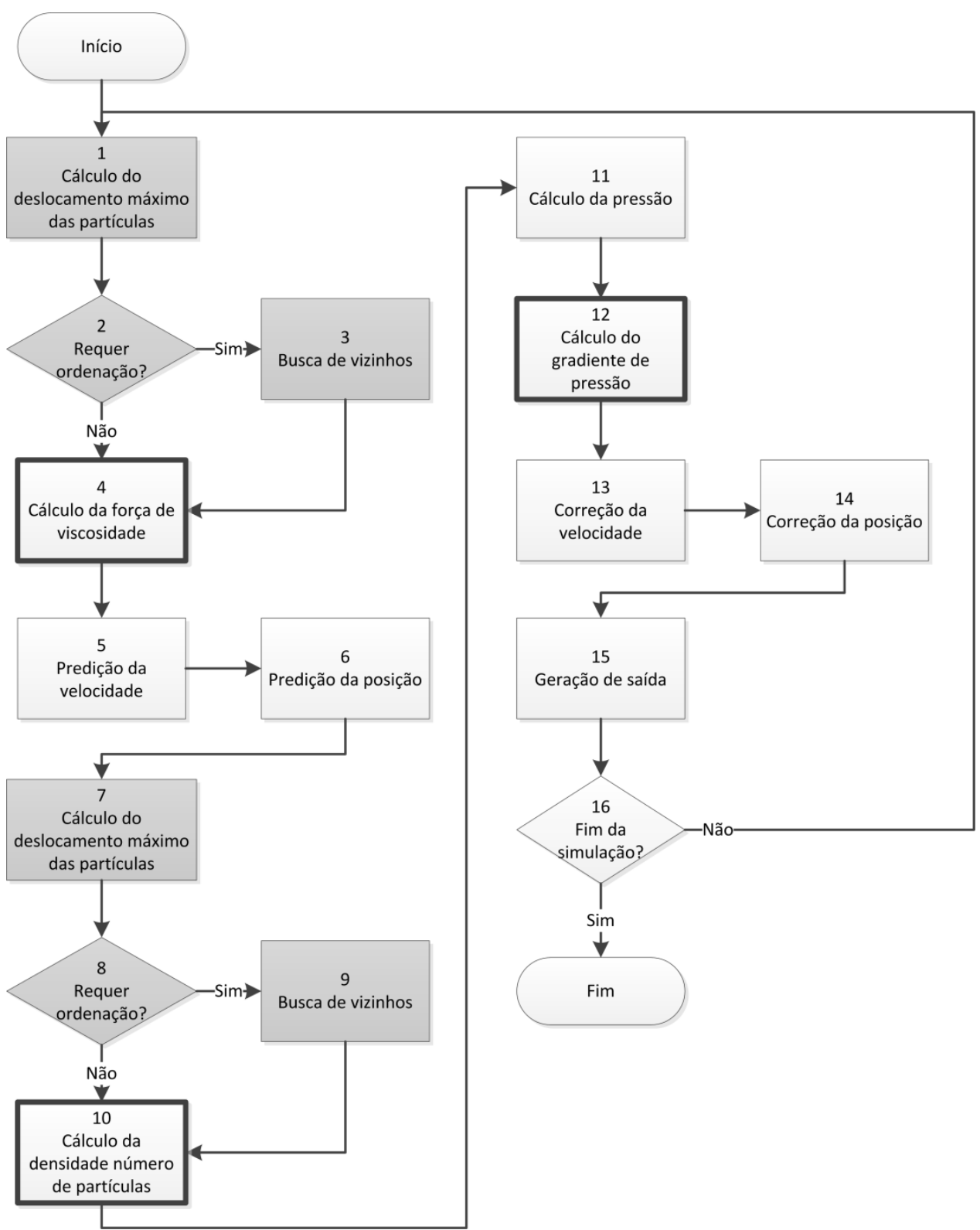

Figura 13 - Fluxograma do método E-MPS com controle de ordenação. 
Portanto a lista de vizinhos é mantida até que o deslocamento de qualquer partícula do domínio seja igual ou superior a $\Delta h / 2$. Ao se alcançar esse limite, a lista de vizinhos é refeita através do processo descrito na subseção 3.3.

A Figura 13 mostra o fluxograma do método E-MPS com o controle do deslocamento das partículas para decisão quanto à necessidade de se refazer a busca de vizinhos. Comparando-se com o fluxograma apresentado na Figura 6 da subseção 3.1.2, nota-se a existência de seis processos antes não presentes, destacados em cinza. Dentre eles, os processos 1 e 7 calculam os deslocamentos das partículas, enquanto nos processos de decisão 2 e 8 verifica-se se algum deslocamento foi igual ou superior a $\Delta h / 2$. Caso haja alguma partícula que alcançou esse limite, os processos 3 e 9 efetuam a ordenação seguindo o algoritmo apresentado na subseção 3.3. Para o caso em que $h=r_{e}$, os processos 1 e 7 não são executados, e a ordenação é sempre realizada a cada deslocamento nos processos 6 e 14.

Na subseção 6.3 é mostrado o impacto da utilização de diferentes valores de $\Delta h$ no desempenho computacional do método. 


\section{COMPUTAÇÃO PARALELA DO MÉTODO E-MPS}

Nesta seção são apresentadas as técnicas propostas de algoritmo de comunicação entre subdomínios e decomposição de domínio. Em um âmbito mais amplo, esta seção é dedicada às técnicas de decomposição de domínio espacial que possibilita o trabalho conjunto de várias máquinas paralelas interligadas, formando uma arquitetura de memória distribuída. A definição de decomposição de domínio que se emprega neste trabalho é realizada de maneira que ela seja puramente espacial e não afete as equações governantes e algébricas (SEAL; ALURU, 2007).

A divisão do domínio em subdomínios possibilita a existência de um conjunto de processos paralelos, que de forma conjunta, faz a computação da simulação do domínio como um todo. Como esse paralelismo é feito numa arquitetura de memória distribuída, cada processo deve possuir em sua memória apenas o conjunto de partículas contidas no seu subdomínio. Isso garante a escalabilidade do método em termos de consumo de memória, mas gera a necessidade de comunicação entre as partículas na vizinhança das fronteiras dos subdomínios. Esse trabalho inclui uma proposta nova de comunicação que se adequou a todos os métodos de decomposição aqui investigados.

Os métodos de decomposição espacial investigadas neste trabalho foram o estático (não adaptativo), ORB e ortogonal. O método cell transfer é proposto neste trabalho para superar as limitações geométricas apresentadas pelos métodos mencionados acima. Porém, a sua implementação deverá ficar a cargo de trabalhos futuros.

A seguir apresenta-se uma série de definições que auxiliam no entendimento dos algoritmos descritos no decorrer desta seção.

\subsubsection{Definições}

A decomposição de um domínio de simulação $\mathcal{D}$ gera um conjunto de subdomínios $\mathcal{S}=\left\{\mathcal{D}^{0}, \mathcal{D}^{1}, \ldots, \mathcal{D}^{N-1}\right\}$, sendo $N$ o número total de subdomínios. Cada subdomínio $\mathcal{D}^{r}$ é processado por um processo $p^{r}$, e possui o seu conjunto de partículas $\mathcal{P}^{r}$ em uma arquitetura de memória distribuída. $\mathcal{P}=\mathcal{P}^{0} \cup \mathcal{P}^{1} \cup \ldots \cup \mathcal{P}^{N-1}$ é 
o conjunto universal de partículas do domínio $\mathcal{D} \cdot \mathcal{C}^{r}$ é o conjunto de células do subdomínio $\mathcal{D}^{r}$, e $\mathcal{C}_{c}$ é o conjunto de partículas de uma célula $c$.

A seguir, listam-se algumas definições que irão auxiliar no entendimento dos algoritmos relacionados aos métodos de decomposição analisados neste trabalho:

- $\quad$ partículas vizinhas - para uma dada partícula $i$, é o conjunto de partículas $\mathcal{V}_{i}=\left\{j \in \mathcal{P} \mid r_{i j}<r_{e}\right\}$, sendo $r_{i j}$ a distância entre as partículas $i$ e $j$, e $r_{e} \mathrm{o}$ raio de influência. Note que $j \in \mathcal{V}_{i} \rightarrow i \in \mathcal{V}_{j}$;

- $\quad$ partículas de borda - dado um subdomínio $\mathcal{D}^{r}$, o seu conjunto de partículas de borda $\mathcal{B}^{r}$, contém todas as partículas $i$ que dentre o seu conjunto $\mathcal{V}_{i}$ de partículas vizinhas possui ao menos uma partícula pertencente a outro subdomínio, ou seja, $\mathcal{B}^{r}=\left\{i \in \mathcal{P}^{r} \mid \exists j \in \mathcal{V}_{i}: j \notin \mathcal{P}^{r}\right\}$.

- subdomínios vizinhos - sendo $\mathcal{W}^{r}$ o conjunto de subdomínios vizinhos de $\mathcal{D}^{r}$, um subdomínio $\mathcal{D}^{k}$ é vizinho de $\mathcal{D}^{r}$ caso exista alguma partícula de borda de $\mathcal{D}^{r}$ que possua uma partícula de $\mathcal{D}^{k}$ dentre as suas partículas vizinhas, ou seja, $\mathcal{W}^{r}=\left\{\mathcal{D}^{k} \in \mathcal{D} \mid \exists i \in \mathcal{B}^{r}: \mathcal{V}_{i} \cap \mathcal{P}^{k} \neq \emptyset\right\}$.

- células transmissoras - para um dado subdomínio $\mathcal{D}^{r}$ e seu subdomínio vizinho $\mathcal{D}^{k}$, o seu conjunto de células transmissoras $\mathcal{T}^{r k}$ são todas as células que possuem partículas para as quais ao menos uma partícula vizinha pertence a $\mathcal{D}^{k}$. Dessa forma, $\mathcal{T}^{r k}=\left\{c \in \mathcal{C}^{r} \mid \exists i \in \mathcal{C}_{c}: \mathcal{V}_{i} \cap \mathcal{P}^{k} \neq \emptyset\right\}$.

- células receptoras - para um dado subdomínio $\mathcal{D}^{r}$ e seu subdomínio vizinho $\mathcal{D}^{k}$, o conjunto de células receptoras $\mathcal{R}^{r k}$ são todas as células de $\mathcal{D}^{k}$ que possuam partículas para as quais ao menos uma partícula vizinha pertença a $\mathcal{D}^{r}$, ou seja, $\mathcal{R}^{r k}=\left\{c \in \mathcal{C}^{k} \mid \exists i \in \mathcal{C}_{c}: \mathcal{V}_{i} \cap \mathcal{P}^{r} \neq \emptyset\right\}$.

- células comunicantes - para um subdomínio $\mathcal{D}^{r}$, o seu conjunto de células comunicantes $\mathcal{U}^{r}$ é a união, para todos os subdomínios vizinhos, das células transmissoras e receptoras. Assim, $\mathcal{U}^{r}=\left(\cup^{k} \mathcal{R}^{r k}\right) \cup\left(\cup^{k} \mathcal{T}^{r k}\right)$.

\subsubsection{Axis Aligned Bounding Box (AABB)}

Ao se decompor o domínio, surge a necessidade de se verificar quais são os subdomínios vizinhos para os quais se deve comunicar as partículas de borda, além 
de se determinar as células comunicantes. Uma maneira simples de se prover essas funcionalidades é o emprego de $\mathrm{AABBs}$ na representação das subgrades que compõem cada subdomínio.

AABB é um hipercubo alinhado aos eixos cartesianos que pode ser definido por dois pontos que delimitam seus hiperplanos inferiores e superiores, muito comumente utilizado para detecção de colisões na área de computação gráfica (GOMEZ, 2001).

Neste trabalho esses pontos são definidos em coordenadas de grade fazendo com que todo AABB seja também uma subgrade, podendo se aplicar, da mesma forma descrita nas subseções 3.2 e 3.3, os algoritmos de linearização dos índices das células e busca de vizinhos. Assim, o AABB pode ser visto como um hipercubo composto de células, podendo ser definido como segue:

$$
\begin{gathered}
A=\left[a_{1}^{i}, a_{1}^{s}\left[\times\left[a_{2}^{i}, a_{2}^{s}\left[\times\left[a_{3}^{i}, a_{3}^{s}[\right.\right.\right.\right.\right. \\
=\left\{\left(x_{1}, x_{2}, x_{3}\right) \in \mathbb{Z}^{3} \mid a_{1}^{i} \leq x_{1}<a_{1}^{s} \text { e } a_{2}^{i} \leq x_{2}<a_{2}^{s} \text { e } a_{3}^{i} \leq x_{3}<a_{3}^{s}\right\}
\end{gathered}
$$

onde $\boldsymbol{a}^{i}$ é o limite inferior e $\boldsymbol{a}^{s}$ o limite superior, em coordenadas de grade, do AABB A.

O AABB $A^{+}$é chamado de AABB estendido de $A$ da forma:

$$
A^{+}=\left[a_{1}^{i}-1, a_{1}^{s}+1\left[\times\left[a_{2}^{i}-1, a_{2}^{s}+1\left[\times\left[a_{3}^{i}-1, a_{3}^{s}+1[\right.\right.\right.\right.\right.
$$

A interseção de dois AABBs é dada por:

$$
\begin{gathered}
A \cap B=\left\{\left(x_{1}, x_{2}, x_{3}\right) \in \mathbb{Z}^{3} \mid \max \left(a_{1}^{i}, b_{1}^{i}\right) \leq x_{1}<\min \left(a_{1}^{s}, b_{1}^{s}\right) e \max \left(a_{2}^{i}, b_{2}^{i}\right) \leq x_{2}\right. \\
\left.<\min \left(a_{2}^{s}, b_{2}^{s}\right) e \max \left(a_{3}^{i}, b_{3}^{i}\right) \leq x_{3}<\min \left(a_{3}^{s}, b_{3}^{s}\right)\right\}
\end{gathered}
$$

$\mathrm{Na}$ próxima seção serão apresentados em detalhes os métodos de se determinar os subdomínios vizinhos e as células comunicantes utilizando-se AABBs.

\subsubsection{Comunicação entre Subdomínios}

Independentemente do método de decomposição escolhido é possível se definir um esquema para comunicação das partículas de borda entre subdomínios vizinhos que atenda a grande maioria deles. Isso se torna evidente ao se analisar que o problema de se distinguir, transmitir e receber as partículas de borda estará presente em qualquer método de decomposição. Ao menos para os métodos investigados neste trabalho a estratégia adotada se mostrou suficiente. 
Além de ser genérico, o método aqui proposto evita qualquer passo adicional de ordenação, diferentemente da proposta apresentada por Valdez-Balderas (VALDEZ-BALDERAS et al., 2013). Além disso, a sua proposta não deixa claro se é possível empregá-la em outros métodos de decomposição, e não há estudos ou comparações nesse sentido. O método proposto neste trabalho e apresentado em (TANIGUCHI; SATO; CHENG, 2012) é uma extensão do método de busca de vizinhos quando se tem múltiplos subdomínios.

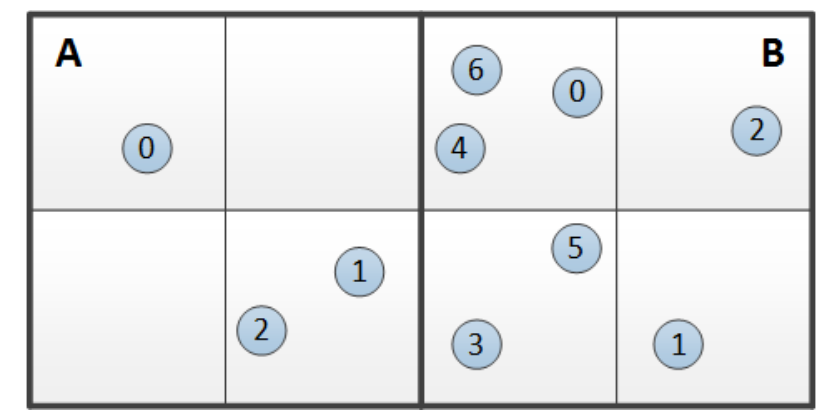

Figura 14 - Dois subdomínios vizinhos com partículas não ordenadas.

A Figura 14 apresenta dois subdomínios vizinhos $A$ e $B$, cada um sendo processado por processos distintos $P_{A}$ e $P_{B}$ respectivamente. As partículas nelas contidas se encontram ainda não ordenadas, com numeração baseada nos índices de cada uma no vetor de dados. Para o correto cálculo da densidade número de partículas da partícula 1 do subdomínio $A$, por exemplo, o processo $P_{B}$ deve enviar as posições das partículas $0,3,4,5$, e 6 para $P_{A}$.

O algoritmo de comunicação aqui proposto requer que todos os subdomínios tenham realizado a busca de vizinhos, e que os dados decorrentes da busca estejam válidos.

Para realizar a busca de vizinhos das partículas de cada subdomínio são utilizados os respectivos AABBs estendidos, como mostra a Figura 15, seguindo o método descrito na Seção 3.3. Dessa forma, note que existe uma sobreposição de células de $A^{+}$e $B^{+}$que ocupam o mesmo espaço, e que os seus índices linearizados são diferentes. O mesmo espaço ocupados pelas células de índice linearizado 6 e 10 de $A^{+}$, é ocupado pelas células 4 e 8 de $B^{+}$. Isso é feito para que existam células em $A^{+}$preparadas para recepcionar as partículas de borda de $B^{+}$, e que elas sejam consideradas ao se fazer a busca de vizinhos de uma partícula de $A^{+}$.

Além da alteração dos índices das partículas decorrente do processo de ordenação, representada pelas setas entre as Tabelas 6 e 7 para o 

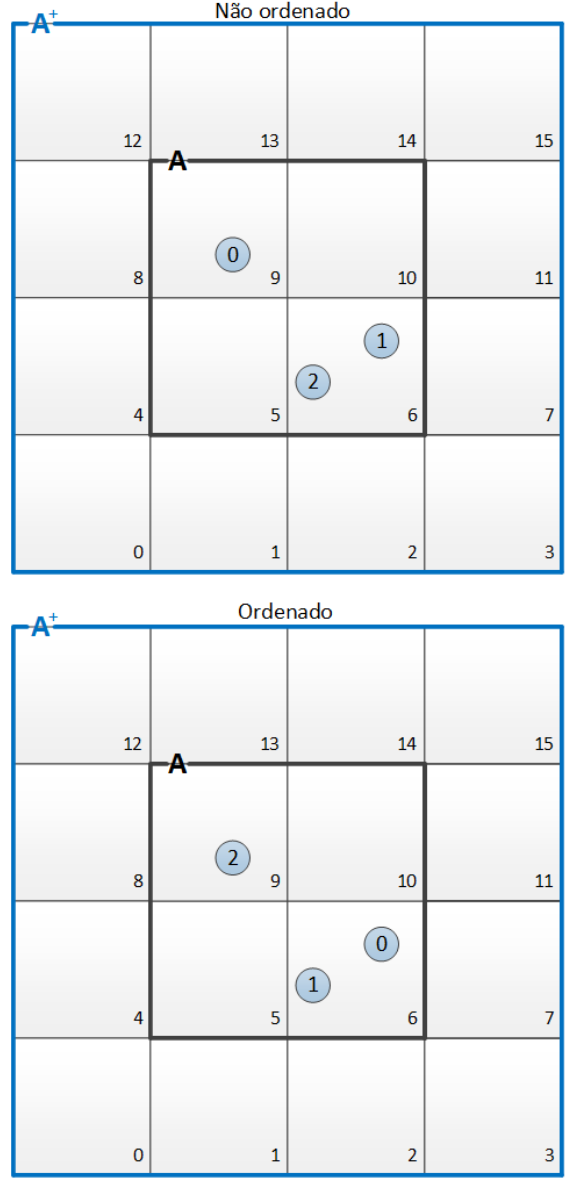
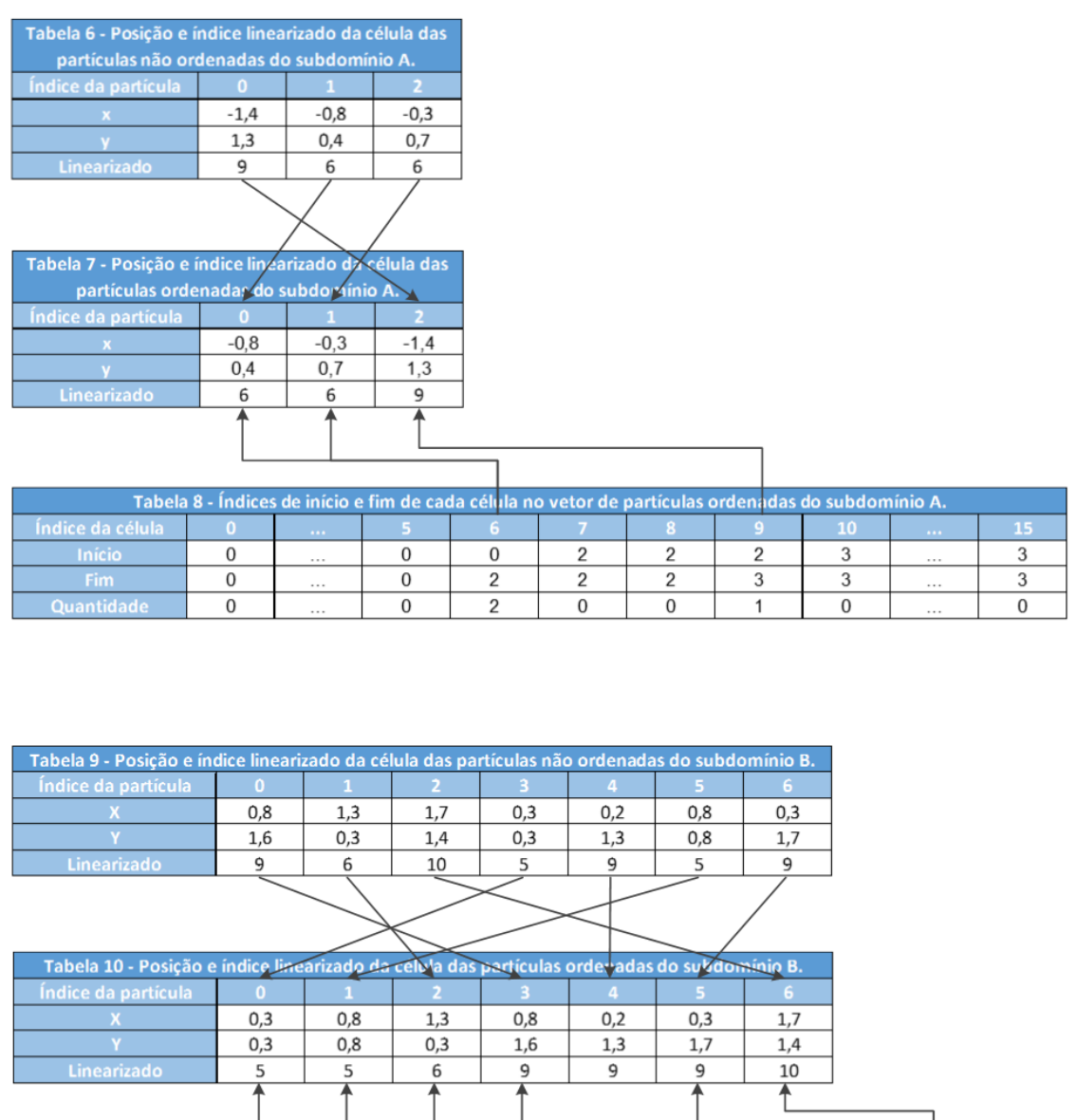

Tabela 11 - Índices de inicio e fim de cada celula no vetor de particulas order adas do st tbdominio B.

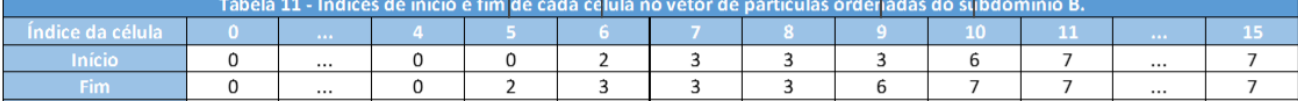

Fim
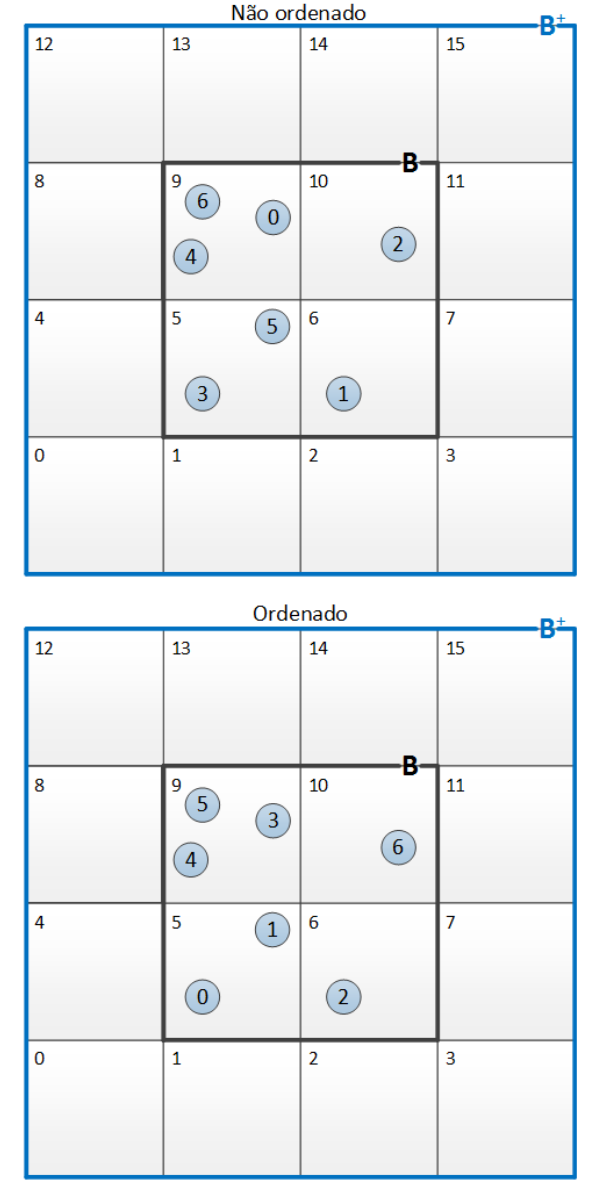

Figura 15 - Processo de ordenação utilizando o AABB estendido de cada subdomínio. 
subdomínio $A$, e entre as Tabelas 9 e 10 para o subdomínio $B$, os índices de início e fim das células no vetor de partículas ordenadas, representadas pelas Tabelas 8 e 11, são de suma importância para permitir que a busca de vizinhos seja feita de forma eficiente.

Dado um subdomínio delimitado pelo AABB $U$, o algoritmo empregado para detecção dos seus subdomínios vizinhos é descrito a seguir:

1. para cada subdomínio com AABB $V \neq U$ participante da simulação, calcular $V^{+} \cap U$

2. caso $V^{+} \cap U$ não for vazio, $V$ é considerado vizinho de $U$, e guardado na lista de vizinhos;

3. para cada vizinho, armazenar a lista dos índices linearizados das células contidas em $V^{+} \cap U$, denominadas de células transmissoras, e contidas em $U^{+} \cap V$, chamadas de células receptoras.

As informações adquiridas no passo 3 são importantes para se diminuir a quantidade adicional de computação introduzidas pela comunicação.

Note que o conjunto $\mathcal{W}^{r}$ de subdomínios vizinhos de $\mathcal{D}^{r}$, definidos empregando-se o algoritmo acima, é um superconjunto da definição de subdomínios vizinhos apresentado na subseção 4.1.1. No entanto, isso não invalida o conjunto de vizinhos, podendo apenas ocorrer casos em que subdomínios que não possuam partículas que interajam com partículas de $\mathcal{D}^{r}$ sejam incluídos em $\mathcal{W}^{r}$. O mesmo ocorre com as células transmissoras e receptoras, visto que podem ser incluídas células que não possuam partículas.

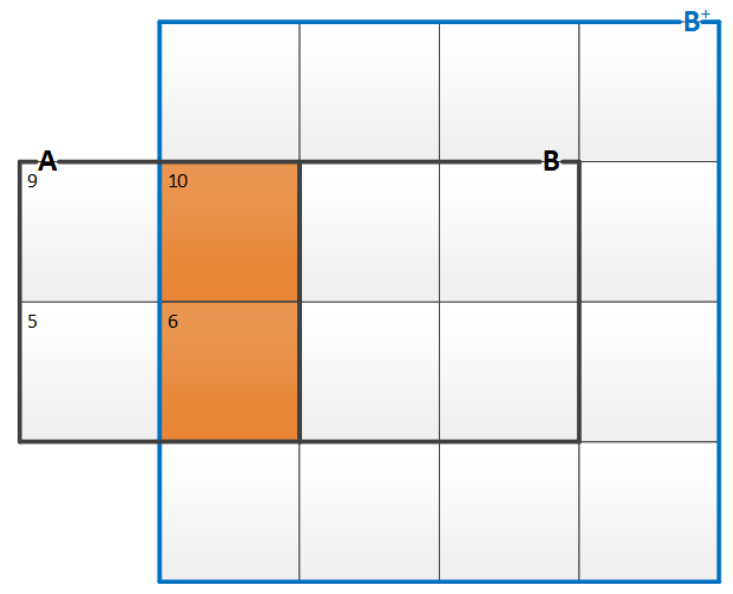

(a)

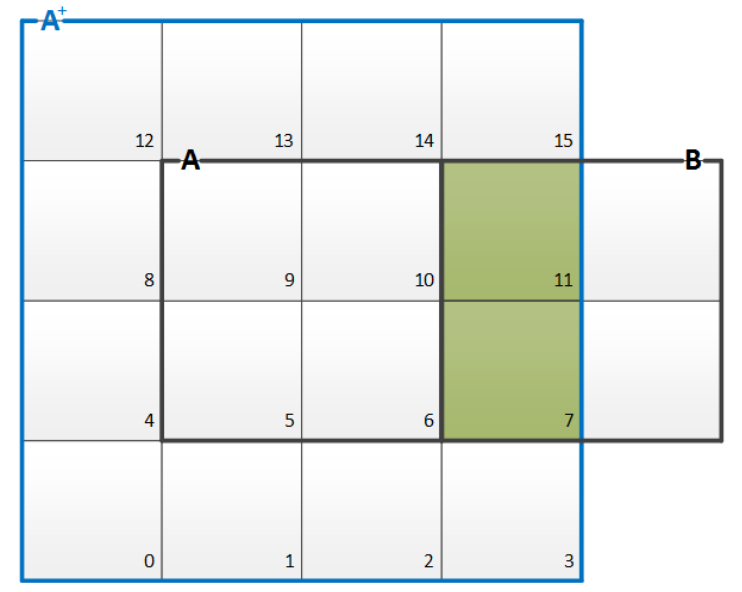

(b)

Figura 16 - Determinação das células receptoras do subdomínio A, destacadas em laranja, e transmissoras, destacadas em verde. 
Tabela 12 - Índices de inicio e fim do vetor de particulas do subdominio B, com células transmissoras em destaque.
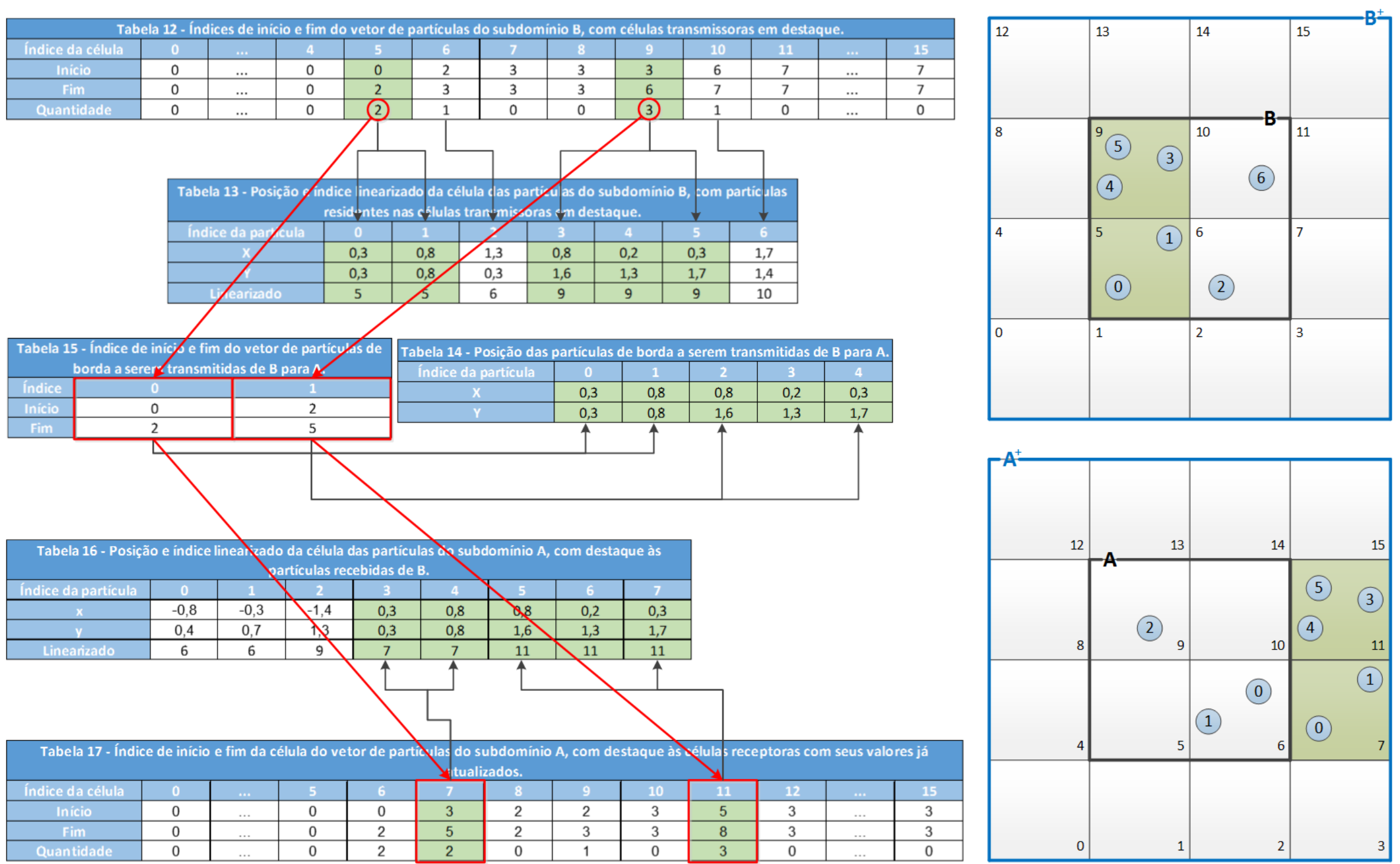

Figura 17 - Processo de transmissão das partículas de borda. 
Para o caso do subdomínio $A$, os índices linearizados das células transmissoras são 6 e 10, determinadas pela intersecção de $A$ com $B^{+}$, e receptoras 7 e 11, determinadas pela intersecção de $A^{+} \operatorname{com} B$, como mostra a Figura 16. Aplicando-se o mesmo procedimento para o subdomínio $B$, tem-se que os índices linearizados das células transmissoras são 5 e 9, e receptoras 4 e 8 .

O processo de transmissão das partículas de borda de $B$ para $A$, retratado na Figura 17, se dá a partir do seguinte algoritmo sendo executado por $P_{B}$ :

1. Para cada célula transmissora copiar os dados das partículas nelas residentes para um vetor. No exemplo, as células transmissoras 5 e 9 estão destacadas na Tabela 16 e as partículas nelas situadas apresentam-se igualmente destacadas na Tabela 17. O vetor das partículas residentes nas células transmissoras é representado pela Tabela 15.

2. Utilizar outro vetor para armazenar os índices linearizados do início e fim de cada célula do vetor criado no passo anterior Tabela 13.

Para se manter a simplicidade do exemplo, apenas a transmissão das posições das partículas é retratada, mas outras informações podem ser enviadas conjuntamente sem o aumento da complexidade do algoritmo.

Os dois vetores, representados pelas Tabelas 15 e 13, devem ser enviados para $P_{A}$, que processa a informação recebida da seguinte forma:

1. Concatenar os dados recebidos ao vetor de dados das partículas correspondente à Tabela 14, na qual são destacados os dados recebidos.

2. Atualizar os índices linearizados de início e fim das células receptoras, destacadas na Tabela 12.

Dessa maneira, ao se realizar a busca de vizinhos em $P_{A}$, as partículas $0,1,3$, 4 e 5 de $B$ serão corretamente consideradas, permitindo que as grandezas ponderadas pela função peso tenham os seus cálculos efetuados corretamente. Outra consequência de se empregar esse método de comunicação é que o processo de busca de vizinhos, embora efetuado de forma local em cada subdomínio, tem a sua validade em todo domínio. Pode-se afirmar, portanto, que a busca de vizinhos é efetuada de maneira paralela entre os subdomínios, e é aplicável a todos os métodos de decomposição investigados neste trabalho. Isso graças à prospecção das células transmissoras e receptoras para cada par de subdomínios vizinhos e a transmissão 
dos intervalos de cada célula para os dados transmitidos. Vale salientar que estes últimos possuem custo computacional e de comunicação reduzidos.

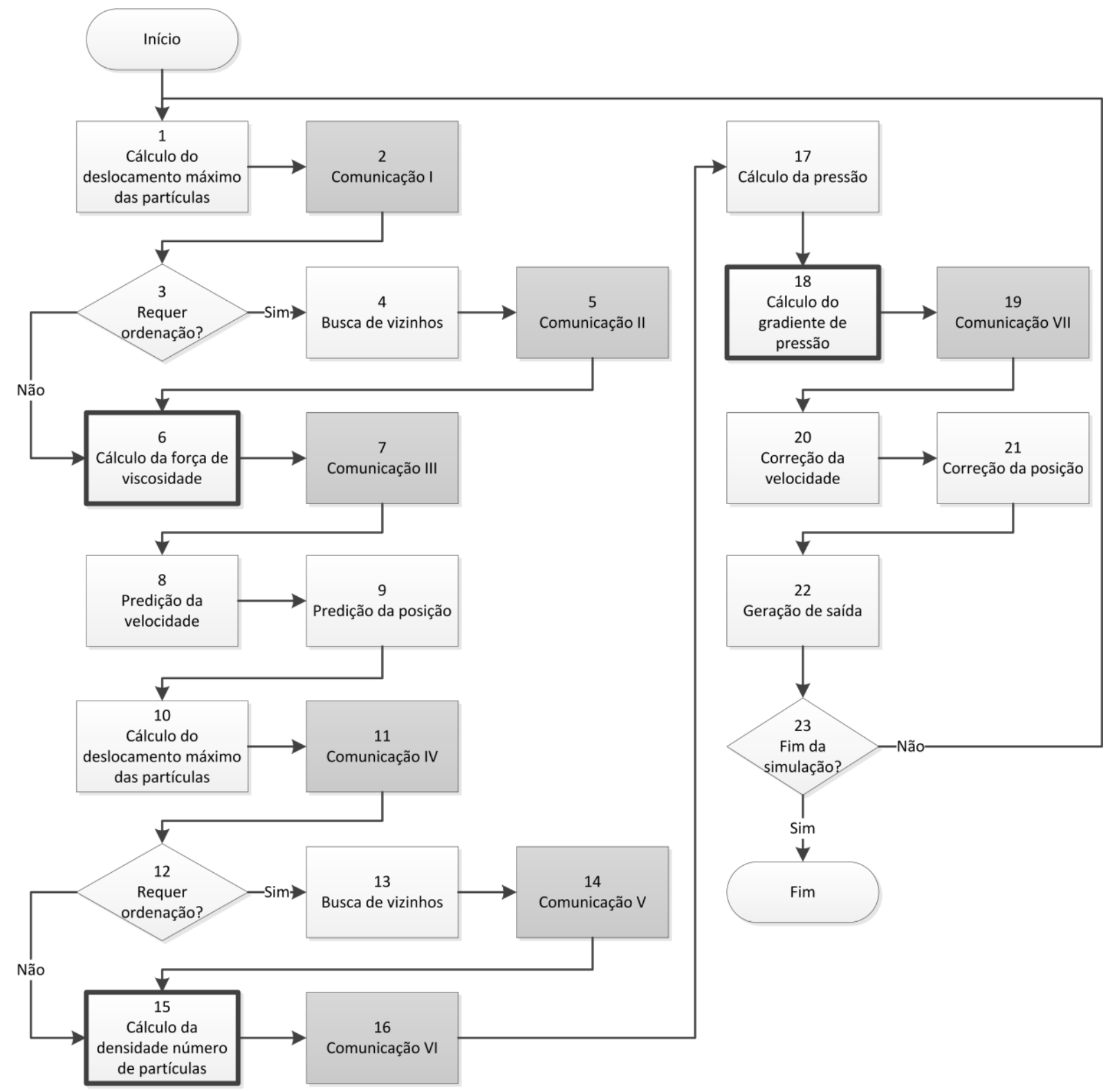

Figura 18 - Fluxograma do método E-MPS com comunicação entre subdomínios.

A clara separação entre as partículas pertencentes ao subdomínio e aquelas advindas de subdomínios vizinhos é a grande vantagem do método exposto. Isso permite, de maneira fácil, a separação da computação e tratamento para cada uma dessas categorias distintas.

Durante o cálculo das grandezas ponderadas pela função peso, itera-se apenas nas partículas pertencentes ao subdomínio, pois trata-se do subconjunto de partículas para as quais se garante o conhecimento de todas as partículas vizinhas. Já em todos os outros processos itera-se no conjunto total das partículas, inclusive as advindas 
dos subdomínios vizinhos. Isso, por sua vez, evita o aparecimento de passos de comunicação a cada cálculo de variável.

Na Figura 18 apresenta-se o fluxograma do método E-MPS quando algum método de decomposição é utilizado. Nele é possível ver os processos de comunicação acrescentados ao fluxograma apresentado na Figura 13 da subseção 3.3.1 destacados em cinza. O processo de prospecção das células transmissoras e receptoras não é apresentado no fluxograma pois ela é a única parte do algoritmo que depende do método de decomposição empregado, como ficará claro mais adiante.

No processo 1 calcula-se o deslocamento máximo $d_{\max }$ das partículas desde a última busca de vizinhos. Como discutido na seção 3.3.1, caso $d_{\max } \geq \Delta h / 2$, sendo $\Delta h=h-r_{e}, h$ o tamanho da célula, e $r_{e}$ o raio de influência, constata-se a necessidade de uma nova busca de vizinhos.

O passo de comunicação I é responsável por prover, para cada subdomínio, a informação quanto à necessidade de se refazer a busca de vizinhos de todos os subdomínios.

No processo de decisão 3 verifica-se a existência de algum subdomínio que efetuará a busca, e caso exista, todos a executam. Do contrário os processos dos subdomínios que não ultrapassaram o limite de deslocamento entrariam em estado de espera, ficando apenas aguardando os processos de busca de vizinhos serem finalizados. Fazendo-se a busca conjunta elimina-se a existência de qualquer processo em estado de espera, e minimiza a quantidade total de ordenações.

Em consequência do processo de busca de vizinhos há também a necessidade de um novo passo de comunicação (II e V) para atualização das partículas de borda.

Os processos 6, 15 e 18 efetuam os cálculos das variáveis ponderadas pela função peso, e por isso, operam apenas nas partículas dentro dos AABBs de cada subdomínio.

Os passos de comunicação III, VI e VII posteriores a eles transmitem os valores dessas variáveis referentes às partículas de borda. Esses passos de comunicação não são necessários para as variáveis que não são ponderadas pela função peso, pois calcula-se seus valores para todas as partículas dentro do AABB estendido de cada subdomínio. Isso diminui drasticamente a quantidade de passos de comunicação necessária. 
Em resumo, os dados das partículas transmitidos em cada passo de comunicação são:

- Passo de comunicação I e IV - necessidade de executar a busca de vizinhos.

- Passo de comunicação II e V - posição, velocidade, índice do material, índice de início de célula e índice de fim de célula.

- Passo de comunicação III - força de viscosidade.

- Passo de comunicação VI - densidade número de partícula.

- Passo de comunicação VII - gradiente de pressão.

\subsubsection{Método de Decomposição Estático}

Na decomposição de domínio estático não há mudança na configuração dos subdomínios durante a simulação, não se garantindo, portanto, o balanceamento de carga entre os processos. O subdomínio é definido por AABBs estáticos havendo apenas a necessidade de se comunicar as partículas que se encontram na interface dos subdomínios vizinhos, para o correto cálculo das grandezas ponderadas pela função peso.

O fluxograma do método segue o apresentado na Figura 18, sendo que a prospecção das células transmissoras e receptoras deve ser feita apenas uma vez no início da simulação. Como não há alterações dos AABBs, a relação dessas células em cada subdomínio também não sofre mudanças.

O método estático pode ser utilizado em qualquer caso em que não ocorre um desbalanceamento de carga entre subdomínios. Dentre eles pode-se citar os seguintes casos:

- Ausência de superfície livre.

- Fluxo com superfície livre, com fluxo unidirecional alinhado a um eixo cartesiano. 


\subsubsection{ORB Homogêneo por Weiszfeld Iterativo}

Nesta subseção é apresentado o método E-MPS paralelo utilizando-se o método ORB de decomposição de domínio. O método ORB se baseia na bisseção recursiva do domínio por hiperplanos usualmente posicionados na mediana das partículas.

É comum algumas aplicações apresentarem diferentes tipos de partículas com perfis diferentes de carga computacional. Essa heterogeneidade torna a adoção da mediana geométrica insuficiente para garantir um bom balanceamento de carga computacional. Nesses casos é usual atribuir diferentes pesos para as partículas, dependendo da sua característica computacional, que afeta o cálculo da mediana geométrica, fazendo com que se consiga um melhor balanceamento. Nesse trabalho, por simplicidade, adotou-se a mediana geométrica como estratégia inicial, sendo tema de trabalhos futuros a extensão para partículas heterogêneas.

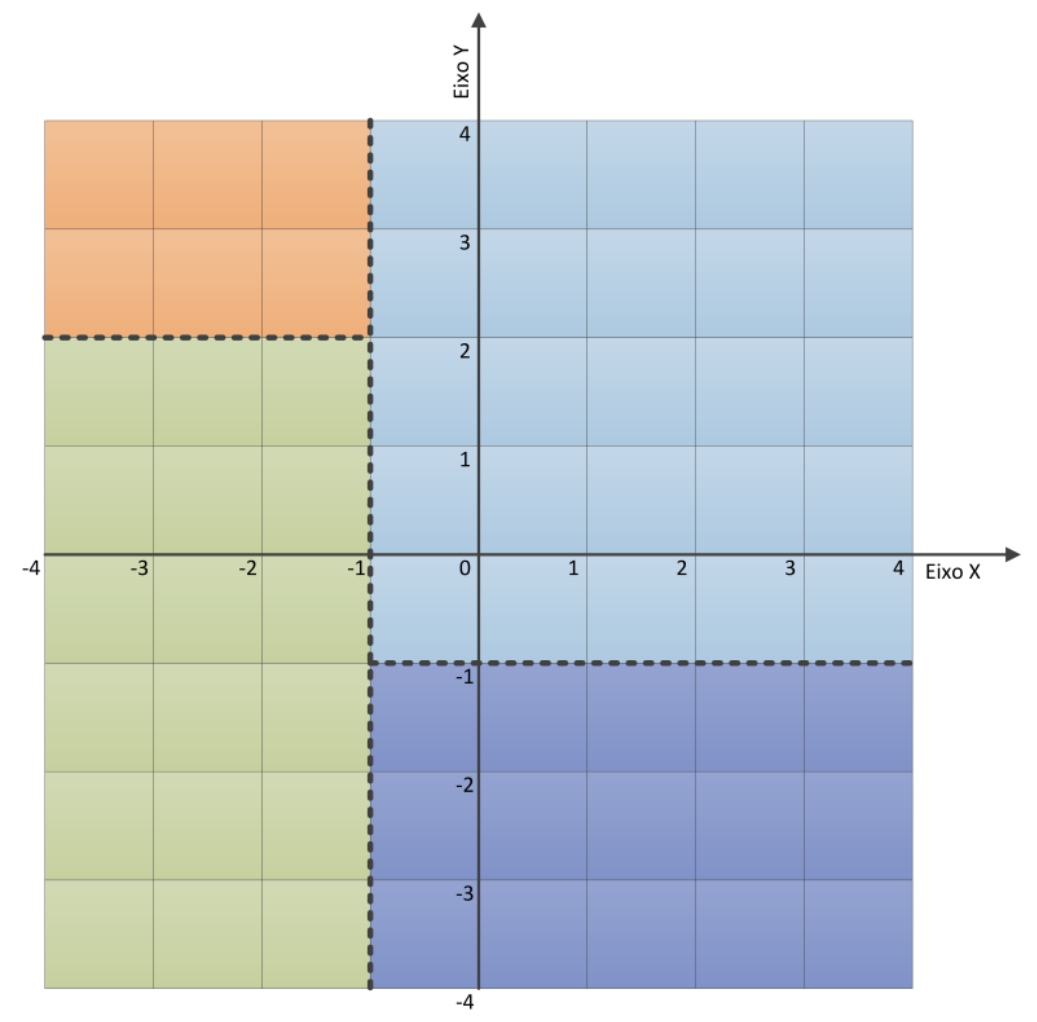

Figura 19 - ORB aplicado a um domínio.

Para o cálculo da mediana, segundo (SEAL; ALURU, 2007), é comum a adoção de algoritmos baseados em quicksort (FLOYD; RIVEST, 1975), ou randômicos (RAJASEKARAN; CHEN; YOOSEPH, 1997). No entanto, ambos possuem a 
desvantagem de sobrecarregar apenas um único processo com o decorrer das iterações, geralmente aquele que possui as partículas mais próximas à mediana. Para evitar esse problema, neste trabalho adotou-se o método iterativo de Weiszfeld para cálculo da mediana, que trata-se de algo novo até onde se conseguiu levantar na revisão bibliográfica.

Diferentemente do esquema estático, o método ORB é adaptativo, através de mudanças nos hiperplanos de bisseção que por fim vão delimitar o AABB de cada subdomínio. Por esse motivo os hiperplanos de bisseção devem ser definidos com base na grade.

A Figura 19 mostra o método ORB sendo arbitrariamente aplicado a um domínio definido pelo AABB $D=[-4,4[\times[-4,4[$ primeiramente bisecionado pela reta $x=-1$, resultando nos subdomínios $L=[-4,-1[\times[-4,4[$ e $R=[-1,4[\times[-4,4[$. Cada um deles é subsequentemente bisecionado pelas retas $y=2$ e $y=-1$ respectivamente, resultando nos subdomínios $L B=[-4,-1[\times[-4,2[$ e $L T=$ $[-4,-1[\times[2,4[$ pela bisseção de $L$, e $R B=[-1,4[\times[-4,-1[$ e $R T=[-1,4[\times[-1,4[$, pela bisseção de $R$.

Ao contrário do exemplo acima, a definição do hiperplano de bisseção deve ser feito de maneira a satisfazer alguma métrica de balanceamento. Para o caso de se adotar a quantidade de partículas como métrica, objetivando a mesma quantidade de partículas em todos os subdomínios, ele estar na mediana das posições das partículas.

O cálculo dessa mediana pelo algoritmo iterativo de Weiszfeld é dado por:

$$
\tilde{x}_{i+1}=\frac{\sum_{j=0}^{n} \frac{x_{j}}{\left\|x_{j}-\tilde{x}_{i}\right\|}}{\sum_{j=0}^{n} \frac{1}{\left\|x_{j}-\tilde{x}_{i}\right\|}}
$$

sendo $\tilde{x}$ a mediana, $n$ o número de partículas, $x$ a posição da partícula em um dos eixos cartesianos, e $i$ o índice de iteração.

Pelo exemplo da Figura 19 nota-se que diferentes medianas devem ser calculadas para cada bisseção de subdomínio.

Lembrando que as informações das partículas encontram-se distribuídas entre os processos, é necessário encontrar um meio de se calcular a mediana sem a necessidade de se centralizar os dados em um único processo. Para isso, beneficiase do fato da somatória poder ser calculada de forma particionada. 

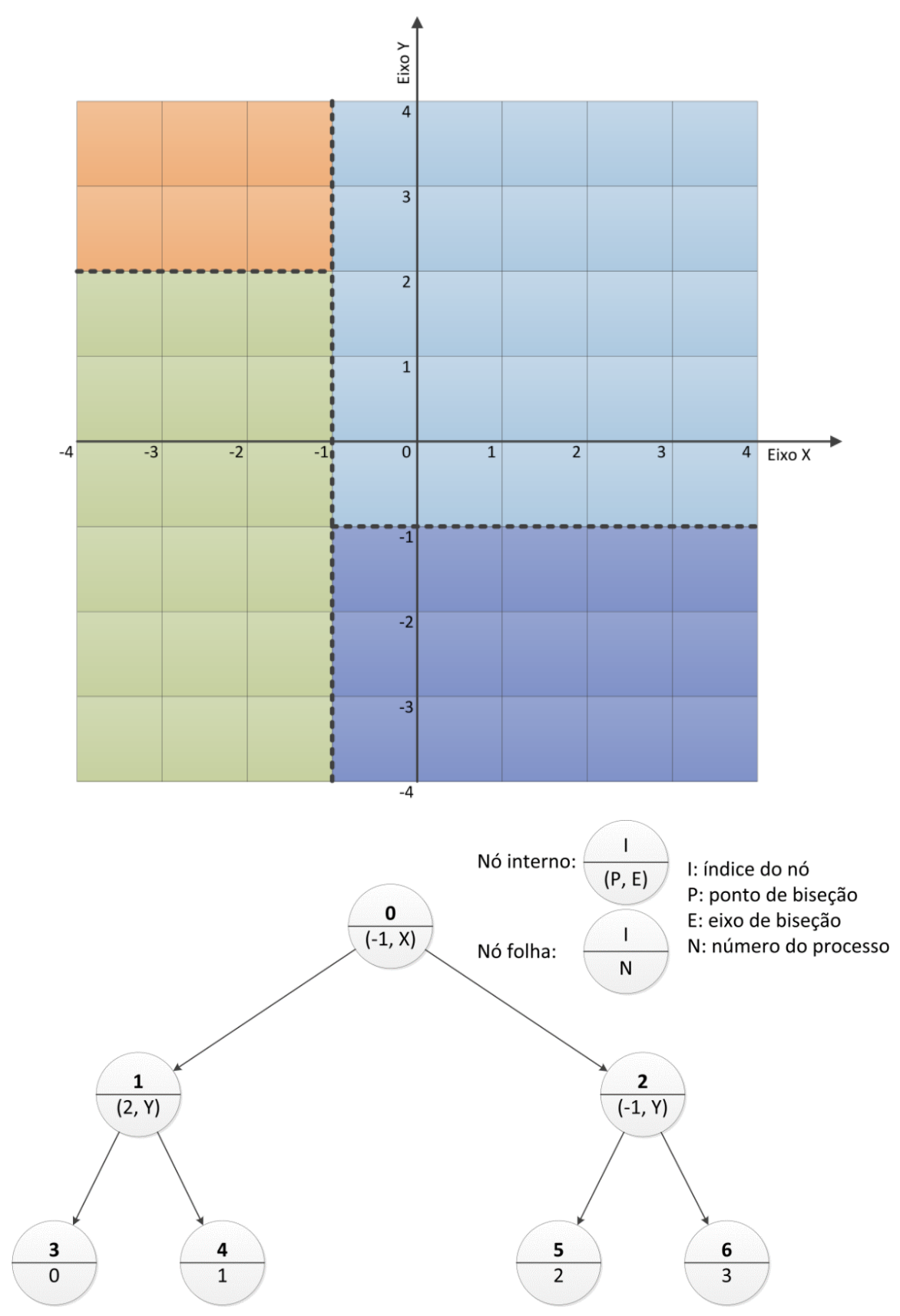

Figura 20 - Representação da bisseção do domínio em forma de árvore binária.

Dada a expressão:

$$
\tilde{x}_{i+1}=\frac{\sum_{j=0}^{m_{0}} \frac{x_{j}^{0}}{\left\|x_{j}^{0}-\tilde{x}_{i}\right\|}+\sum_{j=m_{0}+1}^{m_{1}} \frac{x_{j}^{1}}{\left\|x_{j}^{1}-\tilde{x}_{i}\right\|}+\cdots+\sum_{j=m_{k}+1}^{n} \frac{x_{j}^{k}}{\left\|x_{j}^{k}-\tilde{x}_{i}\right\|}}{\sum_{j=0}^{m_{0}} \frac{1}{\left\|x_{j}^{0}-\tilde{x}_{i}\right\|}+\sum_{j=m_{0}+1}^{m_{1}} \frac{1}{\left\|x_{j}^{1}-\tilde{x}_{i}\right\|}+\cdots+\sum_{j=m_{k}+1}^{n} \frac{1}{\left\|x_{j}^{k}-\tilde{x}_{i}\right\|}}
$$

e escolhendo-se $m_{0}, m_{1}, \ldots, m_{k}$ e $x_{j}^{0}, x_{j}^{1}, \ldots, x_{j}^{k}$ de maneira que representem respectivamente a quantidade e posição do conjunto de partículas já presentes em cada subdomínio, pode-se computar as somatórias parciais de maneira independente 
e paralela em cada processo. Cada processo deve então comunicar o resultado da somatória parcial, tanto do numerador quanto do denominador, para que os demais processos sejam capazes de calcular $\tilde{x}_{i+1}$.

Um fator atrativo desse método é que o termo interno à somatória exige pouco processamento, além de ser possível acessar os dados de forma coalescente durante o cálculo, fatores que o tornam bem adaptado à computação em GPU.

O critério de parada do algoritmo iterativo é quando $\varepsilon=\left|\tilde{x}_{i+1}-\tilde{x}_{i}\right|<\frac{h}{10}$, onde $h$ é o tamanho da célula da grade, ou seja, quando a variação entre iterações não significar uma mudança significativa em termos de coordenadas de grade, considerase que a mediana já foi determinada.

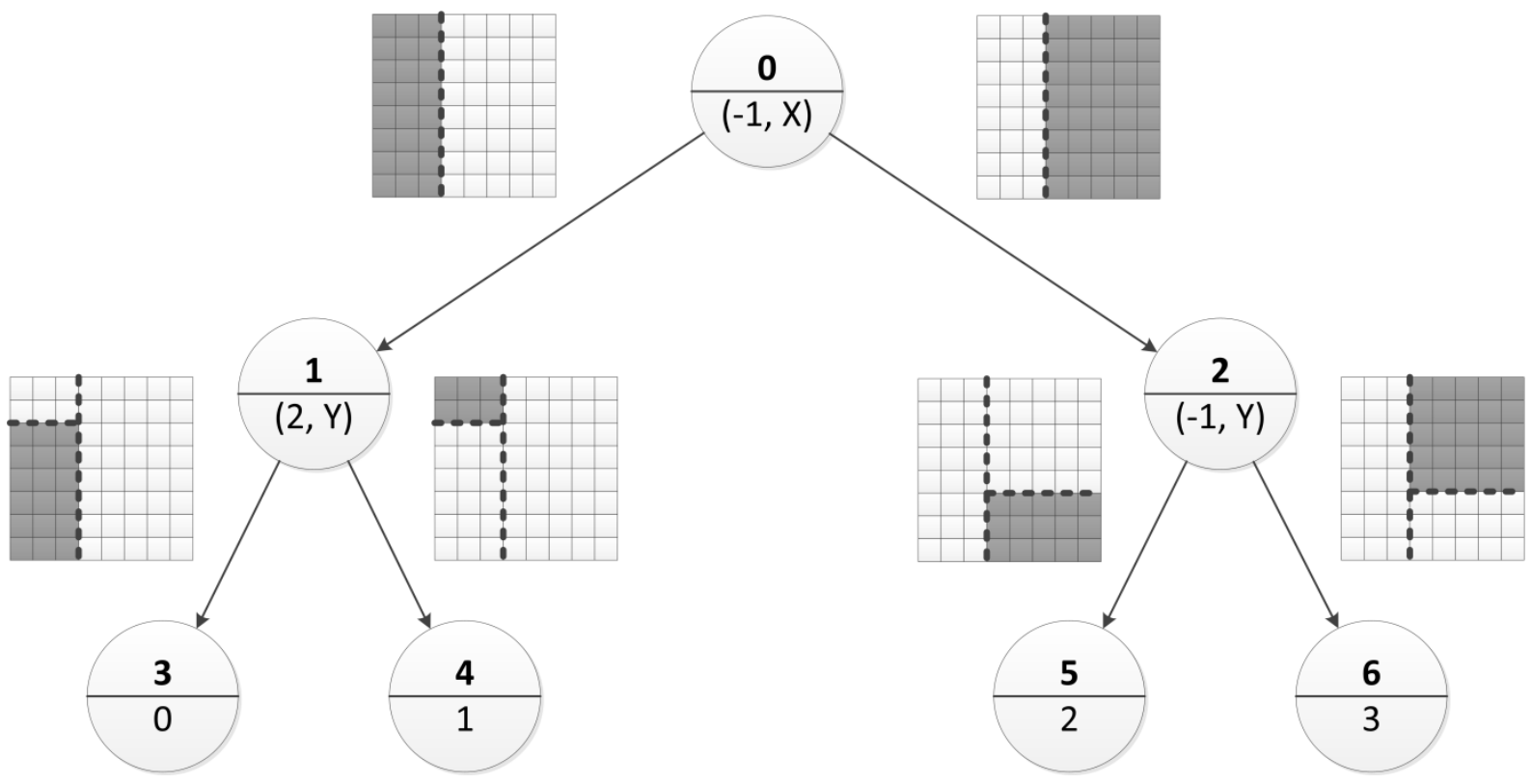

Figura 21 - Determinação do subdomínio de cada processo.

A Figura 20 mostra a bisseção de um domínio e a sua representação em forma de uma árvore binária, na qual os valores dos nós internos são uma dupla composta do ponto de bisseção e a sua orientação, e os valores das folhas são os índices dos processos. Dada essa representação é possível se determinar cada subdomínio resultante do processo de bisseção recursiva caminhando-se do nó raiz até cada uma das folhas, fazendo a bisseção baseando-se nos valores dos nós, como mostra a Figura 21. No procedimento de balanceamento de carga todos os pontos de bisseção devem ser recalculados. 
Para se explicar o método empregado analisa-se a seguir um caso em que o domínio da Figura 19 passa por um processo de balanceamento e tem seus pontos de bisseção alterados.

Inicialmente cada processo deve partir da sua folha correspondente e caminhar de forma ascendente na árvore até chegar à raiz, armazenando os índices dos nós internos que foram visitados durante o processo. Dessa forma, para o processo 2 por exemplo, a lista de nós armazenados seria composta dos índices 2 e 0.

Tomando-se essa lista de maneira reversa, ela corresponde exatamente aos pontos de bisseção que devem ser determinados para que o processo 2 tenha o seu subdomínio totalmente definido.

Partindo-se então do nó 0 , cada processo calcula a sua somatória parcial da Equação 27. Em seguida verifica-se o conjunto de folhas acessíveis a partir do nó 0 , que nesse caso é a totalidade das folhas. Deve-se então considerar, na somatória total para o cálculo da mediana, as somatórias parciais de todos os processos.

Uma vez determinada a nova mediana para o nó 0 , é necessário redistribuir as partículas entre os processos considerando o deslocamento do ponto de bisseção, como mostra a Figura 22.

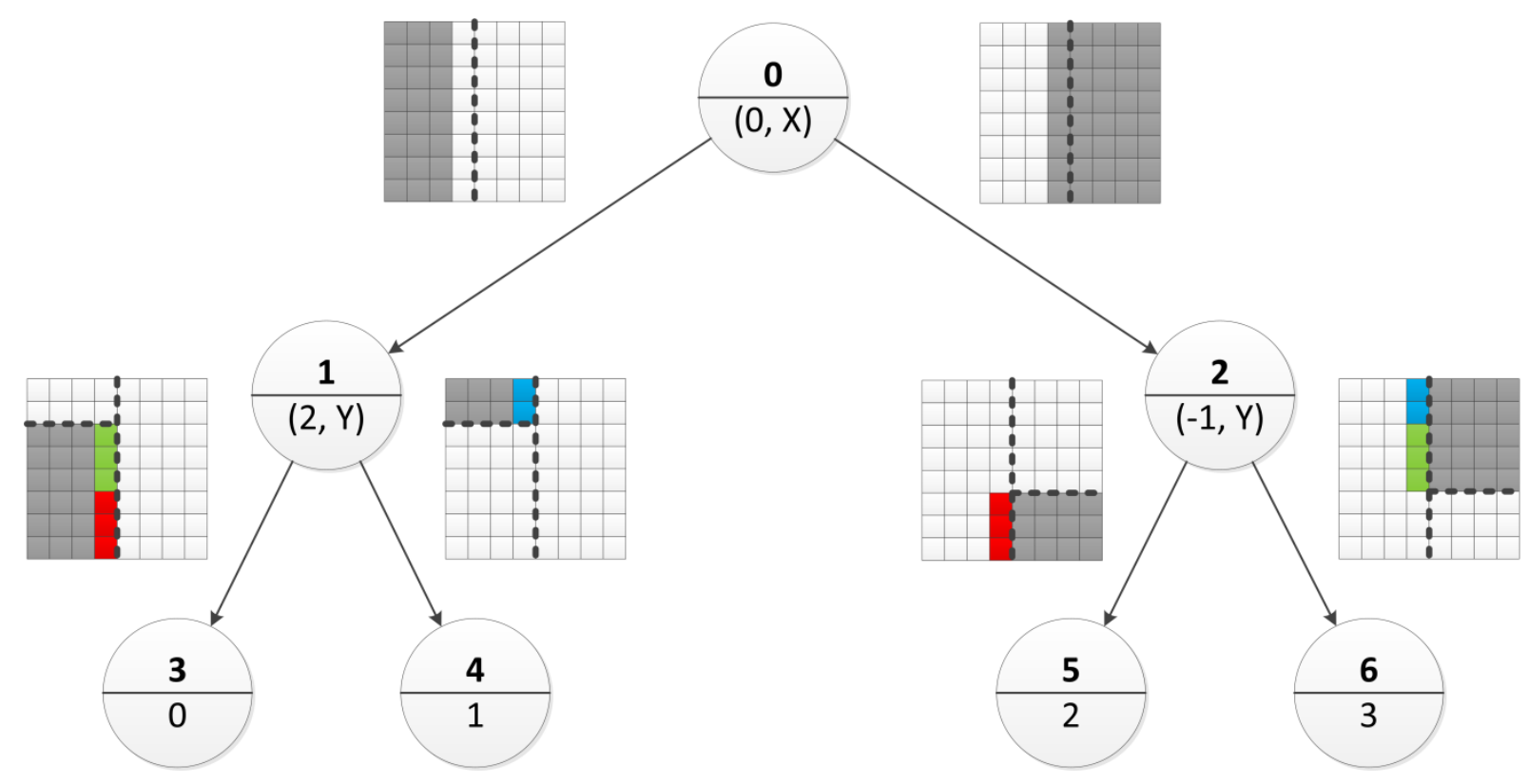

Figura 22 - Comunicação necessária ao se recalcular a mediana do nó raiz.

Esse processo é repetido para os nós filhos do nó 0 , neste caso 1 e 2 . Como o algoritmo é realizado de maneira paralela entre os processos, os processos 0 e 1 devem recalcular a mediana do nó 1 , e os processos 2 e 3 a mediana do nó 2 , seguido de uma nova fase de comunicação. 
A Figura 23 apresenta o fluxograma do método E-MPS paralelo para o caso de decomposição ORB.

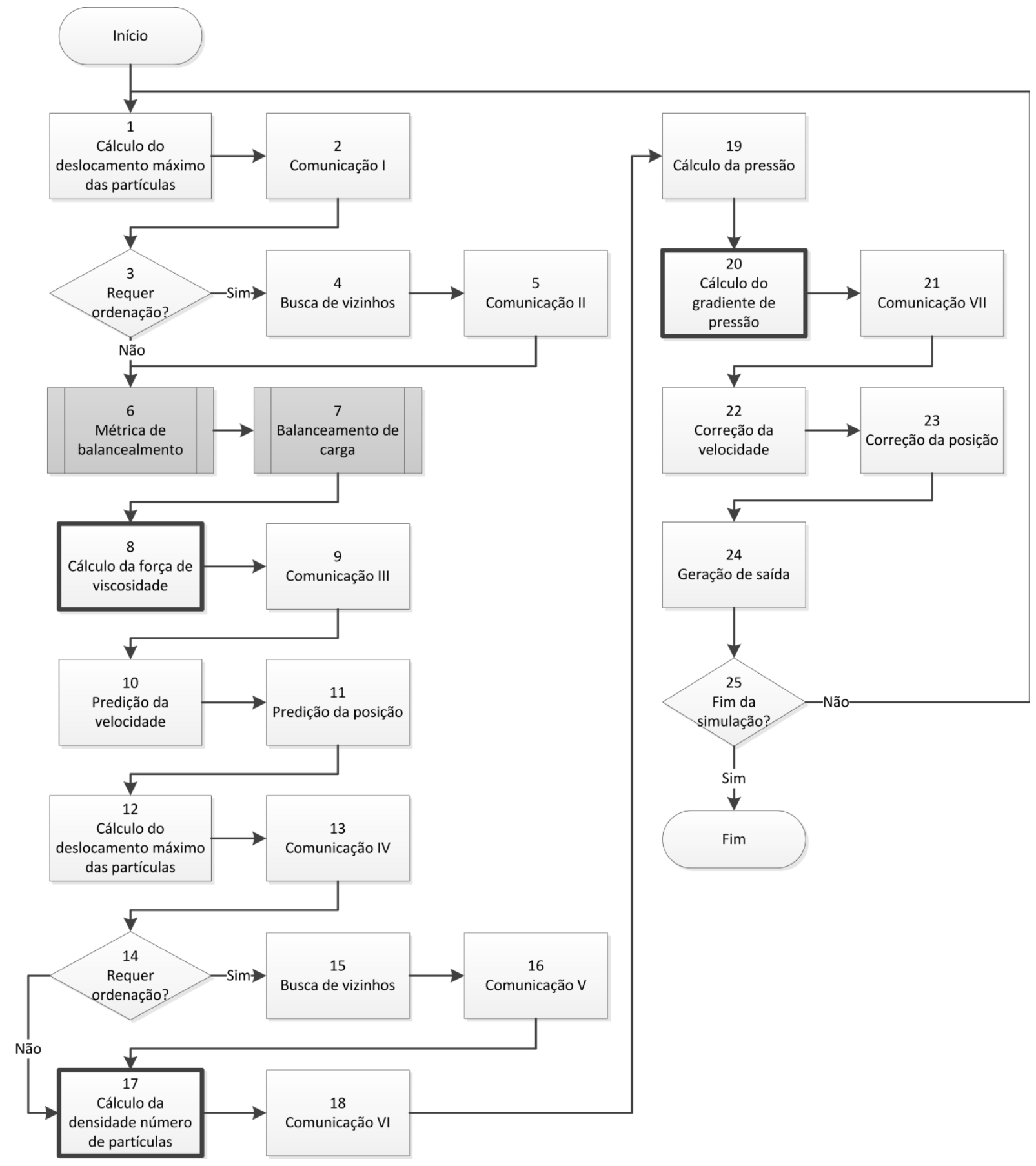

Figura 23 - Fluxograma do método E-MPS paralelo para o método ORB. 


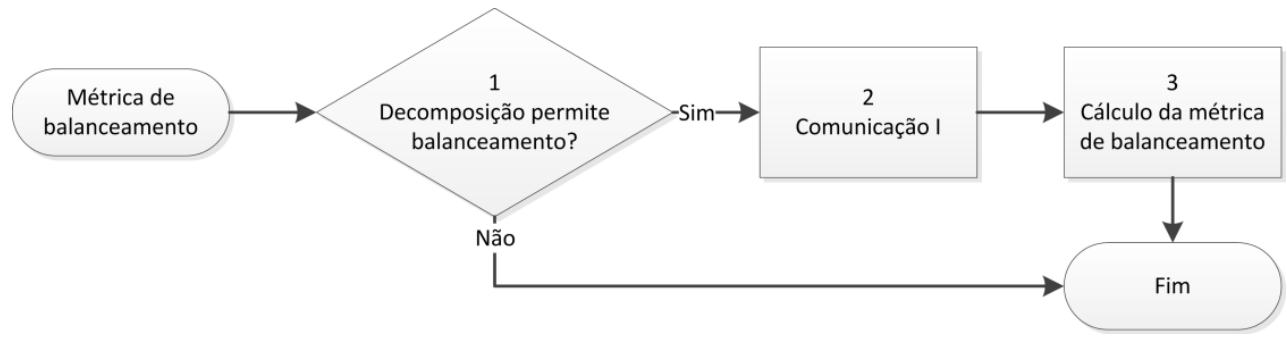

Figura 24 - Fluxograma da métrica de balanceamento do método ORB.

Os processos de métrica de balanceamento e de balanceamento de carga, ambos ausentes na Figura 18, são destacados em cinza (processos 6 e 7, respectivamente).

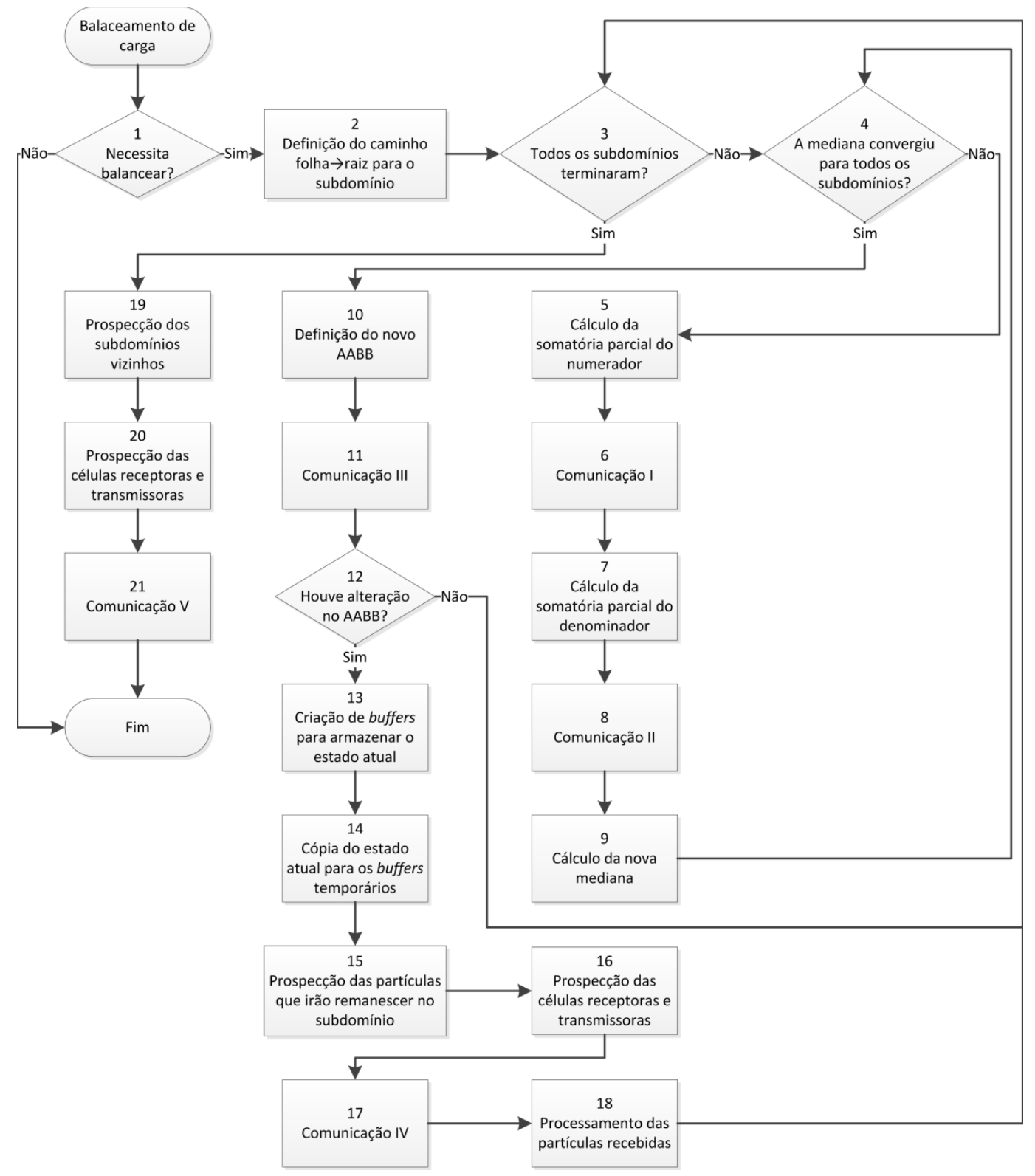

Figura 25 - Fluxograma do balanceamento de carga do método ORB. 
O subprocesso da métrica de balanceamento, detalhado na Figura 24, é efetuado apenas para casos em que o método de decomposição escolhido ${ }^{10}$ permite o balanceamento dinâmico (processo de decisão 1). Dentro desse subprocesso o processo 2 transmite os parâmetros necessários para que todo subdomínio seja capaz de calcular a métrica de balanceamento, efetuado no processo 3.

Para o caso do método ORB, cada subdomínio transmite para todos os outros o número de partículas $n_{i}$ nele presente. Com esse conjunto de valores $\left\{n_{0}, n_{1}, \ldots, n_{N}\right\}$, sendo $N$ o número total de subdomínios, o processo 3 calcula a sua média $\bar{n}$ e desvio padrão $\sigma_{n}$.

A Figura 25 detalha o subprocesso de balanceamento de carga, o qual é efetuado caso $\sigma_{n}>\bar{n} \cdot \tau$, sendo $\tau$ um parâmetro no intervalo [0,1] fornecido pelo usuário (processo de decisão 1).

Dada a representação em árvore binária da decomposição ORB, o processo 2 define o caminho do nó folha, correspondente ao subdomínio, até o nó raiz (caminho folha $\rightarrow$ raiz), informação essa necessária para se poder realizar o balanceamento, como descrito anteriormente nesta subseção.

O laço que itera em cada nível da árvore, ou em cada valor do caminho raiz $\rightarrow$ folha, corresponde aos processos de 10 a 18. Para cada nível, os processos de 5 a 9 configuram o laço que determina as novas medianas através do método iterativo de Weiszfeld.

No processo 5 e 7 calcula-se a somatória do numerador e denominador da Equação 27, respectivamente, para cada subdomínio. No processo 6 e 8 divulga-se, para todos os subdomínios, o resultado das somatórias do numerador e do denominador, respectivamente, de cada subdomínio. Isso permite que no processo 9 todas as novas medianas sejam calculadas. A convergência das medianas é verificada no processo de decisão 4, devendo-se refazer o processo de 5 a 9 para aqueles grupos de subdomínios que ainda não alcançaram o critério de convergência.

Definidos os novos pontos de bisseção de um nível da árvore, deve-se calcular o novo AABB do subdomínio (processo 10) e divulgá-lo para todos os outros (processo 11). No processo de decisão 12 verifica-se a ocorrência de qualquer alteração no AABB do subdomínio, e em caso negativo, nada mais necessita ser feito. Caso contrário cria-se um conjunto de buffers temporários para armazenar o estado atual,

\footnotetext{
${ }^{10}$ No caso deste trabalho os métodos ORB e Ortogonal.
} 
que inclui a posição, velocidade, material, e deslocamento desde a última busca de vizinhos de cada partícula (processo 13 e 14). As partículas que permanecerão no subdomínio são identificadas e copiadas para os buffers permanentes no processo 15. A definição desse conjunto de partículas se dá pelo cálculo, em cada subdomínio, da intersecção do novo AABB com o antigo. Todas as partículas que estiverem dentro dessa intersecção permanecerão no subdomínio.

Sendo $A=\left\{A_{0}, A_{1}, \ldots, A_{N}\right\}$ o conjunto dos antigos AABBs dos $N$ subdomínios, e $B=\left\{B_{0}, B_{1}, \ldots, B_{N}\right\}$ o conjunto dos novos AABBs, a prospecção das células transmissoras e receptoras no processo 16 se dá pelo cálculo, em cada subdomínio $s$, das intersecções de $A_{s} \operatorname{com} B_{i}$, e $B_{s} \operatorname{com} A_{i}$, respectivamente, com $s \neq i$. Com o esse conjunto de células em mãos no processo 17 e 18, consegue-se transferir as partículas que devem mudar de subdomínio utilizando-se a mesma técnica de transferência de partículas de borda descrita na subseção 4.1.3.

Quando todos os níveis da árvore tiverem as suas medianas recalculadas (processo de decisão 3), deve-se atualizar a lista de subdomínios vizinhos (processo 19) e suas respectivas células transmissoras e receptoras (processo 20) como descrito na subseção 4.1.3.

Por fim, o processo 21 faz a comunicação das partículas de borda entre subdomínios vizinhos.

\subsubsection{Método de Decomposição Ortogonal}

O método ortogonal consiste na divisão do domínio em uma única direção alinhada a um eixo cartesiano. Como ele não possui uma estrutura hierárquica, o deslocamento de cada um dos planos de seção afeta apenas os dois subdomínios adjacentes. Isso diminui consideravelmente a complexidade do algoritmo de balanceamento de carga se comparado ao método ORB.

O balanceamento de carga se dá pelo deslocamento de cada plano de seção na direção de sua normal, e no sentido que melhore o balanceamento.

A direção de decomposição deve ser escolhida levando-se em consideração a geometria do caso a ser simulado, de maneira a minimizar a quantidade de balanceamentos durante a simulação. 
Os pontos de seção, como no método ORB, são definidos em coordenadas de grade, pois baseados neles define-se os AABBs de cada subdomínio.

O balanceamento de carga é feito baseado no tempo necessário para computação das grandezas ponderadas pela função peso em cada passo de tempo. Essa métrica de balanceamento foi adotada por dois motivos: o primeiro pelo fato das grandezas ponderadas pela função peso serem o atual gargalo de computação, garantindo-se assim a representatividade da métrica escolhida e o segundo devido à heterogeneidade de processamento de cada tipo de partícula, o que não faz da quantidade de partículas uma boa métrica.
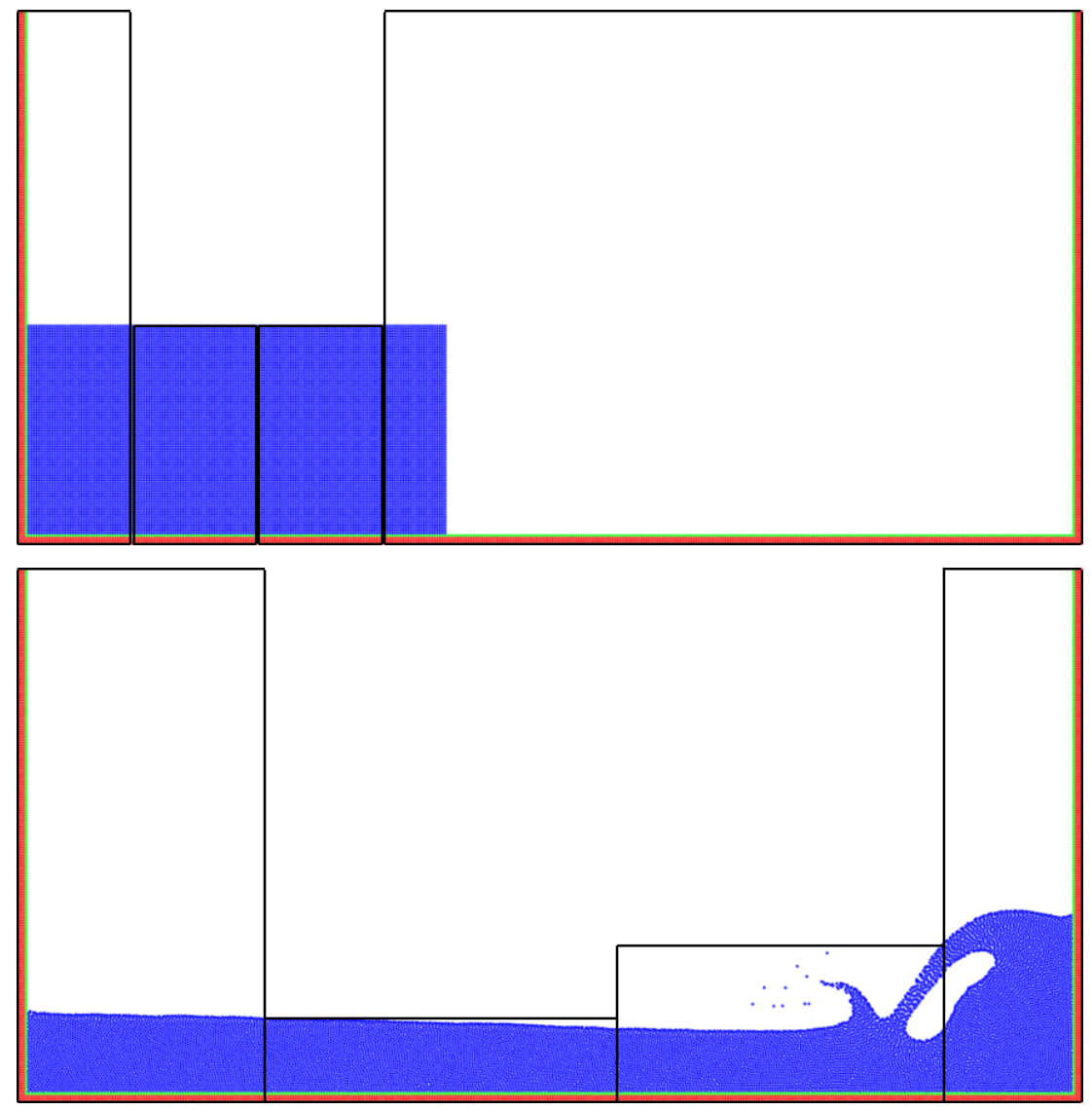

Figura 26 - Divisão dos subdomínios em dois instantes de simulação utilizando-se a decomposição ortogonal.

A carga computacional das partículas de fluido é diferente da carga das partículas de parede, sendo que a primeira exige mais processamento que a segunda. Isso ocorre porque o cálculo da força de viscosidade e do gradiente de pressão, duas grandezas ponderadas pela função peso, é feito apenas para partículas de fluido. Quando há uma discrepância nos tempos de computação entre subdomínios vizinhos, 
o plano de seção que os divide é deslocado no sentido do que apresenta maior tempo de processamento, diminuindo-se a quantidade de partículas no mesmo.

A Figura 26 apresenta dois instantes distintos de uma simulação na qual foi utilizada a decomposição ortogonal. Os retângulos delineados são os de menor área que contém todas as partículas de cada subdomínio, não havendo relação com seus AABBs, sendo utilizados nessa figura apenas como ferramenta para se identificar cada subdomínio. Pode-se notar que os planos de seção são deslocados para se manter uma distribuição uniforme de partículas de fluido entre os subdomínios durante toda a simulação.

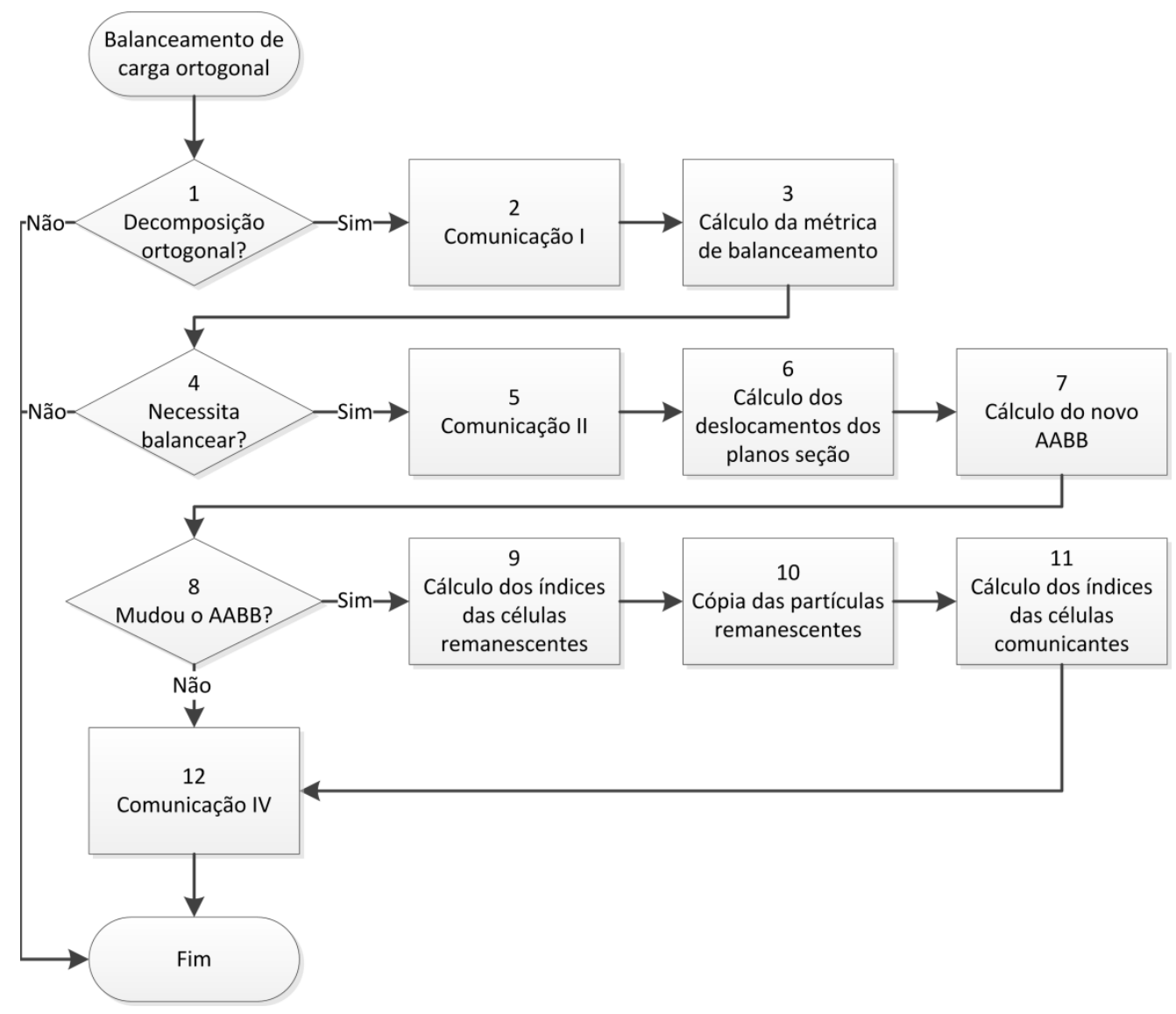

Figura 27 - Subprocesso de balanceamento de carga do método ortogonal.

O fluxograma do método E-MPS paralelo para a decomposição ortogonal segue o mesmo fluxograma do método ORB, apresentado na Figura 23, com um subprocesso de métrica de balanceamento e outro de balanceamento de carga. $O$ primeiro também apresenta um fluxograma idêntico à Figura 24, com a diferença já mencionada que se utiliza o tempo total de processamento das variáveis ponderadas pela função peso como métrica. A cada vez que este último é chamado, os pontos de 
seção definidos em coordenadas de grade podem deslocar-se de uma unidade. Essa limitação foi introduzida para se simplificar o algoritmo de balanceamento.

Além disso, o desbalanceamento tende a ocorrer lentamente ao longo da simulação, fato advindo dos métodos de partículas exigirem um passo temporal reduzido, o que elimina a necessidade de grandes saltos dos pontos de seção.

A Figura 27 detalha o processo de balanceamento de carga, que só ocorre para o método de decomposição ortogonal, como evidenciado pelo processo de decisão 1 . No processo 2 cada subdomínio transmite para os demais o tempo total de processamento das variáveis ponderadas pela função peso. Com esse conjunto $\left\{t_{0}, t_{1}, \ldots, t_{N}\right\}$ de tempos em mãos no processos 3 , caso $\frac{\max \left(t_{i}, t_{i+1}\right)}{\min \left(t_{i}, t_{i+1}\right)}-1>\tau, i<N$, sendo $\tau$ um parâmetro no intervalo $[0,1]$ fornecido pelo usuário, o balanceamento é realizado. Assim como no caso da busca de vizinhos, o balanceamento, quando executado, é feito conjuntamente por todos os subdomínios. Dessa maneira minimizase a quantidade total de balanceamentos na simulação evitando-se o aparecimento de processos em espera.

O processo 5 (passo de comunicação II) garante que todos os subdomínios tenham acesso à informação do AABB de qualquer outro subdomínio participante. Em particular há a necessidade de se saber qual o estado dos AABBs dos subdomínios vizinhos nos processos 6 e 7, para se garantir a eles um tamanho mínimo.

No processo de decisão 8 verifica-se o ocorrência de alteração no AABB. Em caso afirmativo, as células remanescentes são identificadas, e as partículas nelas residentes são copiadas (processos 9 e 10). Essa identificação inclui as células do AABB estendido do subdomínio, ou seja, inclui as células comunicantes dos subdomínios, e por consequência, as partículas de borda.

Com a limitação do deslocamento dos pontos de seção de apenas uma unidade, nesta fase do processo de balanceamento (processos 9 e 10), cada subdomínio, em resumo, apropria-se das partículas de borda do subdomínio vizinho, ou cede as suas partículas de borda ao vizinho. Essas partículas já se encontram localmente disponíveis no processo de cada subdomínio, como descrito na subseção 4.1.3, não havendo, portanto, a necessidade de comunicá-las.

O processo 11 faz o novo acerto das células comunicantes de cada subdomínio, para ser possível o emprego do método descrito em 4.1.3. 
Ao final, precisa-se comunicar as novas partículas de borda entre subdomínios (processo 12), para que seja possível o cálculo das variáveis ponderadas pela função peso.

\subsubsection{Método de Decomposição Cell Transfer}

O método cell transfer é proposto neste trabalho para superar algumas limitações encontradas nos métodos já existentes na literatura. A principal é a imposição geométrica encontrada em métodos como o ORB, com seus hiperplanos hierárquicos de bisseção, e o SFC, com a própria geometria da curva, que tem grande impacto na qualidade de balanceamento e no custo de comunicação. A dependência desses métodos em algoritmos capazes de ordenação ou cálculo de mediana em memória distribuída é outro ponto que se deseja evitar.

Considere que no instante inicial de simulação exista a garantia de balanceamento de carga entre os processos. A criação desse novo método foi motivada pela constatação de que a comunicação imposta pelo padrão de acesso à região esférica nas interfaces dos subdomínios já deveria ser suficiente para garantir a manutenção do balanceamento. Essa afirmação é reforçada tendo-se em vista que o passo temporal é pequeno nos métodos de partículas em geral, e ainda menor em métodos puramente explícitos. Assim, pode-se dizer que as variações espaciais das partículas entre passos temporais são pequenas.

Portanto, contramedidas de balanceamento baseadas somente na troca de partículas de interface entre subdomínios tem grande probabilidade de serem efetivas na garantia do balanceamento de carga. Essa afirmação é reforçada por ser improvável que haja um desbalanceamento abrupto entre passos temporais que necessite transferir um grande número de partículas entre subdomínios. Isso também traria uma grande vantagem ao método pelo fato dele não necessitar de passos de comunicação adicionais àquelas que já são inerentes à decomposição do domínio.

Supondo que exista um conjunto $N$ de partículas separadas igualmente em $s$ subdomínios, e que inicialmente cada subdomínio contém $\mathrm{N} / \mathrm{s}$ partículas, relacionamse os motivos pelos quais a manutenção do mesmo conjunto inicial de partículas em cada subdomínio é impraticável: 
1. O fluxo pode separar espacialmente as partículas, fazendo com que aumente a carga de comunicação devido ao crescimento do tamanho da interface entre subdomínios.

2. Pelo mesmo motivo, pode ocorrer um aumento do número de vizinhos, aumentando não só a quantidade de dados que devem ser transmitidos, mas também o número de pares de processos comunicantes.

3. Caso haja conflito de células, ou seja, exista mais de um subdomínio com partículas em uma determinada célula, o método para comunicação das partículas de interface entre subdomínios descrito na subseção 4.1 .2 não pode ser aplicado, perdendo-se todas as suas vantagens.

O aparecimento de células com conflito é inerente à existência de movimento das partículas. Pode-se também afirmar que elas sempre acontecem nas interfaces dos subdomínios e na direção do fluxo. É natural, portanto, que esses conflitos sejam vistos como uma oportunidade de balanceamento, visto que já são regidas pela tendência natural do fluxo, e estão localizadas na interface, região na qual subdomínios vizinhos compartilham os mesmos dados, o que permite a troca de controle de forma facilitada. Assim, a ideia central do método cell transfer é avaliar o balanceamento de carga entre subdomínios vizinhos na decorrência de conflitos de células.

Considere no exemplo da Figura 14 que em um determinado instante a partícula 1 do subdomínio A faça a transição para a célula da direita. Nesse instante na mesma célula haverá partículas do subdomínio A (1) e B (3 e 5) o que configura um conflito de célula. Deve-se então decidir se a partícula 1 deve fazer a transição para o subdomínio B ou se A deve tomar o controle de 3 e 5 . Nesse caso é claro que a segunda opção é a mais adequada pois possibilita que tanto $A$ quanto $B$ tenham o mesmo número de partículas. Nota-se pelo exemplo que o subdomínio deixa de ter relação direta com o AABB porque o subdomínio é definido pelo conjunto das suas partículas. Isso se opõe ao que se adota para o caso da decomposição de domínio estático no qual o subdomínio é definido por um AABB. Dessa forma evita-se qualquer tipo de limitação geométrica no método, salvo o fato das partículas serem organizadas em células.

A obtenção do balanceamento inicial pode ser realizada por algum método já mencionado, como ORB, SFC ou ortogonal. Na realidade constata-se que esses métodos são mais adaptados para cenários estáticos ou com pouco deslocamento 
das partículas, que é o caso da busca pelo balanceamento inicial, pois não levam em consideração a dinâmica das partículas. Já o método cell transfer faz o balanceamento levando em conta a dinâmica das partículas.

Para que seja possível a implementação do método, alguns pontos chaves ainda devem ser definidos. São eles:

1. A definição de uma métrica para servir de base de decisão na ocorrência de um conflito de célula é necessária. É importante que ela seja absoluta, no sentido de que todos os processos devem chegar à mesma decisão quanto às células conflitantes. Caso contrário, pode haver a ocorrência de decisões inconsistentes.

2. É necessário definir como incluir no balanceamento as partículas estáticas (ex.: paredes) pois a probabilidade de ocorrência de conflito de células nas quais elas se encontram é baixa.

3. Deve-se encontrar uma forma de se resguardar a forma do subdomínio, para que ele não se degenerar, e sobrecarregar a comunicação devido ao aumento da quantidade de partículas de interface entre subdomínios.

É importante ressaltar que o método continua utilizando o algoritmo de prospeç̧ão das células transmissoras e receptoras. Desse modo, evita-se a necessidade de reordenação após a comunicação das partículas de interface entre subdomínios, e tem-se a clara separação entre as partículas pertencentes ao subdomínio e aquelas advindas de subdomínios vizinhos. A diferença está na necessidade de se comunicar as células transmissoras para os subdomínios vizinhos de modo que, a partir delas, eles sejam capazes de aferir as células receptoras.

Relacionam-se, a seguir, algumas desvantagens que já podem ser levantadas:

1. Não é possível desagregar o procedimento de ordenação ao de balanceamento. Diferentemente do método ortogonal, todo processo de balanceamento acarreta em um processo de ordenação sendo executado. Os conflitos de células devem ser obrigatoriamente resolvidos para que se possa continuar a simulação.

2. Não é intuitivo geometricamente e de difícil implementação. 


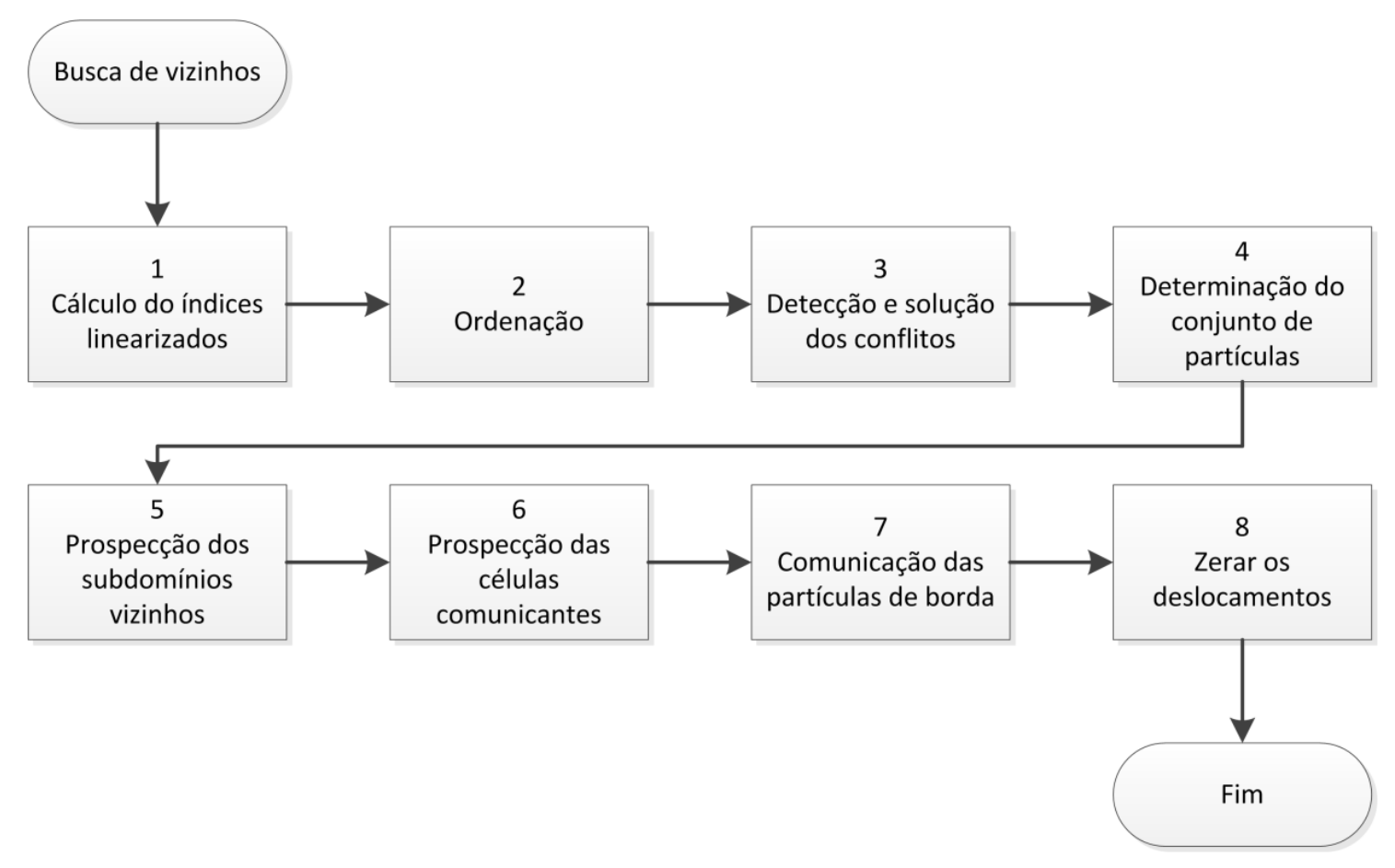

Figura 28 - Fluxograma da busca de vizinhos para o método Cell Transfer.

A Figura 28 apresenta o fluxograma do processo de busca de vizinhos para o método cell transfer. $O$ processo 1 calcula o índice linearizados da célula de cada partícula. As partículas são ordenadas, no processo 2, de acordo com esse índice seguindo o mesmo algoritmo apresentado na subseção 3.3. O processo 3 é responsável por detectar os conflitos de células, e para cada uma delas decidir qual subdomínio deve possuí-la de acordo com as contramedidas de balanceamento necessárias. Fica a cargo do processo 4 a separação das partículas que farão parte do subdomínio sendo processado. Com esse conjunto determinado, o processo 5 determina o novo conjunto de subdomínios vizinhos e as células comunicantes no processo 6. Deve-se então atualizar as partículas de borda do subdomínio (processo 7), e zerar os deslocamentos para controle do instante em que uma nova busca de vizinhos deve ser realizada (processo 8). 


\section{IMPLEMENTAÇÃO}

Nesta seção, apresenta-se como os métodos descritos na seção anterior foram implementados e integrados em um sistema de simulação. Primeiramente, definiu-se qual seria o ambiente de produção: um cluster multicore com dispositivos GPU. Em seguida, criou-se um ambiente de desenvolvimento com os compiladores, bibliotecas e ferramentas necessárias.

Tratando-se de um simulador de engenharia, adotou-se a separação entre as fases de pré-processamento, processamento, e pós-processamento, pois constituem tarefas claramente independentes. Na fase de pré-processamento o objetivo é construir a geometria inicial com uma distribuição de partículas que represente o problema a ser simulado, com a garantia de que haja uma estabilidade inicial para computação do método de partículas. Após a fase de processamento, na qual os cálculos da simulação são realizados, no pós-processamento deve-se permitir a visualização do fenômeno simulado e promover a obtenção e análise dos dados gerados durante o processamento. Como já existia uma ferramenta que atendia os requisitos de pós-processamento (Paraview), o desenvolvimento foi focado nos aplicativos de pré-processamento e processamento.

Vale salientar que não foi encontrada nenhuma ferramenta que satisfizesse os requisitos de pré-processamento para geração da geometria inicial das partículas. Uma tentativa foi feita com a ferramenta Hypermesh, mas ela se mostrou extremamente difícil de utilizar, além de não atender a todos os requisitos. Um requisito que não era garantido é o alinhamento inicial de todas as partículas. Este, quando não assegurado, gera um transiente considerável já nos primeiros passos de simulação. Como os casos a serem investigados neste trabalho não envolviam uma geometria muito complexa, foi desenvolvido um pré-processador que será detalhado no decorrer desta seção. Neste trabalho, deixa-se em aberto a questão da geração de casos com geometrias arbitrárias, devendo ser tema de trabalhos futuros.

O processador foi desenvolvido com enfoque no método E-MPS, no entanto, graças a uma arquitetura modular, poderia ser implementado, sem muito esforço, um simulador baseado no método SPH. A clara separação entre os algoritmos envolvidos nos métodos de partículas com as especificidades de cada método garante essa versatilidade. 


\subsection{AMBIENTE DE DESENVOLVIMENTO}

O sistema foi desenvolvido no sistema operacional Linux, distribuição CentOS 5.6, compilador gcc 4.4, e CUDA Toolkit 4.2, utilizando a linguagem de programação $\mathrm{C}++$.

Complementarmente utilizaram-se as seguintes bibliotecas:

- Standard Template Library (STL) - biblioteca padrão do C++, com uma série de algoritmos, estruturas de dados, além de outras facilidades que aceleram o desenvolvimento do sistema.

- OpenMPI 1.6.5 - implementação do padrão MPI 2 que permite a utilização da interconexão Infiniband.

- MVAPICH2 2.0a - outra implementação do padrão MPI 2 que também permite o uso da interconexão Infiniband.

- VTK 5.6.1 - para manipulação de arquivos do tipo VTU.

- Boost 1.52 - é uma coleção de bibliotecas que proveem as mais diversas funcionalidades. Em particular foram utilizadas as relacionadas a template metaprogramming (Boost Type Traits e MPL), manipulação de enuplas (Boost Fusion), serialização e deserialização de tipos de dados (Boost Serialization), medição de tempo (Boost Chrono), smart pointers (Boost Smart Ptr), e MPI (Boost MPI).

A Boost MPI não é uma implementação do padrão MPI, e sim um conjunto de classes e funções que facilitam o a passagem de mensagens em $\mathrm{C}++$. Para isso ela se baseia em alguma implementação existente (OpenMPI, MVAPICH2, etc.) para criar essa camada facilitadora. De fato, a partir dela, qualquer tipo de dado serializavel pela Boost Serialization se torna comunicável entre processos. Além disso, os conceitos de contêiners e iteradores da STL, amplamente utilizados nas implementações, já se encontram presentes na biblioteca.

Para facilitar e automatizar o processo de compilação das diversas bibliotecas e aplicativos que compõem o sistema, foi utilizada a ferramenta CMake que também possibilita a definição de uma série de testes de unidade. Os testes de unidade são programas dedicados a testar funcionalidades providas por um determinado número de códigos fonte de maneira isolada e controlada Através da execução desses 
programas pode-se realizar testes para cada funcionalidade e atestar o seu correto comportamento.

A adoção de testes de unidade foi de grande valia para o desenvolvimento do trabalho. Pode-se argumentar que a adoção de tal prática se reduz ao ambiente coorporativo e para projetos de grandes proporções, que não é o caso deste trabalho. $\mathrm{Na}$ verdade, as constantes mudanças que ocorrem nos métodos numéricos com propostas que afetam diferentes níveis do código, faz com que o uso de testes de unidade seja igualmente recomendado para o ambiente científico. Isso não apenas ajuda na detecção de eventuais erros de código, mas também obriga o programador a promover uma modularização do mesmo. Caso isso não seja feito, depara-se com uma grande dificuldade de se definir as unidades a serem testadas, o que acabaria incorrendo em testes sem significância. Portanto, a adoção de testes de unidade no meio científico não só colabora com a melhoria da qualidade do código desenvolvido, mas também promove a modularização do sistema, e consequentemente a sua expansibilidade.

\subsection{ARQUIVO DE DESCRIÇÃO DO CASO}

Todo sistema de simulação possui um ou mais arquivos que descrevem o caso a ser estudado. No sistema desenvolvido neste trabalho, um caso representa uma geometria, os tipos de materiais envolvidos, e os diferentes parâmetros físicos. $O$ mesmo caso pode possuir diferentes esquemas de decomposição de domínio, e diferentes formas de execução.

Neste trabalho, é importante ter a capacidade de variar os métodos de decomposição para um mesmo caso, para possibilitar a comparação de seus desempenhos. Da mesma forma, é vantajoso poder ter diferentes execuções, por exemplo, com variados tempos totais de simulação e intervalo de geração de saída. Assim, foi definido neste trabalho um padrão de arquivo de descrição de caso que segue o padrão Extensible Markup Language (XML).

No Apêndice A é apresentado um exemplo de um arquivo de descrição para um caso de quebra de dam break bidimensional. A Tabela 18 apresenta uma descrição da semântica atrelada a cada tag. 
Tabela 18 - Semântica de cada tag do arquivo de descrição de caso.

\begin{tabular}{|c|c|c|}
\hline & Tag & Semântica \\
\hline \multicolumn{2}{|c|}{ case } & Agrega toda descrição do caso. \\
\hline \multicolumn{2}{|c|}{ dimension } & $\begin{array}{l}\text { Define se o caso é bidimensional ou } \\
\text { tridimensional. }\end{array}$ \\
\hline & time_step & Passo temporal. \\
\hline & distance_between_particles & Distância de referência entre as partículas. \\
\hline & influence_radius_coefficient & $\begin{array}{l}\text { Coeficiente para determinação do raio de } \\
\text { influência. }\end{array}$ \\
\hline · & gravity & Aceleração da gravidade. \\
\hline & speed_of_sound & Velocidade do som na densidade de referência. \\
\hline & free_surface_threshold & $\begin{array}{l}\text { Coeficiente utilizado na detecção de superfícies } \\
\text { livres. }\end{array}$ \\
\hline$\cdot$ & free_surface_pressure & Pressão imposta na superfície livre. \\
\hline • & material & Define um material. \\
\hline & . type & Tipo do material: fluido, sólido ou fantasma. \\
\hline & . motion & $\begin{array}{l}\text { Define se a movimentação do material é fixa ou } \\
\text { livre. }\end{array}$ \\
\hline & . viscosity & Viscosidade dinâmica do material. \\
\hline & . density & Densidade do material. \\
\hline & generator & $\begin{array}{l}\text { Agrega as informações necessárias para } \\
\text { geração da geometria inicial pelo pré- } \\
\text { processador. }\end{array}$ \\
\hline & - rectangle & $\begin{array}{l}\text { Define um retângulo no plano } X Y \text { alinhado aos } \\
\text { eixos cartesianos. }\end{array}$ \\
\hline & material & Determina o material do retângulo \\
\hline & lower & Canto inferior do retângulo. \\
\hline & upper & Canto superior do retângulo. \\
\hline & . cuboid & $\begin{array}{l}\text { Define um ortoedro alinhado aos eixos } \\
\text { cartesianos. }\end{array}$ \\
\hline & material & Designa o material do ortoedro. \\
\hline & lower & Canto inferior do ortoedro. \\
\hline & upper & Canto superior do ortoedro. \\
\hline
\end{tabular}


decomposition

method

\section{subdomain}

lower

upper

generator

file

axis

domain

lower

upper

point

execution

steps

steps_per_output

enable_profiling

particle_capacity

inbound_particle_capacity

maximum_imbalance
Define uma decomposição de domínio.

O método de decomposição a ser utilizada: statical (estática), ou orthogonal (ortogonal).

Utilizado para determinar os subdomínios do método estático.

Limite inferior do subdomínio.

Limite superior do subdomínio.

Agrega informações necessárias para o préprocessador.

Arquivo de saída de cada processo do préprocessador.

Determina qual o eixo de seção para o método ortogonal: $\mathrm{x}, \mathrm{y}$ ou z.

Define o domínio de simulação para o método ortogonal.

Limite inferior do domínio.

Limite superior do domínio.

Ponto de seção para o método ortogonal.

Representa uma execução do caso de simulação. Obrigatoriamente referencia uma decomposição de domínio.

Número de passos de simulação.

Número de passos por geração de saída.

Ativa a medição dos tempos de processamento para controle do desempenho computacional.

Controla a quantidade de partículas que cada processo comporta.

Controla a quantidade máxima de partículas que são transferidas entre processos.

Dado o conjunto $\left\{t_{0}, t_{1}, \ldots, t_{N}\right\}$ de tempos que cada subdomínio leva para computar as variáveis ponderadas pela função peso, um novo processo de balanceamento é feito toda 
file

vez que $\frac{\max \left(t_{i}, t_{i+1}\right)}{\min \left(t_{i}, t_{i+1}\right)}-1>\alpha, i<N$, sendo $\alpha$ o valor dessa tag.

Designa o nome dos arquivos de saída da simulação para cada processo.

A adoção do formato $X M L$ foi importante para garantir o fácil acesso às informações contidas no arquivo em diferentes momentos. Todos os aplicativos desenvolvidos, mesmo que em linguagem de programação diferentes, foram facilmente capazes de acessar os dados no arquivo.

\subsection{APLICATIVOS}

A partir da definição do arquivo de descrição do caso, passa-se por uma fase de pré-processamento para geração do arquivo de geometria inicial. Nele está definida a posição, velocidade e material de cada partícula no instante inicial. O aplicativo denominado Generator, desenvolvido neste trabalho, é responsável por esse pré-processamento.

A simulação propriamente dita é efetuada em seguida pelo aplicativo Parallel MPS, também fruto deste trabalho.

O resultado da simulação pode ser visualizado pelo aplicativo Paraview, um visualizador científico baseado na biblioteca VTK, ambos de código aberto.

Tanto o Generator como o Parallel MPS utilizam essa biblioteca para geração dos arquivos de saída no formato VTU.

$\mathrm{Na}$ subseção 5.3.1, é detalhado o funcionamento do pré-processador Generator. Na subseção seguinte (5.3.2), apresenta-se como foram implementados os diversos algoritmos utilizados no aplicativo Parallel MPS, sendo este último analisado em detalhes na subseção 5.3.3 


\subsubsection{Generator}

O Generator tem como objetivo gerar a geometria inicial do caso baseado nas primitivas (retângulos e ortoedros) definidas no arquivo de descrição do caso.

Para cada subdomínio de uma determinada decomposição de domínio nele especificado, deve ser gerado um arquivo com as posições, velocidades e materiais de cada partícula no instante inicial da simulação. O fato de cada subdomínio obter separadamente o seu arquivo de condição inicial torna posteriormente a leitura por parte do Parallel MPS mais facilitada e rápida.

A geração das partículas de cada subdomínio é conduzida por um processo MPI. Dessa maneira, um caso com uma decomposição contendo 8 subdomínios terá a sua geração da geometria inicial efetuada por 8 processos MPI. Note que não há necessidade de comunicação entre processos, visto que não existe dependência entre subdomínios para geração das suas partículas. Além disso, todas as informações necessárias se encontram disponíveis no arquivo de descrição de caso que é lido por todos os processos.

O processamento em cada processo MPI se dá da seguinte forma:

- definir o $\mathrm{AABB}^{11}$ de cada subdomínio;

- testar a intersecção do AABB com cada primitiva (retângulo ou ortoedro) especificado no arquivo de descrição do caso.

- caso a intersecção não for vazia, gerar as partículas dessa primitiva.

Embora tenha sido implementada apenas a definição de retângulos e ortoedro, é possível a extensão para outras primitivas como esferas, cones, cilindros, entre outras.

Os arquivos de geometria inicial são gerados no formato VTU, o que possibilita verificar de maneira fácil a correta geração, utilizando-se o aplicativo Paraview.

11 O AABB é um hipercubo composto de células alinhado aos eixos cartesianos que define uma subgrade, conforme apresentado na subseção 4.1.2. 


\subsubsection{Algoritmos}

O desenvolvimento do aplicativo Parallel MPS foi baseado na biblioteca Thrust que faz parte do CUDA Toolkit. Ela utiliza os conceitos e arquitetura da biblioteca STL da linguagem $\mathrm{C}++$, provendo a capacidade de se processar os algoritmos de forma paralela em dispositivos GPU ou multicore. Isso é feito através da escolha de diferentes back-ends, que inclui CUDA, OpenMP e Intel TBB.

Grande parte dos algoritmos utilizados na implementação são providos pela Thrust, como é o caso do algoritmo de ordenação. Outros que eram de propósito bem específicos foram desenvolvidos e providos com paralelização em OpenMP e CUDA, seguindo a arquitetura da biblioteca Thrust.

Dentre os algoritmos presentes na biblioteca Thrust, o mais utilizado na implementação foi o transform, também presente na STL. Ela itera em uma sequência de elementos aplicando uma função unária em cada elemento, e armazenando o resultado em uma sequência de saída.

A STL provê diferentes tipos de sequências que são denominadas contêineres. Cada um possui vantagens e desvantagens diretamente relacionadas às estruturas de dados que as embasam. O contêiner do tipo vector é um bloco contíguo de memória, o que possibilita o acesso randômico aos dados. Já o tipo list é implementado em termos de uma lista duplamente ligada, permitindo rápida inserção e remoção de elementos internos à sequência.

O algoritmo transform aceita iteradores de qualquer tipo de contêiner como parâmetro. Iteradores são objetos que apontam para um determinado elemento de um contêiner, podendo ser comparado aos ponteiros da linguagem $\mathrm{C}^{12}$. Através deles pode-se iterar sobre uma sequência de elementos de um contêiner, ou acessar o elemento para o qual ele aponta, ação que é conhecida como "dereferenciar um iterador". Note que avançar um determinado número de elementos de um iterador de vector tem complexidade computacional diferente de um iterador de list. Enquanto para o vector o acesso pode ser randômico, os iteradores de list exigem um avanço sequencial, devido à lista duplamente ligada.

\footnotetext{
${ }^{12} \mathrm{Na}$ realidade, os ponteiros são um tipo válido de iterador na linguagem C++ (iterador de acesso randômico).
} 
Algoritmo 1 - Algoritmo transform.

\begin{tabular}{ll}
\hline começo: & O começo da sequência de entrada \\
fim: & O fim da sequência de entrada \\
saída: & O começo da sequência de saída \\
f: & A função unária de transformação \\
\hline 1 & função transform(começo, fim, saída, f) : \\
2 & enquanto começo $\neq$ fim: \\
3 & deref (saída) $\leftarrow$ f (deref (começo)) \\
4 & começo $\leftarrow$ próximo (começo) \\
5 & saída $\leftarrow$ próximo (saída) \\
\hline
\end{tabular}

O Algoritmo 1 mostra um pseudocódigo da função transform, no qual os parâmetros começo, fim e saída são iteradores, e $f$ é uma função unária. A função deref $(i)$, presente na linha 3 , faz o dereferenciamento do iterador $i$, e a função próximo $(i)$ retorna o iterador $i$ avançado para o próximo elemento.

Devido à natureza simples do algoritmo transform ele permite o funcionamento com iteradores de qualquer tipo de contêiner. Dessa forma, os iteradores formam uma camada de abstração que possui as funcionalidades necessárias e suficientes para os algoritmos, que são diretamente beneficiados com uma maior reusabilidade.

A Thrust vai um passo além provendo também o paralelismo do algoritmo transform. Para o caso em que se utiliza o OpenMP, deve-se apenas inserir uma diretiva $^{13}$ antes da linha 1 do Algoritmo 1 . Com isso a biblioteca consegue realizar transformações arbitrárias de forma paralela em qualquer tipo de contêiner. Isso é suficiente, por exemplo, para a implementação dos processos de predição, cálculo da pressão e correção do método E-MPS.

Algoritmo 2 - Algoritmo transform com função binária.

\begin{tabular}{|c|c|}
\hline $\begin{array}{l}\text { começo1: } \\
\text { fim1: } \\
\text { começo2: } \\
\text { saída: } \\
\text { f: }\end{array}$ & $\begin{array}{l}\text { O começo da primeira sequência de entrada } \\
\text { o fim da primeira sequência de entrada } \\
\text { o começo da segunda sequência de entrada } \\
\text { o começo da sequência de saída } \\
\text { A função binária de transformação }\end{array}$ \\
\hline $\begin{array}{l}1 \\
2 \\
3 \\
4 \\
5 \\
6\end{array}$ & $\begin{array}{l}\text { ção transform(começo1, fim1, começo2, saída, f): } \\
\text { nquanto começol f fim1: } \\
\text { deref (saída) } \leftarrow \text { f(deref (começo1), deref(começo2)) } \\
\text { começo1 } \leftarrow \text { próximo(começo1) } \\
\text { começo } \leftarrow \text { próximo(começo2) } \\
\text { saída } \leftarrow \text { próximo(saída) }\end{array}$ \\
\hline
\end{tabular}

\footnotetext{
13 \#pragma omp parallel for.
} 
$\mathrm{Na}$ realidade esses processos utilizam a variante com função binária do algoritmo transform, também provida pela Thrust, apresentado no Algoritmo 2. Com isso, analisando-se somente o algoritmo de solução do método E-MPS, resta a implementação dos processos que fazem a computação de variáveis ponderadas pela função peso. A implementação desses processos envolveu o desenvolvimento de um novo algoritmo.

Algoritmo 3 - Algoritmo for_each.

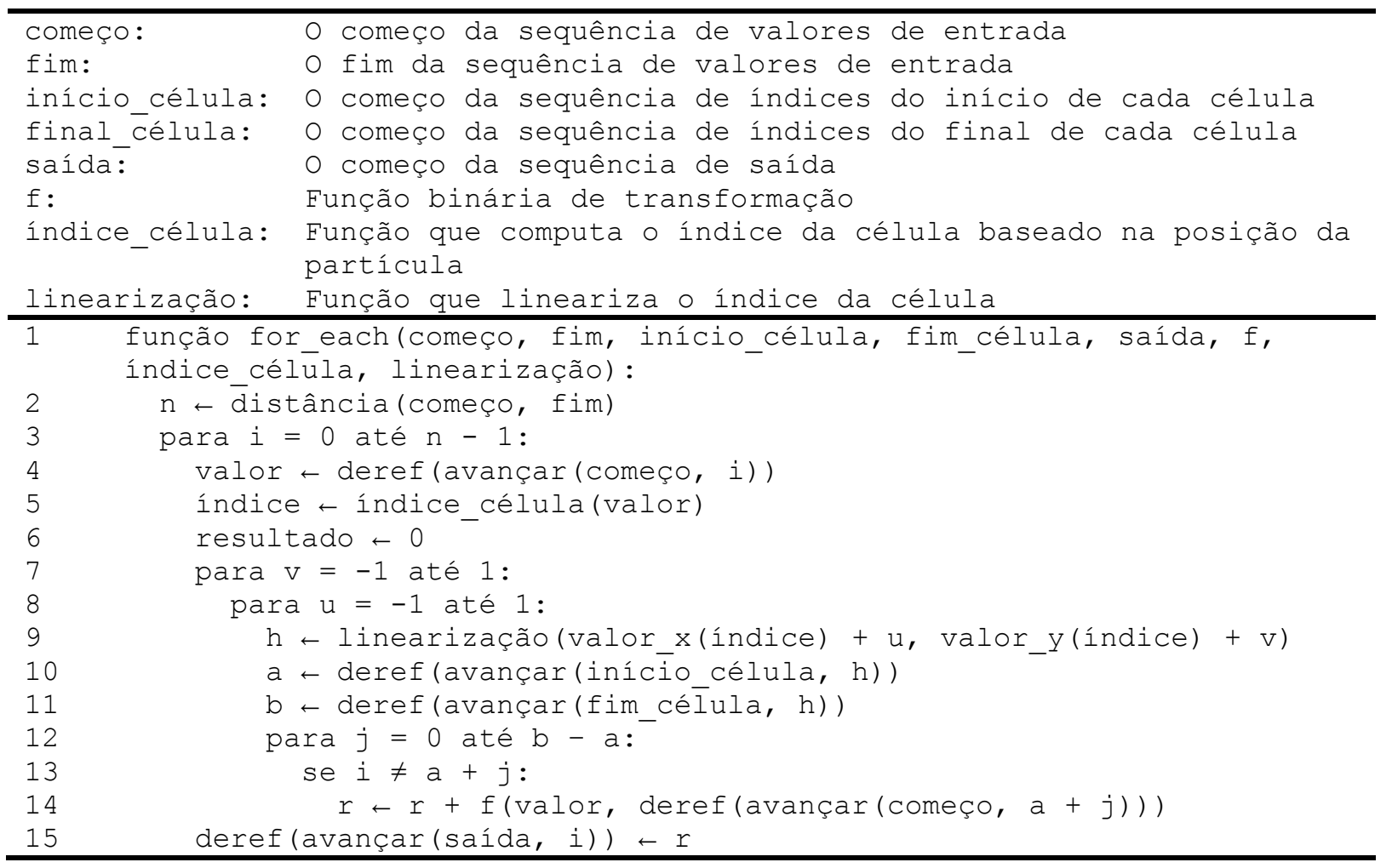

Assim como visto na subseção 3.1.1, dada uma partícula $i$ e seu conjunto de partículas vizinhas $\mathcal{V}_{i}=\left\{j: r_{i j}<r_{e}\right\}$, uma variável ponderada pela função peso é calculada pela seguinte fórmula geral:

$$
\langle x\rangle_{i}=k \sum_{i \neq j}\left(f\left(a_{i j}^{1}, a_{i j}^{2}, \ldots, a_{i j}^{n}\right) w\left(r_{i j}, r_{e}\right)\right)
$$

onde $x$ é uma variável ponderada pela função peso, $k$ é uma constante, $a$ é uma variável qualquer da partícula (ex: velocidade, pressão, etc.), $a_{i j}=a_{j}-a_{i}$, $f\left(a_{i j}^{0}, a_{i j}^{1}, \ldots, a_{i j}^{n-1}\right)$ é uma função que depende de $n$ variáveis (escalares ou vetores) da partícula $i$ e de uma partícula vizinha $j$, e $w\left(r_{i j}, r_{e}\right)$ é a função peso. 
Seguindo a interface dos algoritmos da Thrust e STL, foi desenvolvido o algoritmo for_each como mostra o Algoritmo 3. A função distância $\left(i_{1}, i_{2}\right)$ retorna a distância entre os iteradores $i_{1}$ e $i_{2}$, ou seja, informa o número de elementos entre eles. A função avançar $(i, n)$ devolve o iterator que se encontra $n$ elementos adiante de $i$. As funções valor_x $(c)$ e valor_y(c) retornam o índice da célula $c$ correspondente ao eixo cartesiano $x$ e $y$, respectivamente.

Para o caso da paralelização utilizando-se o OpenMP a diretiva de paralelização foi inserida antes da linha 3 do Algoritmo 3. Já para o CUDA o kernel foi implementado fazendo com que cada thread processe uma partícula, ou seja, a paralelização foi feita no nível do laço da linha 3.

A principal vantagem da implementação ter sido feita nos moldes apresentado anteriormente é que o mesmo algoritmo pode ser utilizado para o cálculo da força de viscosidade, densidade número de partículas e gradiente de pressão.

Como será visto na seção seguinte, o principal gargalo computacional do sistema é exatamente o algoritmo for_each. A partir de medições feitas durante as simulações, descobriu-se que a GPU não consegue ocupar todos os cores dos stream multiprocessors, ou seja, a GPU fica com um baixo nível de ocupação. Isso sempre se deve a alguma falta de recurso para processar o kernel como memória compartilhada ou registradores.

No caso do algoritmo for_each foi averiguado que o recurso que gera um baixo nível de ocupação são os registradores. Estar limitado pelos registradores significa que o kernel do algoritmo é muito complexo, ou seja, possui um número muito grande de operações e estas requerem muitos registradores para armazenar os valores intermediários.

Para proporcionar uma diminuição no número de registradores alocados por cada thread é necessário simplificar o kernel, o que significa, em última instância, uma alteração na granularidade do paralelismo. Isso seria possível se fosse realizado, primeiramente, a prospecção dos pares de partículas interagentes. No entanto isso ocasionaria um aumento considerável de memória necessária para se armazenar todos os pares.

Para um caso típico de simulação tridimensional, cada partícula terá em média 125 partículas vizinhas considerando-se um coeficiente de raio de influência de 2,1. Utilizando-se a estratégia de se armazenar os índices das partículas interagentes isso significaria a alocação de 500MB apenas para essa lista para um caso de 1 milhão de 
partículas. No entanto esse valor não é proibitivo, além do fato de ser superestimado, pois nem todas as partículas terão a sua vizinhança cheia de partículas. Portanto, a viabilidade dessa estratégia deve ser foco de trabalhos futuros.

A busca de vizinhos foi implementada empregando-se o algoritmo sort_by_key da biblioteca Thrust, que utiliza o método Radix de ordenação ${ }^{14}$. A computação dos índices inicial e final de cada célula, detalhada na subseção 3.3, foi realizada a partir dos algoritmos upper_bound e lower_bound vetoriais da biblioteca Thrust.

Algoritmo 4 - Algoritmo for_each_cell.

\begin{tabular}{ll}
\hline aabb: & O AABB de entrada \\
saída: & O começo da sequência de saída \\
f: & A função únária de transformação \\
\hline 1 & função for each cell(abbo, saída, f): \\
2 & para cada índíce da célula c de aabb: \\
3 & deref (saída) $\leftarrow$ f(c) \\
4 & saída $\leftarrow$ próximo(saída) \\
\hline
\end{tabular}

A comunicação exigida entre subdomínios envolveu a criação de dois algoritmos: for_each_cell e copy. O primeiro aplica uma função arbitrária a cada índice da célula de um $A A B B$, armazenando o resultado em uma sequência de saída, como mostra o Algoritmo 4. Ele é utilizado principalmente para calcular o índice linearizado das células de um determinado AABB, e com isso aplicar o algoritmo copy.

O paralelismo foi alcançado no OpenMP inserindo-se a diretiva de paralelismo antes da linha 2 do Algoritmo 4. Para o paralelismo em CUDA cada thread foi alocada para o processamento de uma célula.

Algoritmo 5 - Algoritmo copy.

\begin{tabular}{|c|c|}
\hline $\begin{array}{l}\text { começo: } \\
\text { fim: } \\
\text { mapa: } \\
\text { início célula: } \\
\text { fim_célula: } \\
\text { valores } \\
\text { saída: }\end{array}$ & $\begin{array}{l}\text { O começo da sequência de índices linearizados de célula } \\
\text { o fim da sequência de índices linearizados de célula } \\
\text { Índices da sequência de saída } \\
\text { O começo da sequência de índices do início de cada célula } \\
\text { o começo da sequência de índices do final de cada célula } \\
\text { o começo da sequência de valores a serem copiados } \\
\text { o começo da sequência de saída }\end{array}$ \\
\hline $\begin{array}{l}\text { função co } \\
\text { saída) } \\
\text { n } \leftarrow \text { dis } \\
\text { para } i \\
\text { it } \leftarrow \\
\quad \mathrm{a} \leftarrow d\end{array}$ & $\begin{array}{l}\text { oy (começo, fim, mapa, início_célula, fim_célula, valores, } \\
\text { =ância (começo, fim) } \\
=0 \text { até n - 1: } \\
\text { avançar(começo, i) } \\
\text { eref(avançar(início_célula, deref(it)) }\end{array}$ \\
\hline
\end{tabular}

\footnotetext{
${ }^{14} \mathrm{Na}$ realidade a ordenação da biblioteca Thrust utiliza o método Radix Sort quando o dado a ser ordenado é um tipo integral (char, short, int, float, etc.), e a função de comparação é thrust::less. Nos demais casos utiliza-se o método Merge Sort.
} 


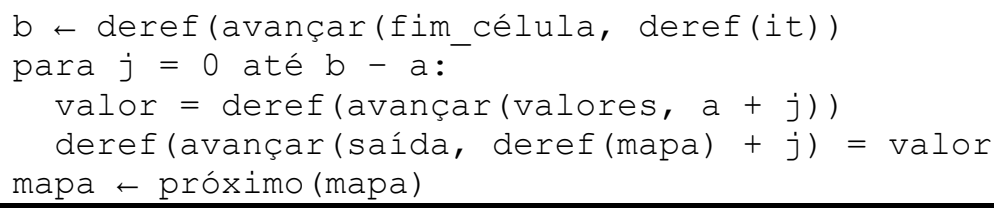

Dada uma sequência de índices linearizados de célula e outra que mapeia a subsequência correspondente a cada célula na sequência de saída, o algoritmo copy permite a cópia de um conjunto especificado de atributos das partículas residentes nas células para a sequência de saída, como mostra o Algoritmo 5. Ele é utilizado nos processos relacionados à comunicação entre subdomínios descritos na subseção 4.1.3, assim como no balanceamento de carga ortogonal descrito na subseção 4.1.6.

\subsubsection{Parallel MPS}

Assim como no Generator, no Parallel MPS cada subdomínio é processado por um processo MPI, mas diferentemente do primeiro, a comunicação entre os processos é necessária.

Os arquivos de entrada são o arquivo de descrição de caso e a geometria inicial de cada subdomínio, sendo este último gerado pelo aplicativo Generator.

Como descrito na subseção anterior, a filosofia de desenvolvimento seguiu a biblioteca Thrust e a STL.

A comunicação em memória distribuída foi realizada a partir do padrão MPI, com as chamadas sendo feitas de forma assíncronas (MPI_Isend, MPI_Irecv e MPI_Waitall). Na realidade, a única vez que foi utilizada uma chamada não assíncrona foi para verificar se algum subdomínio necessitava de balanceamento no método ortogonal, ocasião em que se empregou a chamada MPI_Allgather.

A comunicação assíncrona permite com que múltiplas transmissões e recepções de dados sejam requisitadas, o que possibilita algum tipo de otimização na camada de implementação do MPI. Isso ocorre nos processos de cada subdomínio devido à presença de múltiplos subdomínios vizinhos.

Por ser um dispositivo de processamento paralelo, a GPU conta com um escalonador que gerencia os processos que foram submetidos pelo processo host. Para facilitar o processamento concorrente entre o host e o dispositivo, as chamadas 
para funções a serem executadas no dispositivo são na maioria assíncronas, sendo o controle retornado ao processo host antes que o dispositivo tenha terminado a requisição. Para se garantir que todas as funções chamadas foram finalizadas, devese chamar a função cudaStreamSynchronize, que bloqueia o processo host até que todas as funções pendentes no escalonador do dispositivo tenham sido completadas. Essa sincronização é extremamente importante para garantir que os dados tenham sido completamente processados antes que haja qualquer tipo de comunicação entre os processos, evitando-se assim a transmissão de dados inconsistentes.

Outro ponto importante a se comentar a respeito da integração do dispositivo GPU com a comunicação MPI é a necessidade de transferência dos dados da memória do dispositivo para a memória principal para envio dos dados. Para se evitar a transferência explícita de dados, por meio de chamadas de funções de transferência de dados entre host e o dispositivo (cudaMemcpy), utiliza-se uma funcionalidade chamada de Page Locked Memory. Ela dispensa o uso de streams para se ter concorrência entre transferência de dados e execução de processos no dispositivo, pois isso já é feito implicitamente. Note, no entanto, que a chamada para cudaStreamSynchronize antes de qualquer procedimento de comunicação se torna ainda mais importante.

Os métodos de decomposição de domínio foram implementados de acordo com os processos detalhados na subseção 4 . 


\section{APLICAÇÃO E RESULTADOS}

A fim de verificar a eficiência das técnicas investigadas neste trabalho, incluindo aquelas aqui propostas, existe a necessidade de se analisar os ganhos de desempenho computacional. A partir deles pode-se averiguar o quanto este trabalho colaborou para o aumento da quantidade de partículas em uma simulação e na redução do tempo de computação.

Esta seção inicialmente apresenta os resultados de ganho de desempenho computacional alcançados com o método de decomposição de domínio estático.

Simulações com diferentes números de processos foram efetuadas para se testar a escalabilidade do método, verificando-se, principalmente, se existe perda de desempenho significativa devido à comunicação. Os resultados comprovaram que o algoritmo proposto na subseção 4.1.3 é eficiente e garante uma boa escalabilidade. Além disso, os testes incluíram execuções com processamento em CPU multicore e GPU, separadamente.

Em seguida, são apresentados apenas resultados qualitativos do método ORB, que comprovam que ele é pouco atrativo devido à sua característica hierárquica e rigidez geométrica. Portanto, o método ortogonal se mostra mais atrativo pela ausência de hierarquia e simplicidade do método.

Para se verificar que existem vantagens reais no emprego de um método de decomposição com balanceamento dinâmico em certas aplicações, e comprovar a eficiência do método ortogonal nesses casos, foi realizada uma comparação entre os métodos estático e ortogonal. Comparou-se os tempos de processamento de um passo temporal, o ganho de desempenho do método ortogonal e os níveis de balanceamento para ambos os métodos.

Outro ponto, que impacta o desempenho computacional, é a escolha do tamanho da célula para minimizar o número de buscas de vizinhos realizadas durante um simulação, como discutido na subseção 3.3.1. Foram realizados testes de desempenho variando-se o tamanho da célula de 4 valores distintos, com o processamento sendo realizado em GPU e CPU multicore. 


\subsection{MÉTODO DE DECOMPOSIÇÃO DE DOMÍNIO ESTÁTICO}

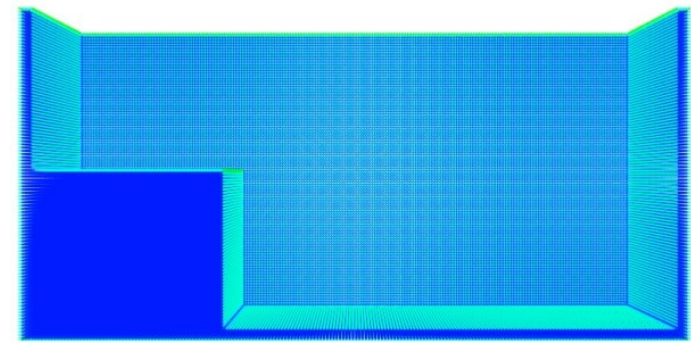

1

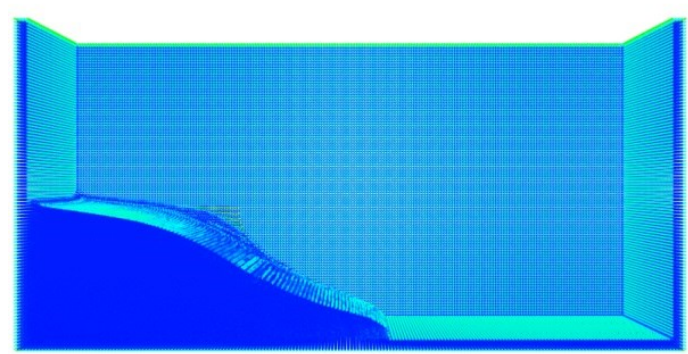

3

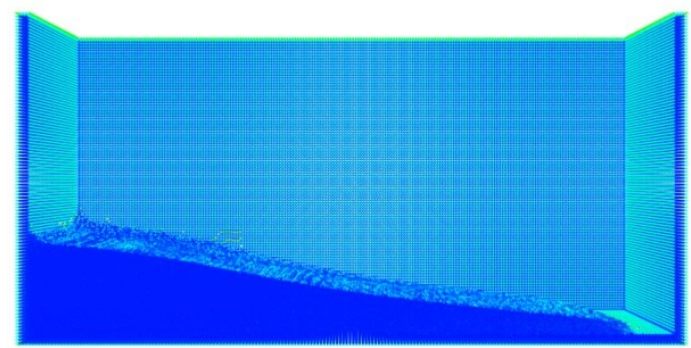

5

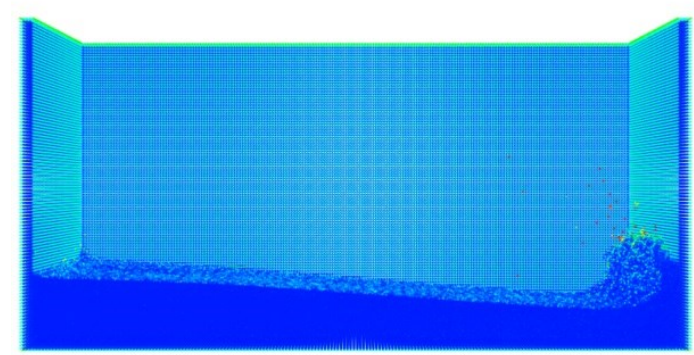

7

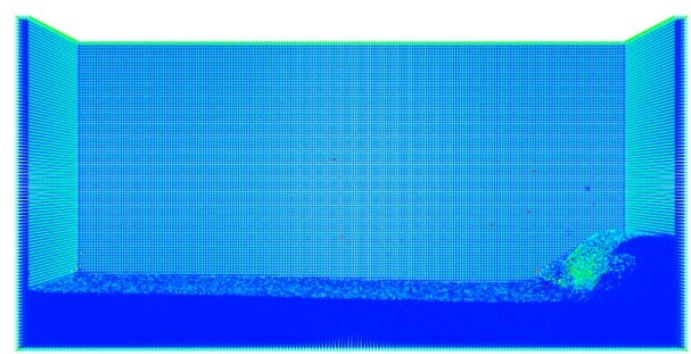

9
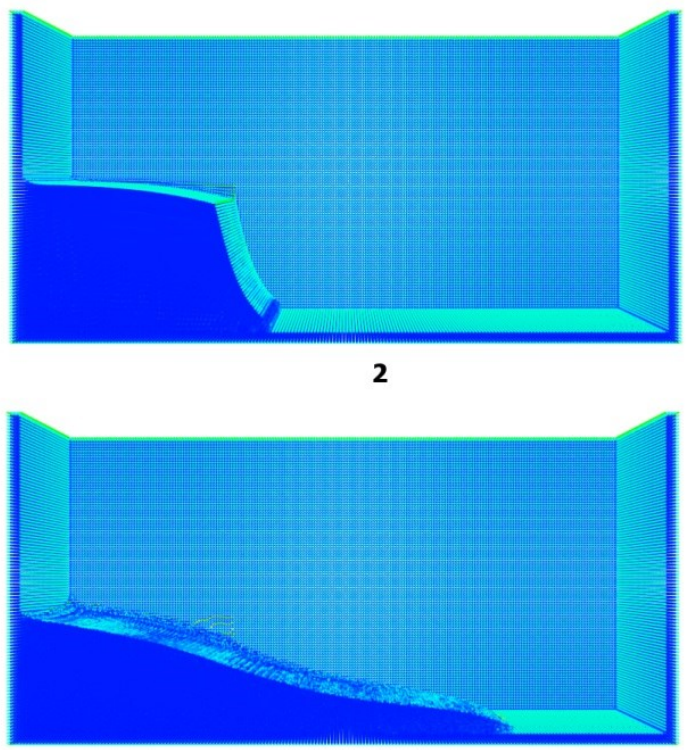

4

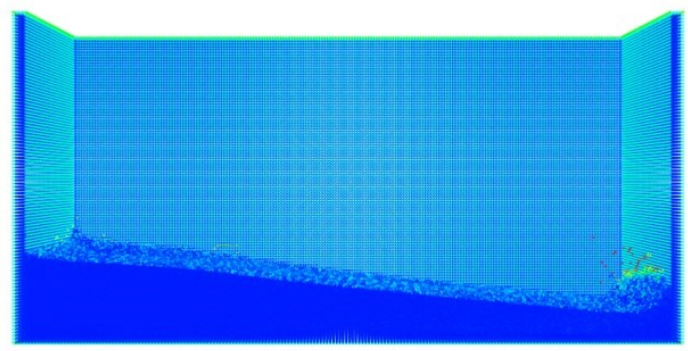

6

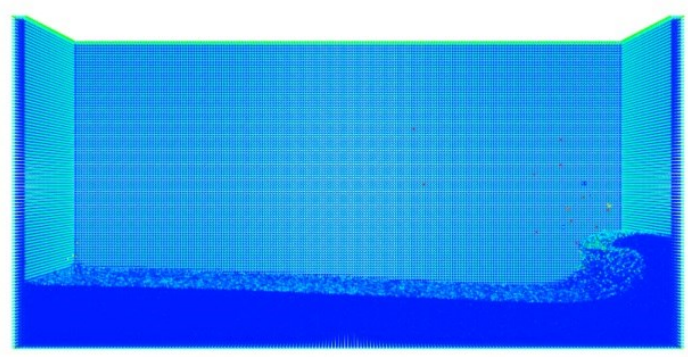

8

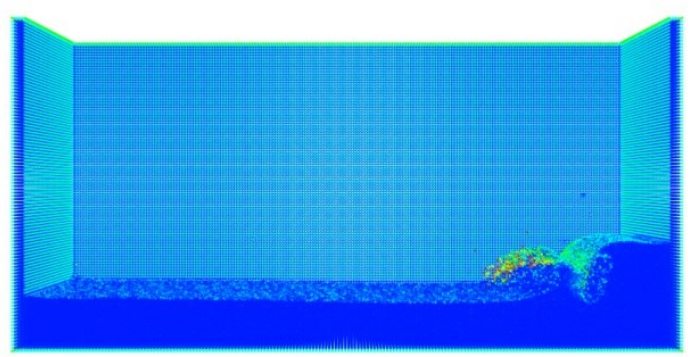

10

Figura 29 - Exemplo de um caso de dam break tridimensional. 
Os resultados foram obtidos utilizando-se dois clusters, um contendo dispositivos GPU e outro apenas com nós multicore convencionais como mostram a Tabela 19 e a Tabela 20, respectivamente.

Tabela 19 - Configuração do cluster GPU.

\begin{tabular}{cc}
\hline Processador & AMD Opteron 8384 2.7GHz \\
\hline Quantidade de nós & 16 \\
Núcleos por nó & 16 \\
Memória & $32 \mathrm{~GB}$ \\
Dispositivo GPU & NVIDIA's Tesla S1070 \\
Quantidade de dispositivos GPU & 32 \\
Dipositivos GPU por nó & 2 \\
Interconexão & Infiniband QDR 4x \\
\hline Tabela 20 - Configuração do cluster CPU. \\
\hline Processador \\
\hline Núcleos por nó \\
Memória \\
Interconexão & 8 \\
\hline
\end{tabular}

A Tabela 21 apresenta os resultados obtidos para cinco casos de testes de um caso de dam break tridimensional com diferentes números de partículas:

- $\quad$ CPU 1 thread, CPU 4 threads, CPU 4 threads - execução utilizando-se o cluster CPU com um, quatro e oito threads OpenMP, respectivamente.

- GPU, GPU 4 processos, GPU 9 processos - execução utilizando-se um, quatro e nove processos MPI, respectivamente, e um dispositivo GPU por processo.

A Figura 29 ilustra diferentes instantes do mesmo tipo de caso, em que ocorre o colapso de uma coluna de fluido somente pelo efeito da gravidade.

Tabela 21 - Tempo médio para computação de um passo temporal (em segundos).

\begin{tabular}{ccccccc}
\hline Particles & $\begin{array}{c}\text { CPU } \\
\text { 1 thread }\end{array}$ & $\begin{array}{c}\text { CPU } \text { threads } \\
\text { 8 threads }\end{array}$ & $\begin{array}{c}\text { GPU } \\
\text { 4 processos }\end{array}$ & $\begin{array}{c}\text { GPU } \\
\text { 9 processos }\end{array}$ \\
\hline $\mathbf{1 4 1 . 1 6 8}$ & 1,097 & 0,389 & 0,206 & 0,101 & - & - \\
$\mathbf{4 5 2 . 5 2 8}$ & 3,973 & 1,671 & 0,888 & 0,282 & - & - \\
$\mathbf{6 9 8 . 5 7 8}$ & 7,467 & 2,628 & 1,389 & 0,513 & 0,163 & 0,092 \\
\hline
\end{tabular}


A partir dos resultados obtidos para os casos em que se utilizou a CPU com 1, 4, e 8 threads, é possível avaliar a escalabilidade da implementação quanto ao número de núcleos utilizados sem decomposição do domínio.

Embora as comparações sejam feitas com base em um executável compilado com instruções OpenMP e configurado para que utilize apenas 1 núcleo durante a execução, considera-se que a perda de performance seja insignificante se comparado a um executável puramente serial. Para ser possível a comparação com base neste último, seria necessária a confecção de um programa especialmente para esse fim, e sem aplicação prática, o que se considerou um purismo exagerado.

A paralelização via OpenMP conseguiu um ganho de até 5 vezes quando se utilizam 8 threads. Ao se comparar esse ganho com o obtido quando se utiliza apenas 1 dispositivo GPU sem decomposição de domínio, observa-se que o alto número de núcleos presentes na GPU proporciona um ganho de mais de 14 vezes, quase 3 vezes mais do que a CPU.

Analisando-se os resultados obtidos no cluster GPU com a utilização de decomposição de domínio estático, constata-se um ganho de mais de 80 vezes se comparado ao caso executado na CPU com apenas uma thread, e mais de 5 vezes se comparado ao caso no qual se utiliza apenas um dispositivo GPU, ambos sem decomposição de domínio.

Para se determinar os gargalos de processamento em GPU, utilizou-se a ferramenta Compute Visual Profiler para analisar a dinâmica de execução do caso no qual se utiliza apenas 1 dispositivo GPU sem decomposição de domínio. A ferramenta revelou que 95\% do tempo de computação é gasto nos processos 1, 4 e 6 da Figura 6 , ou seja, no cálculo de grandezas ponderadas pela função peso.

Devido à complexidade do cálculo, principalmente para o operador gradiente, a utilização de registradores é grande, o que faz com que o nível de ocupação dos núcleos GPU seja de apenas 40\%.

Para se determinar os gargalos de execução quando se utiliza a decomposição de domínio estática, foram feitos mais um conjunto de testes de outro caso de dam break tridimensional com 8, 12, 16, 20 e 24 processos MPI e 16.714.218 partículas. 


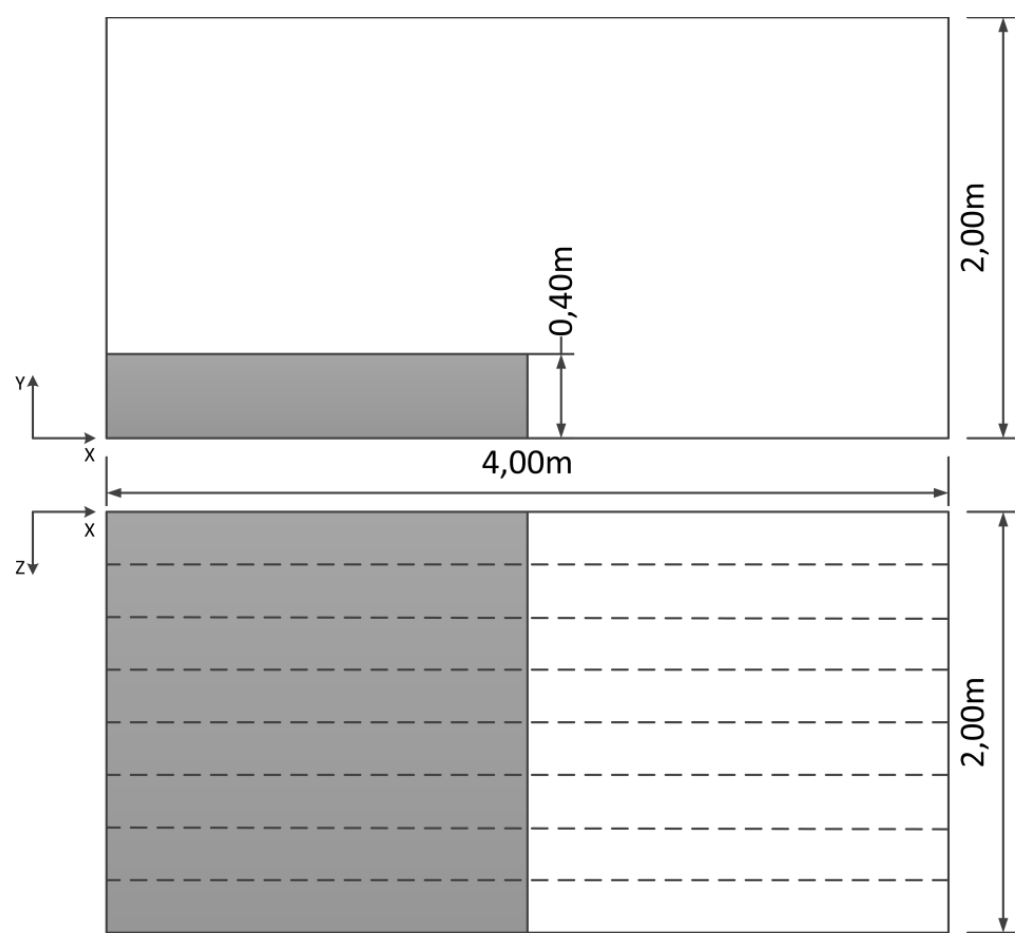

Figura 30 - Caso de dam break tridimensional utilizando decomposição de domínio estático com 8 subdomínios. O volume do fluido é representado em cinza, e as linhas tracejadas são o planos que dividem os subdomínios.

A Figura 30 descreve o caso com 8 processos que são subdivididos na direção do eixo Z, ou seja, perpendicular ao fluxo que se dá na direção do eixo $X$ apenas pelo efeito da gravidade. Assim, como o fluxo na direção do eixo Z é mínimo, espera-se que um bom balanceamento seja mantido entre os processos.

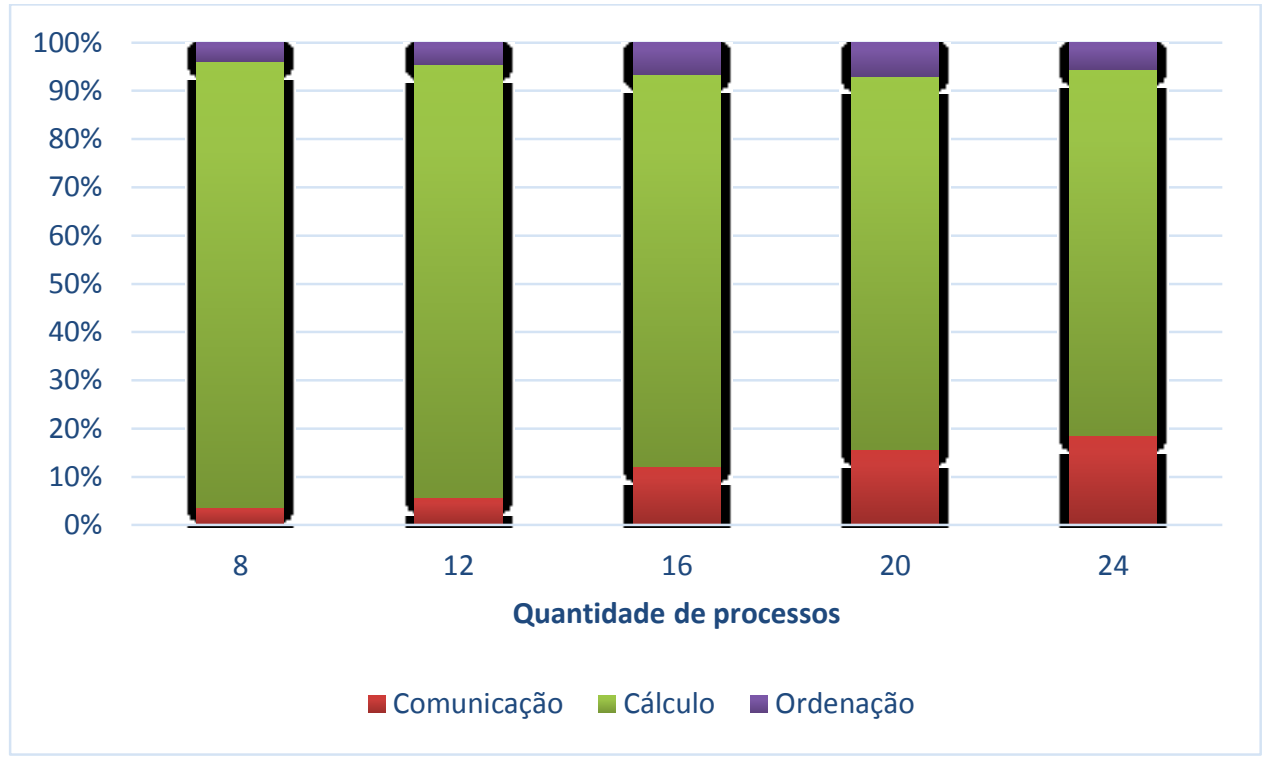

Figura 31 - Porcentagem de tempo gasto em um passo temporal em ordenação, cálculo e comunicação com a variação do número de processos. 
A Figura 31 apresenta a distribuição de tempo gasto nos primeiros 1000 passos de simulação nas seguintes tarefas:

- $\quad$ busca de vizinhos - processo 1 da Figura 18;

- cálculo - processo 2 a 10 da Figura 18;

- $\quad$ comunicação - passos de comunicação I a IV da Figura 18.

Observa-se pelo gráfico que as tarefas de ordenação e comunicação representam menos de $25 \%$ do tempo de computação em um passo temporal, mesmo para o caso com o maior número processos $\mathrm{MPI}$.

O gráfico da Figura 32 apresenta a média dos tempos de computação de um passo temporal para cada um dos casos rodados. Aqui, analisa-se a escalabilidade da implementação para um caso de dezenas de milhões de partículas, mostrando-se os tempos obtidos em cada caso, juntamente com os tempos esperados caso se alcançasse a escalabilidade ideal. A escalabilidade ideal é obtida com base no tempo obtido utilizando-se 8 processos pois esse era o menor número de processos que possibilita a execução de um número tão elevado de partículas (por volta de 2 milhões de partículas por dispositivo). Pode-se constatar uma boa escalabilidade do programa, com tempos que se mantêm muito próximo do ideal.

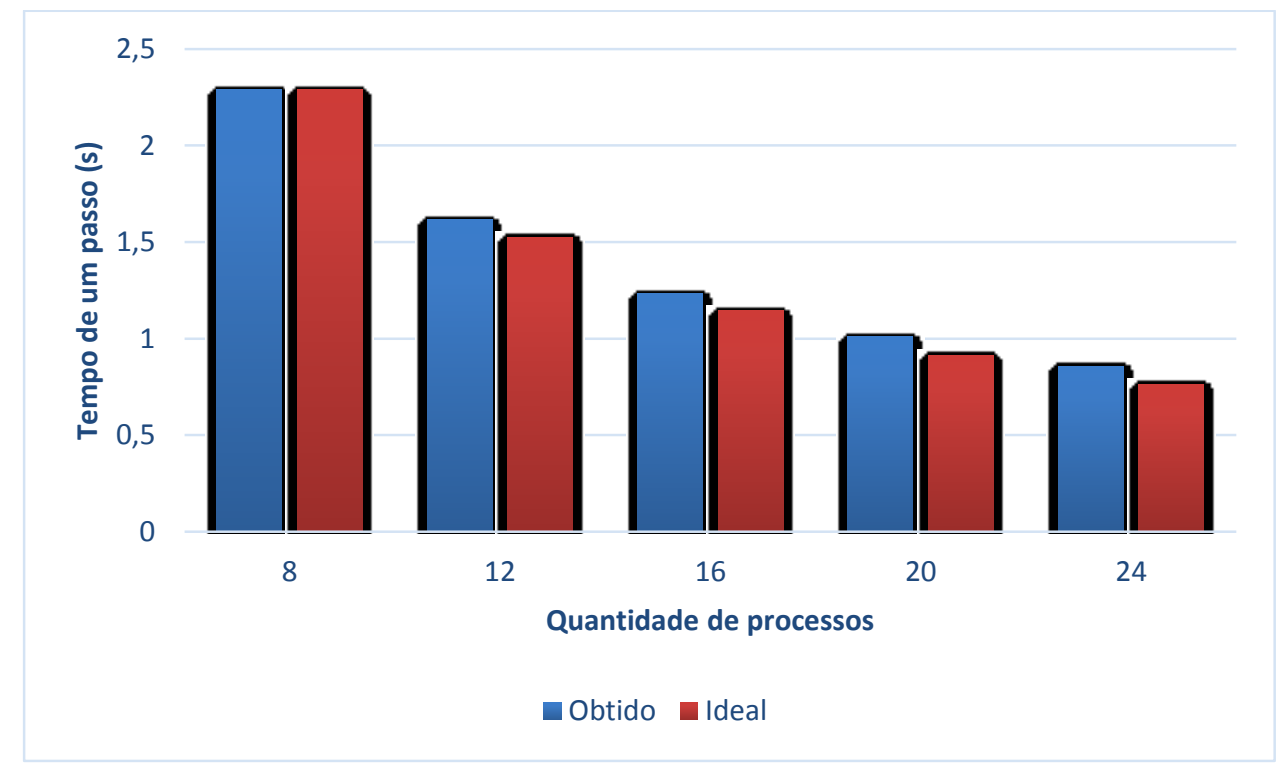

Figura 32 - Escalabilidade ao se aumentar a quantidade de processos MPI. 


\subsection{MÉTODO DE DECOMPOSIÇÃO DE DOMÍNIO ORTOGONAL}

Foi conduzido um estudo comparativo entre os métodos de decomposição de domínio estático e ortogonal. O objetivo era verificar qual era o ganho de desempenho alcançado com o balanceamento dinâmico. Não se trata, no entanto, de mostrar a superioridade do método ortogonal frente ao estático, visto que o ganho depende muito da geometria do caso sendo estudado. Os resultados aqui mostrados devem apenas comprovar que existem casos em que o emprego do método ortogonal proporciona ganhos reais, mesmo com a introdução de processos que requerem uma computação adicional. Alguns critérios para escolha do método de decomposição são levantados no final dessa subseção.

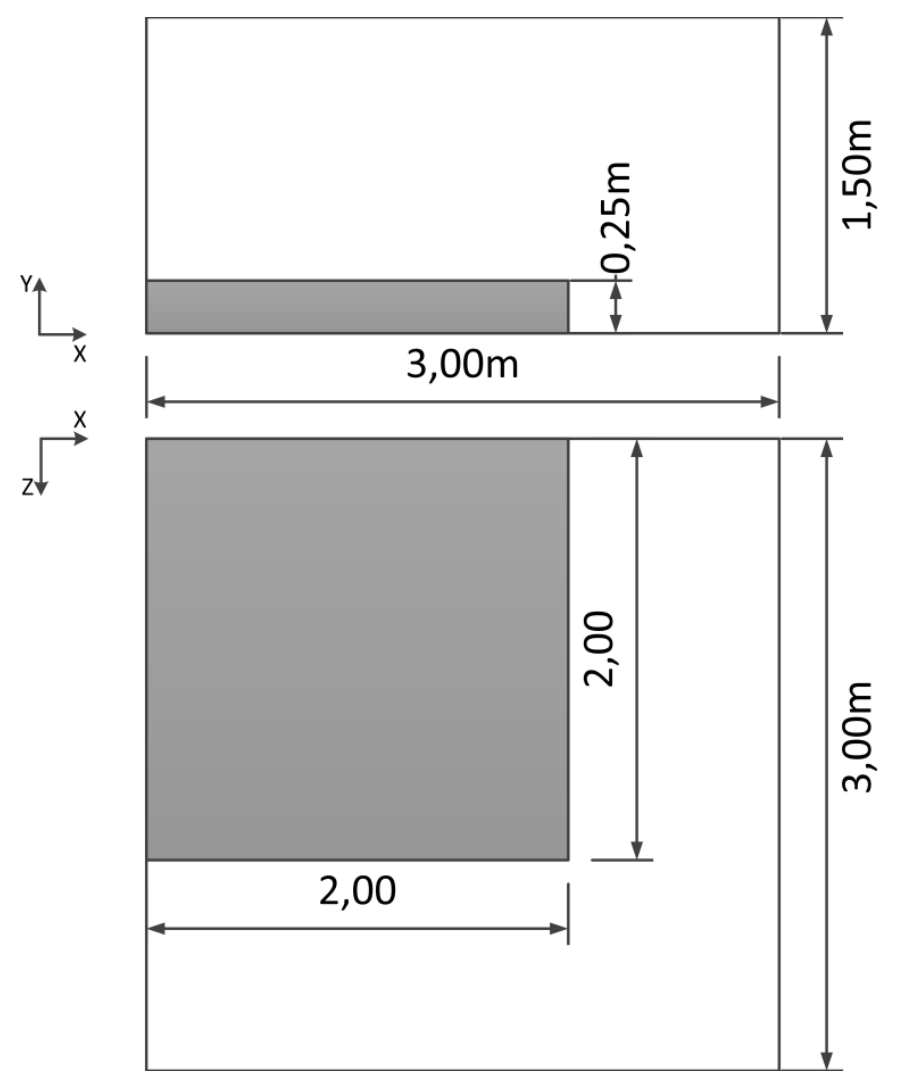

Figura 33 - Caso de dam break 3D utilizado para comparação de desempenho entre os métodos estático e ortogonal.

O hardware utilizado para o teste foi o mesmo especificado na Tabela 19 utilizado no estudo do método estático, tanto para processamento GPU quanto para CPU.

Utilizou-se um caso de dam break tridimensional contendo por volta de 11 milhões da partículas para a comparação dos métodos de decomposição, cuja 
geometria é mostrada na Figura 33. O parâmetro maximum_imbalance teve o seu valor definido em 0,1 . Tanto para o método estático como para o ortogonal a decomposição foi realizada no eixo $Z$.

No caso da decomposição estática os subdomínios foram divididos de maneira que cada um possuísse inicialmente o mesmo tamanho. Essa escolha é justificada pelo fato de qualquer outra escolha beneficiar apenas um instante limitado da simulação, enquanto adotar o mesmo tamanho beneficia a tendência final do fluxo, que é se estabilizar com uma distribuição uniforme de partículas em todos os subdomínios.

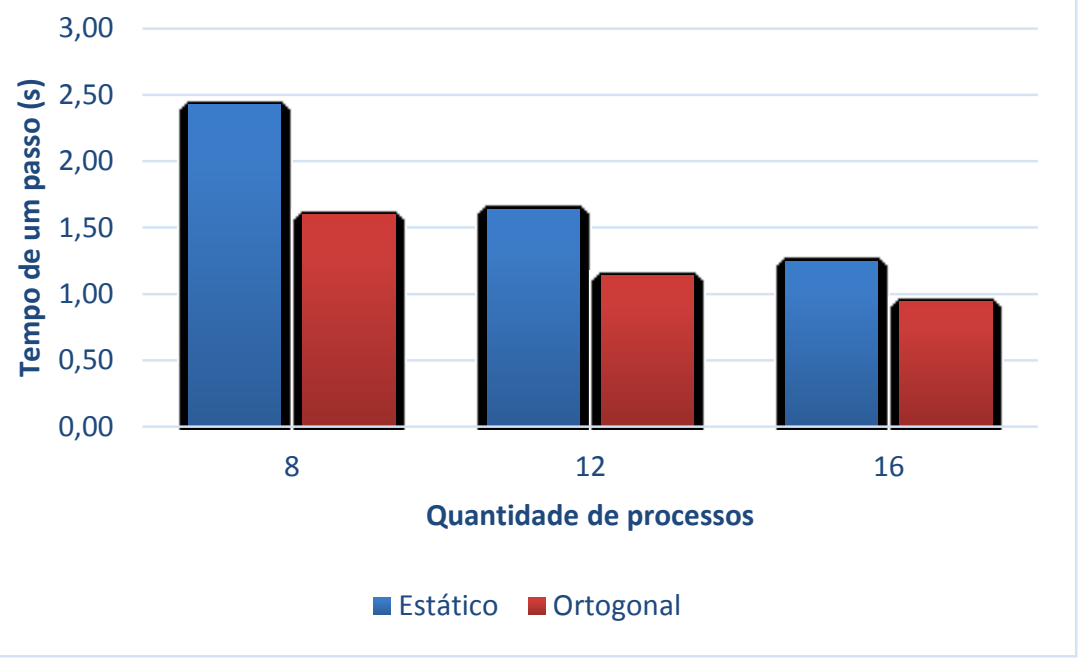

Figura 34 - Comparação do tempo de processamento de um passo temporal.

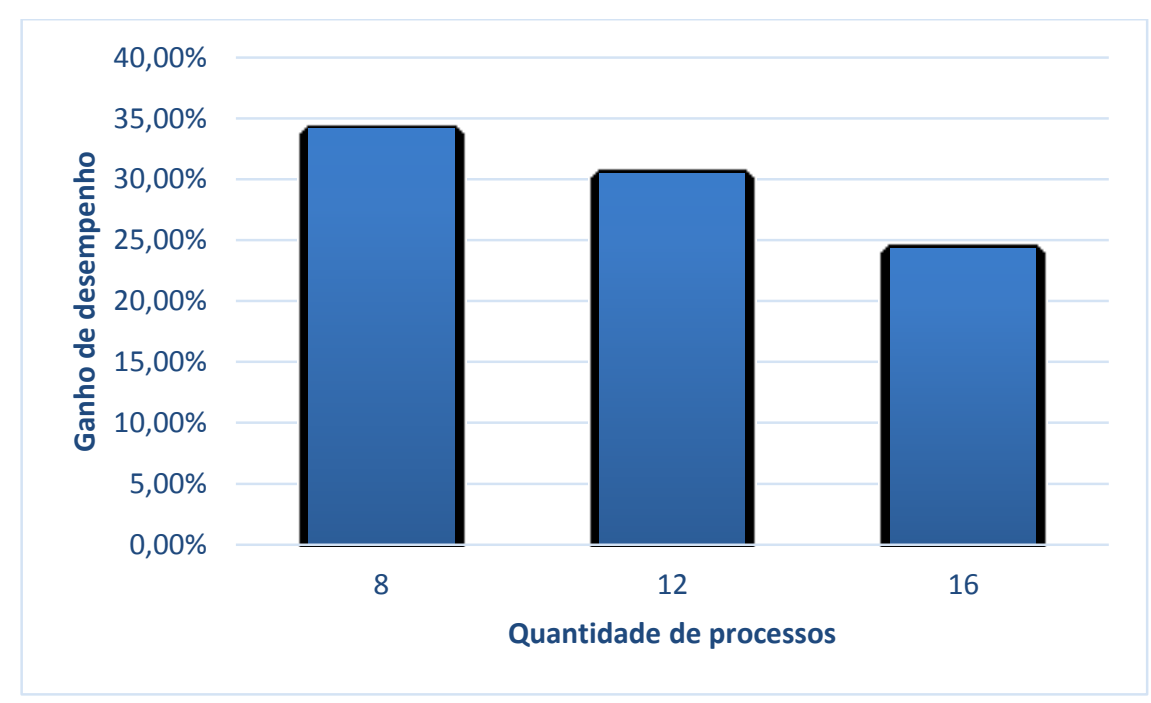

Figura 35 - Gráfico do ganho de desempenho do método ortogonal frente ao estático.

Já para o método ortogonal os subdomínio são divididos de maneira a equalizar o número de partículas já inicialmente. 
A Figura 34 apresenta os tempos de processamento de um passo temporal para 8, 12 e 16 subdomínios utilizando-se os métodos de decomposição estático e ortogonal.

Os ganhos de desempenho do método ortogonal para cada um dos 3 casos pode ser verificada na Figura 35. Nota-se que o maior ganho é obtido no caso de 8 subdomínios, devido à maior carga de processamento em cada processo e ao maior desbalanceamento entre eles, como pode ser comprovado na Figura 36.

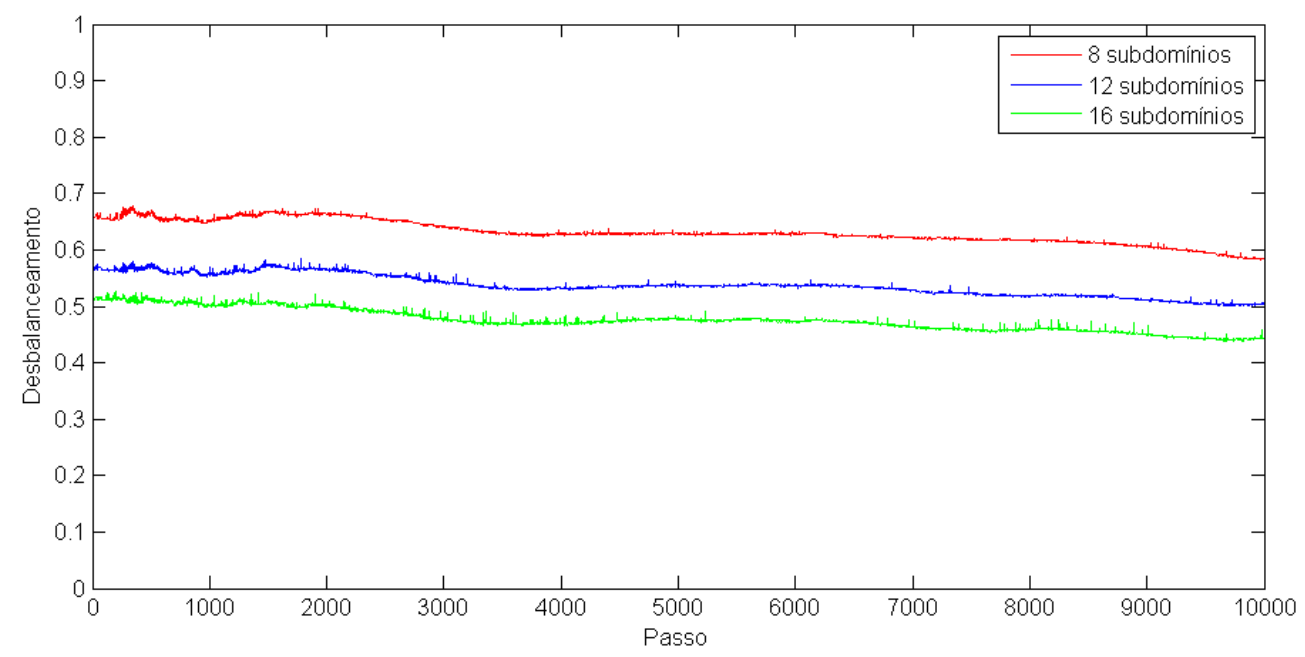

Figura 36 - Gráfico do nível de desbalanceamento entre os subdomínios para os casos em que se utilizou o método de decomposição estático.

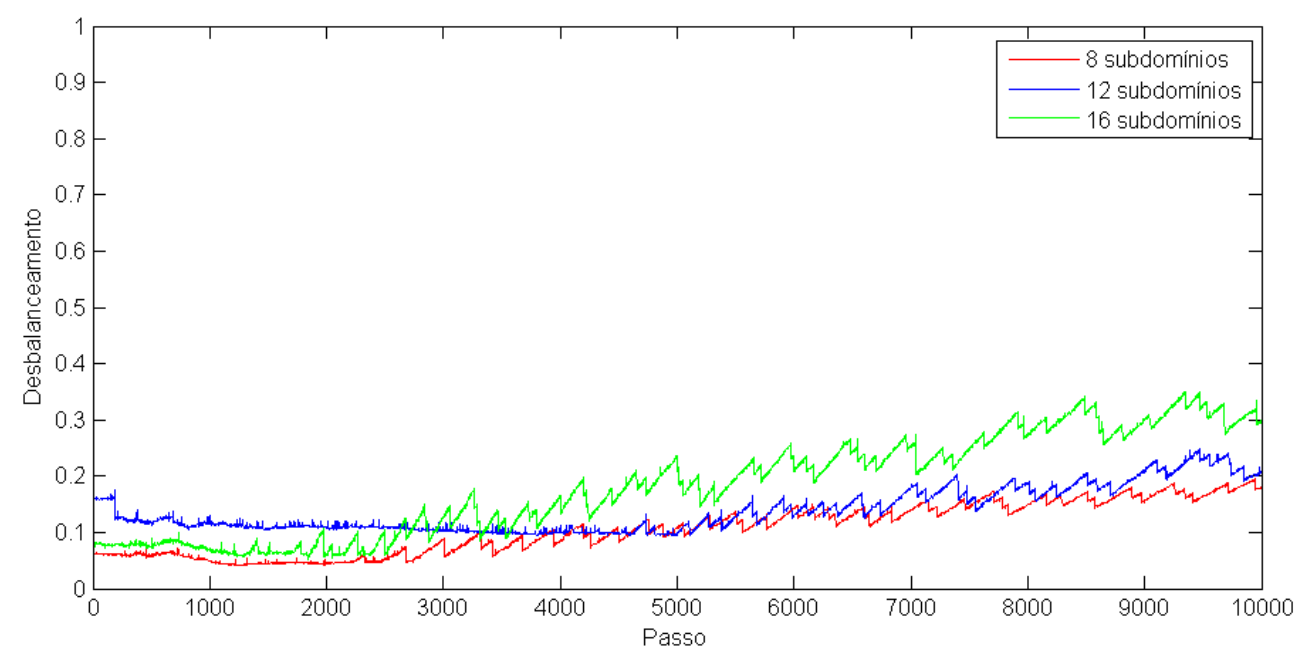

Figura 37 - Gráfico do nível de desbalanceamento entre os subdomínios para os casos em que se utilizou o método de decomposição ortogonal. 
Dado o conjunto $L=\left\{L_{1}, L_{2}, \ldots, L_{N}\right\}$ de tempos de computação de um passo temporal de cada um dos $N$ subdomínios, o desbalanceamento entre subdomínios foi calculado utilizando-se a seguinte equação:

$$
\lambda=\frac{L_{\max }}{\bar{L}}-1
$$

sendo $L_{\text {max }}$ o valor máximo de $L$, e $\bar{L}$ a sua média.

A Figura 36 mostra que o método estático apresentou uma leve tendência de melhora do balanceamento proporcionada pelo fluxo, mas o desbalanceamento é, de modo geral, maior que $50 \%$. Todos os casos do método ortogonal já iniciam com um nível de desbalanceamento consideravelmente menor do que os do método estático, graças à uniformização da quantidade de partículas inicial. Nota-se também que os níveis de desbalanceamento alcançados por todos os casos do método ortogonal são consideravelmente menores que os níveis verificados nos casos com decomposição estática. Pode-se notar claramente os instantes em que o balanceamento foi realizado, evidenciado pela redução abrupta do valor de $\lambda$ entre passos temporais.

Embora tenha-se escolhido um nível máximo de desbalanceamento entre subdomínios adjacentes $\tau=0,1$, verifica-se a existência de valores de desbalanceamento maiores em todos os casos simulados. A garantia de que $\frac{\max \left(L_{i}, L_{i+1}\right)}{\min \left(L_{i}, L_{i+1}\right)}-1 \leq \tau$ para todo subdomínio $i \leq N$, não garante que $\lambda \leq \tau$. Particularmente, é esperado que $\frac{\max \left(L_{0}, L_{N}\right)}{\min \left(L_{0}, L_{N}\right)}-1>\tau$. Em suma, a garantia de um nível desbalanceamento máximo entre subdomínio adjacentes não garante um nível global de desbalanceamento, e isso justifica os valores obtidos na Figura 37. Previa-se que a tendência de $\lambda$ ultrapassar $\tau$ seria maior quanto maior o número de subdomínios participantes da simulação, fato comprovado pelo gráfico da Figura 37.

\subsection{MINIMIZAÇÃO DO NÚMERO DE BUSCAS DE VIZINHOS}

Como apresentado na subseção 3.3.1, o tamanho das células $h$ da grade não deve ser menor que o raio de influência $r_{e}$ adotado nos cálculos, para garantir que todas as partículas vizinhas sejam consideradas no cálculo de variáveis ponderadas pela função peso. Por outro lado, a adoção de um valor de $h>r_{e}$ mantém a consistência nos cálculos e pode diminuir o número de ordenações necessárias, 
reduzindo assim o custo computacional. No entanto, quanto maior o valor de $h$, é maior o número médio de partículas vizinhas, afetando diretamente o desempenho computacional de todas as variáveis ponderadas pela função peso.

A análise do impacto da variação do tamanho das células no desempenho computacional foi realizada a partir de um caso de dam break tridimensional sem decomposição de domínio.

O hardware utilizado é o mesmo especificado na Tabela 19 tanto para os testes com processamento GPU, quanto para CPU.

Foram realizados testes, tanto utilizando CUDA como OpenMP, com 500 mil, 700 mil e 1 milhão de partículas.

A geometria de cada um desses casos é detalhada no Apêndice $B$, sendo que em cada uma deles variou-se o tamanho das células de $r_{e}, 1,05 r_{e}, 1,1 r_{e}$ e $1,15 r_{e}$.

Primeiramente analisam-se os casos em que o processamento é realizado em dispositivos GPU utilizando-se CUDA, e posteriormente os casos com processamento multicore via OpenMP.

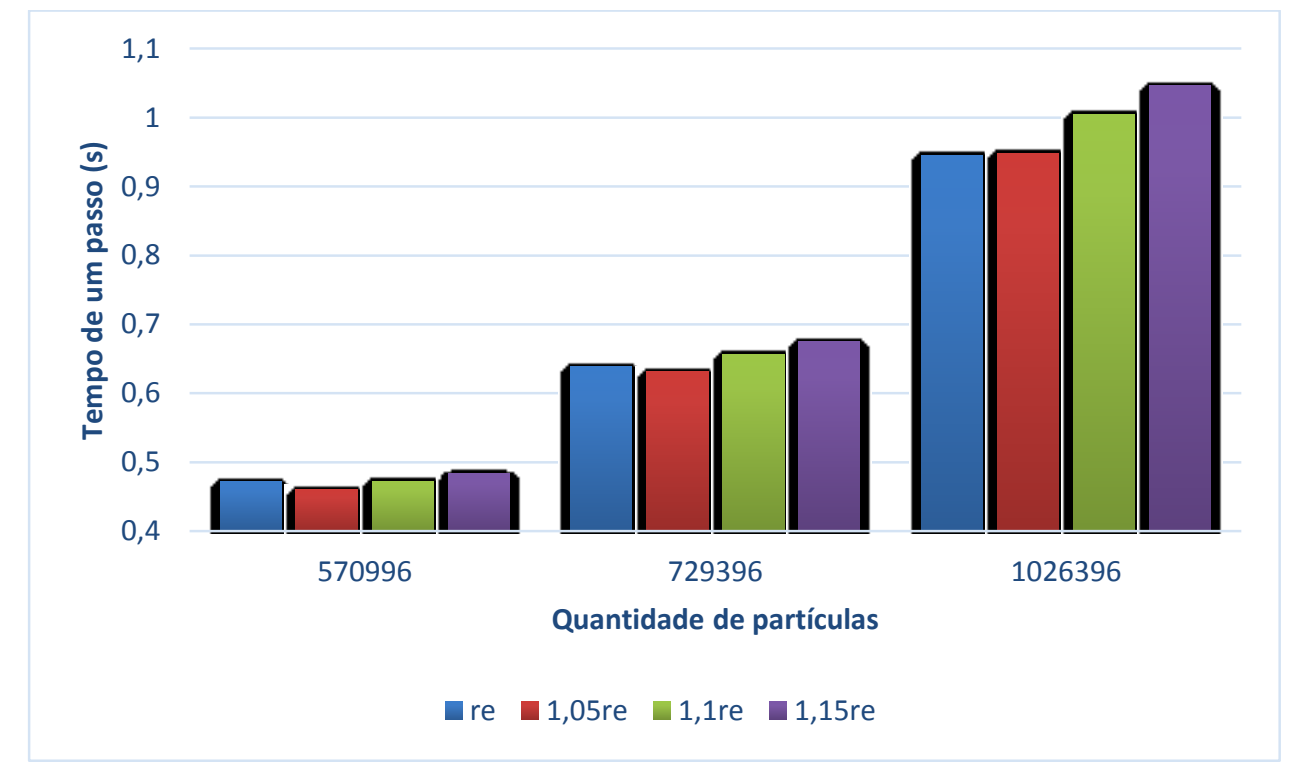

Figura 38 - Tempo de processamento em CUDA de um passo temporal, variando-se o tamanho das células.

A Figura 38 mostra o tempo de processamento em CUDA de um passo temporal para cada combinação de contagem de partículas e tamanho de células. 


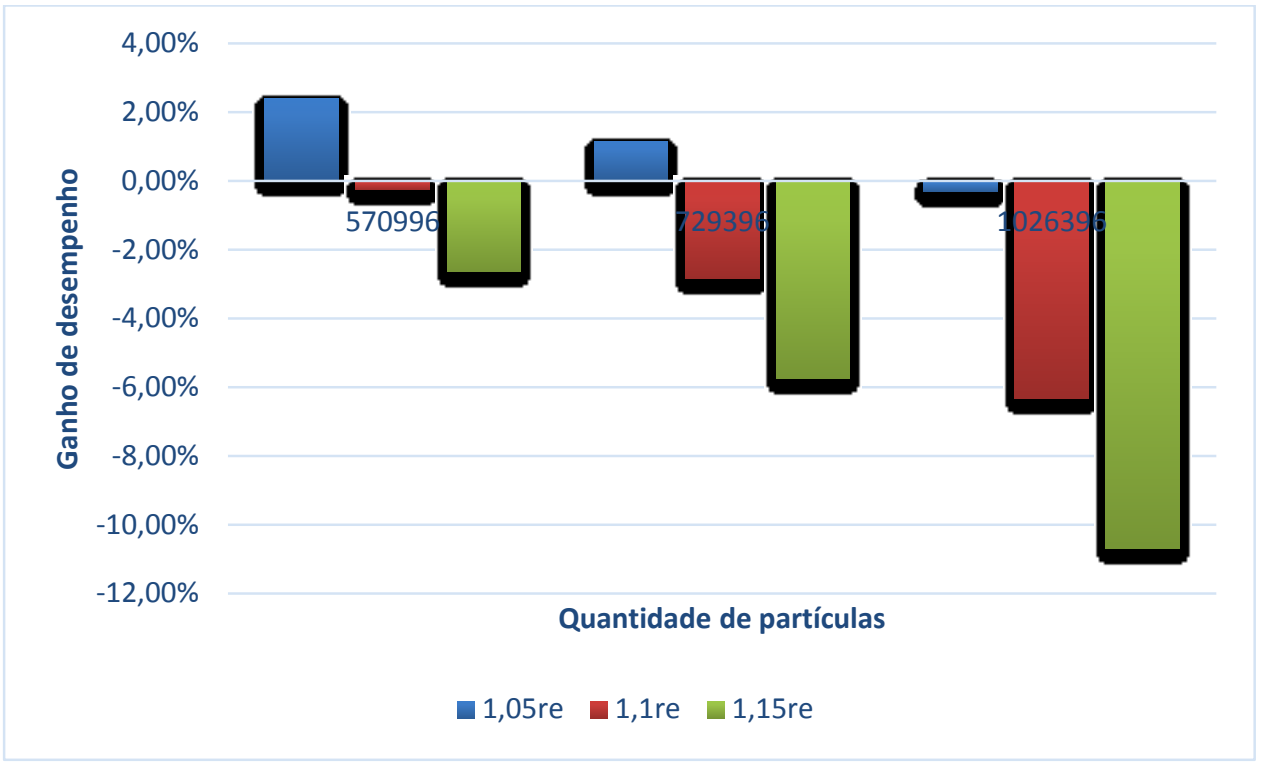

Figura 39 - Ganho de desempenho em CUDA com diferentes tamanhos de célula.

A Figura 39 mostra o ganho de desempenho alcançado para cada tamanho de célula, tomando-se como base o desempenho obtido quando $h=r_{e}$, para todos os três casos simulados. Nota-se que há perda desempenho para os casos em que $h>$ $1,05 r_{e}$, chegando a uma perda de $10 \%$ para o caso de 1 milhão de partículas com $h=$ $1,15 r_{e}$.

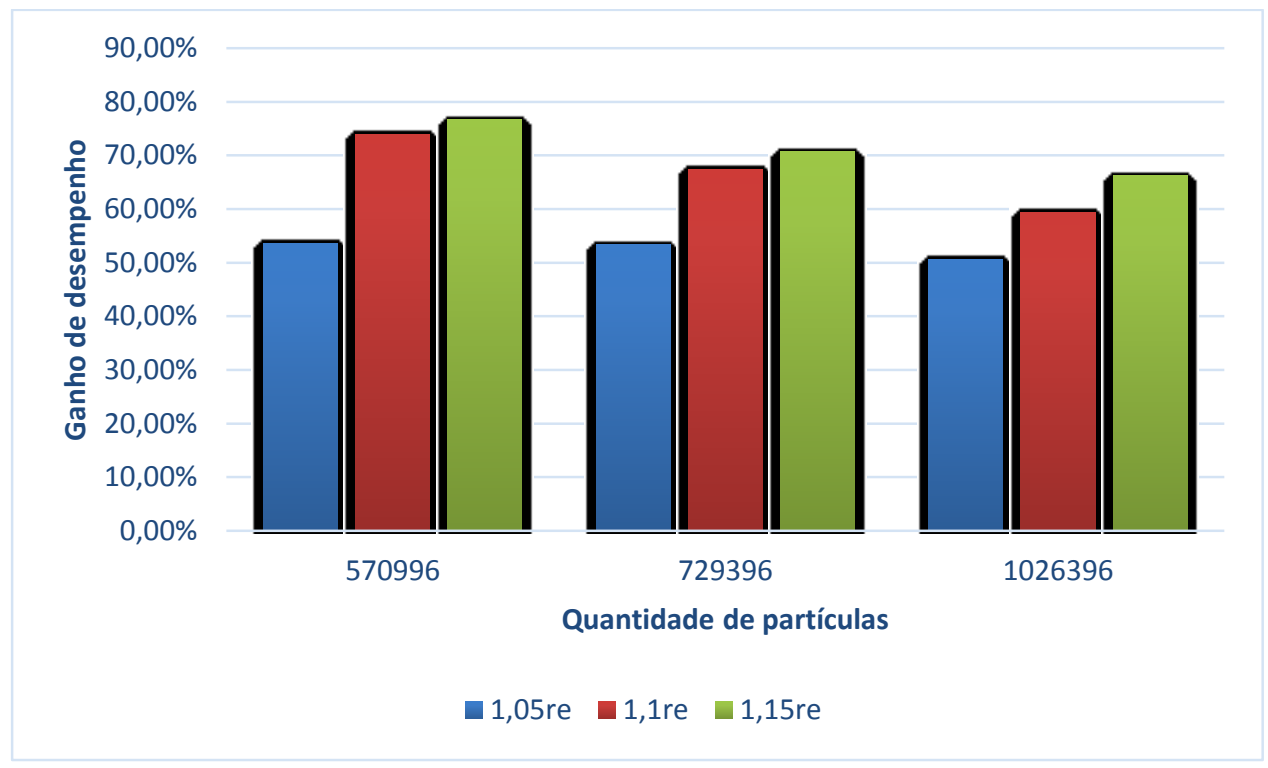

Figura 40 - Ganho de desempenho em CUDA na ordenação com diferentes tamanhos de célula. 


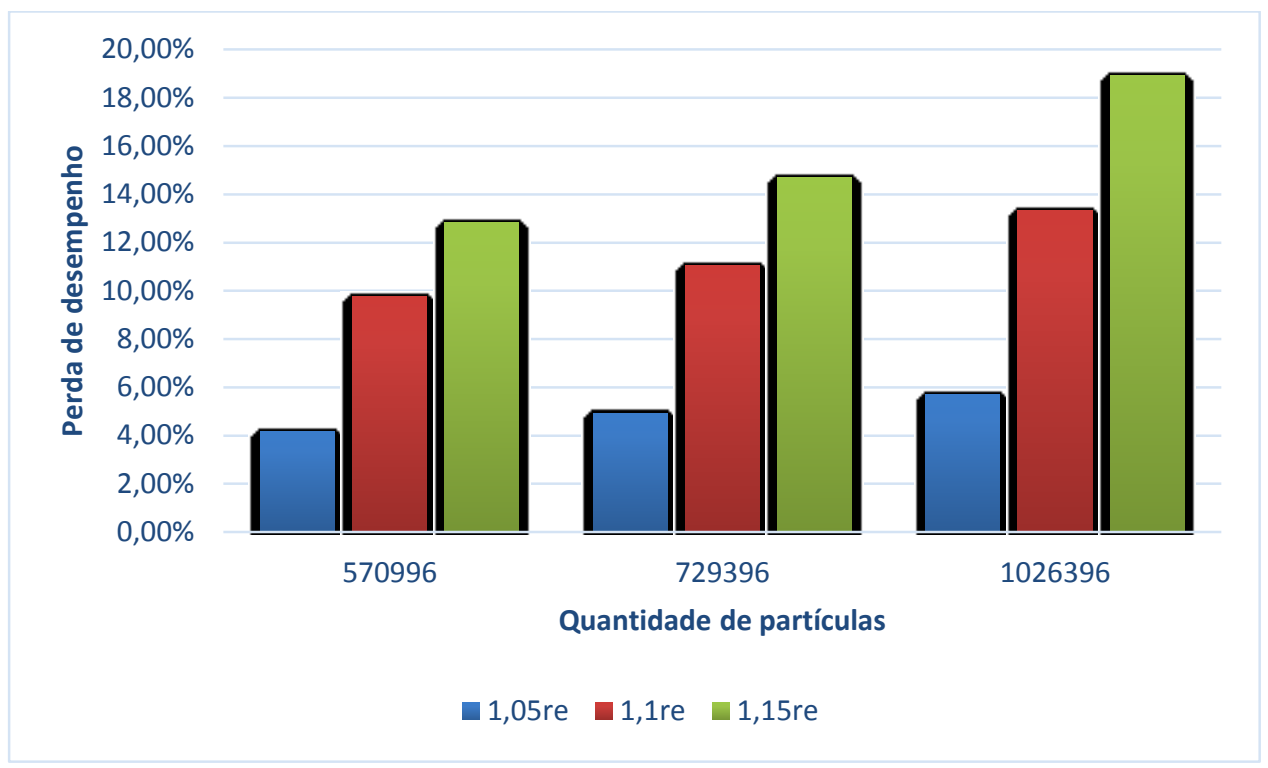

Figura 41 - Perda de desempenho em CUDA no cálculo das variáveis ponderadas pela função peso com diferentes tamanhos de célula.

A Figura 40 apresenta o ganho de desempenho na ordenação advindo da redução do número de vezes que ele é executado.

O aumento no tempo necessário para computar as variáveis ponderadas pela função peso (força de viscosidade, número densidade de partículas e gradiente de pressão) é mostrado na Figura 41.

Analisando esses dois gráficos, comprova-se que o ganho de desempenho na ordenação não é capaz de compensar as perdas nas variáveis ponderadas pela função peso, sendo estes últimos o atual gargalo de computação.

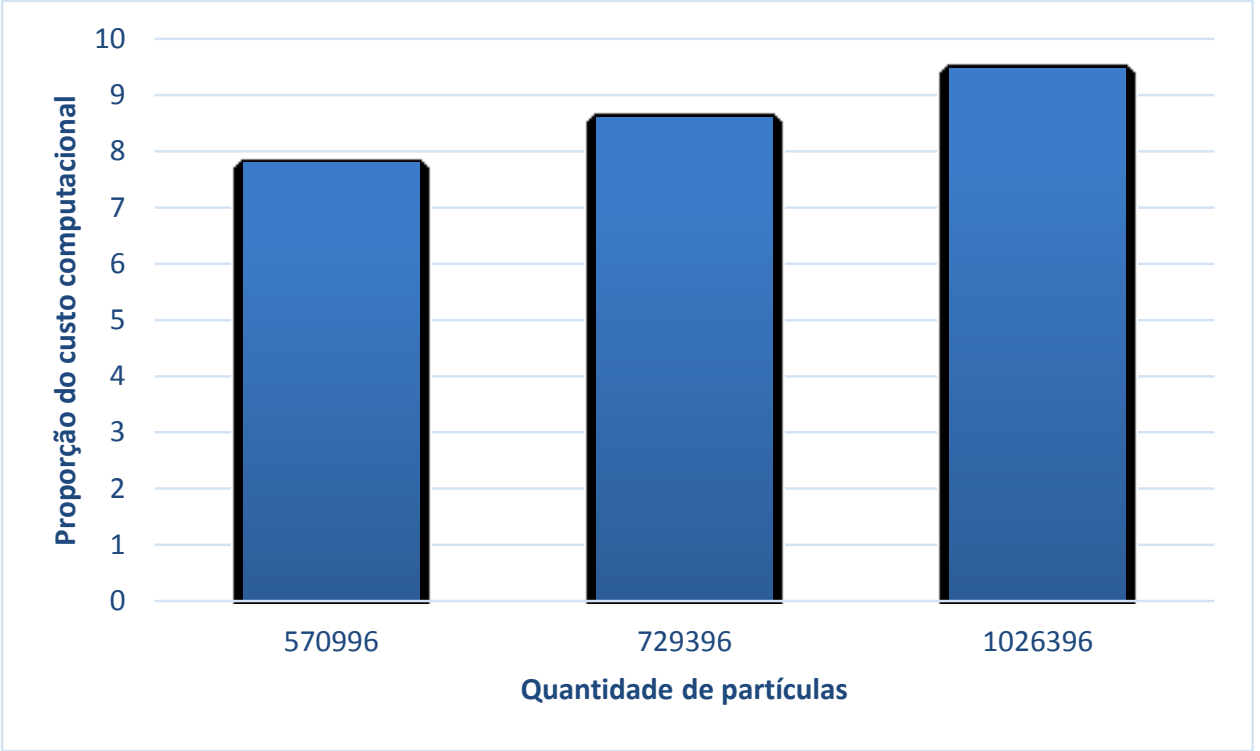

Figura 42 - Proporção entre os custos computacionais de ordenação e cálculo das variáveis ponderadas pela função peso para o caso CUDA. 
Como mostra a Figura 42, para o caso de processamento em GPU, o custo computacional do cálculo das variáveis ponderadas pela função peso é 7,8 a 9,5 vezes mais custoso do que a ordenação. Portanto, para o caso de 1 milhão de partículas e $h=1,1 r_{e}$ por exemplo, um ganho de $60 \%$ na ordenação não compensou uma perda de $13 \%$ no cálculo das variáveis ponderadas pela função peso.

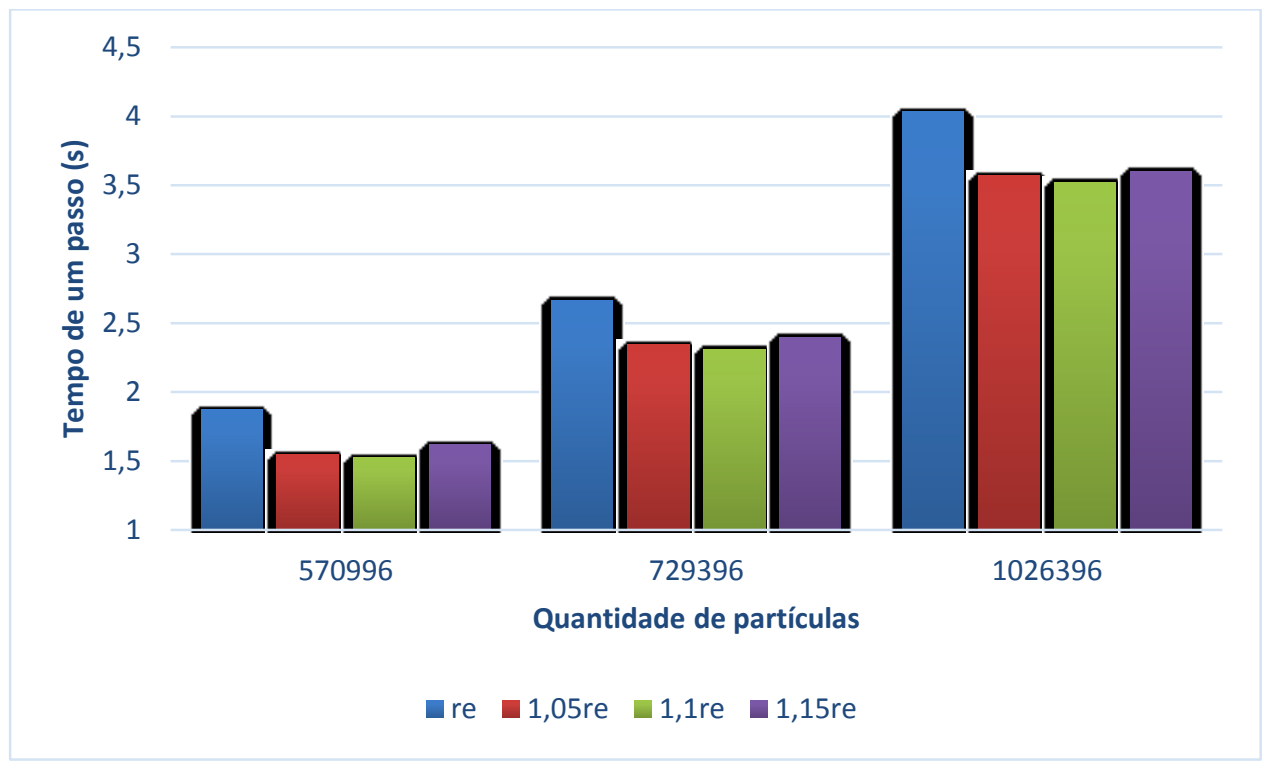

Figura 43 - Tempo de processamento em OpenMP de um passo temporal, variando-se o tamanho das células.

O tempo de processamento de um passo temporal utilizando-se processadores multicore via OpenMP é apresentado na Figura 43.

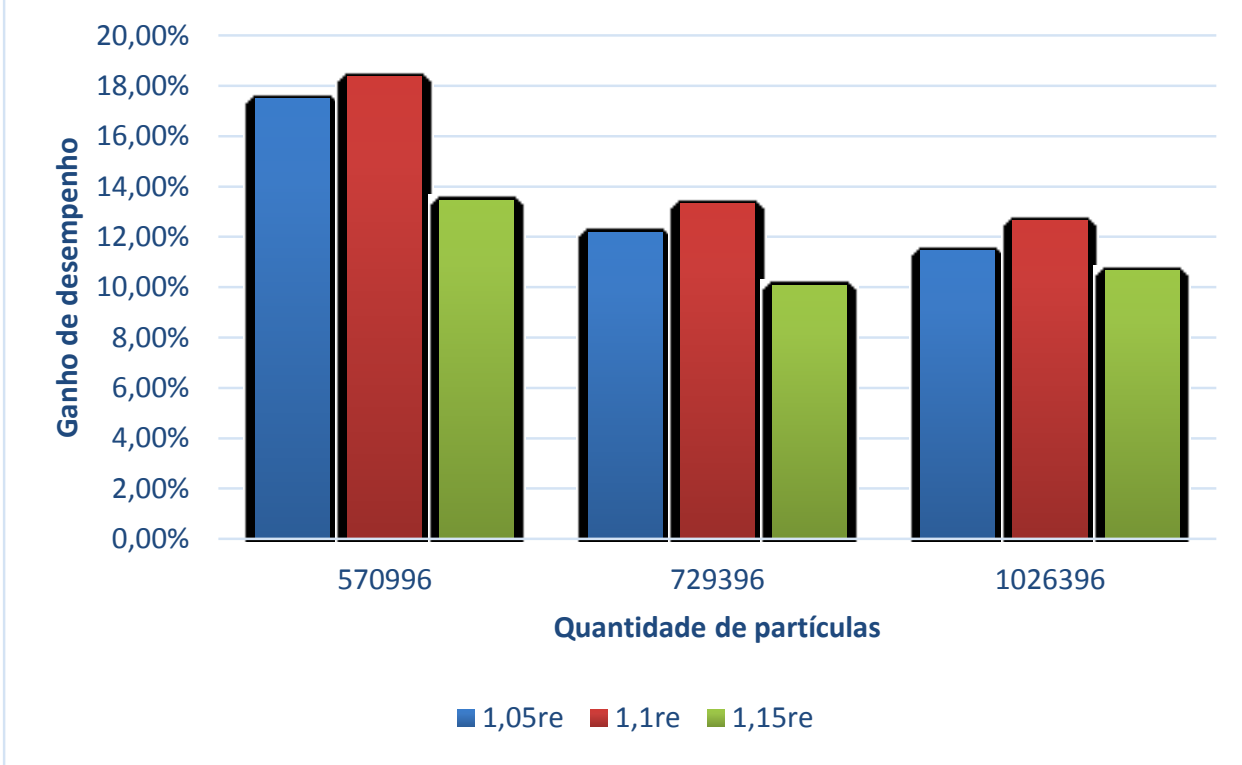

Figura 44 - Ganho de desempenho em OpenMP com diferentes tamanhos de célula. 


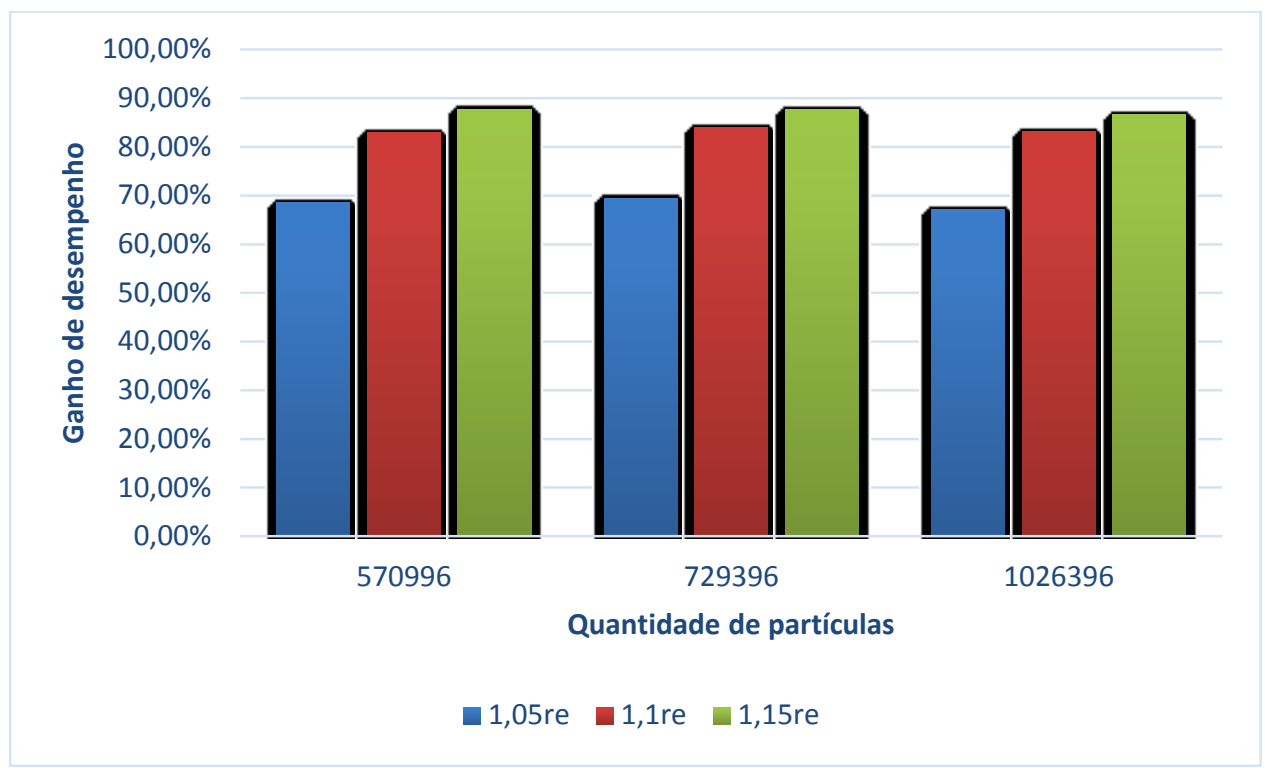

Figura 45 - Ganho de desempenho em OpenMP na ordenação com diferentes tamanhos de célula.

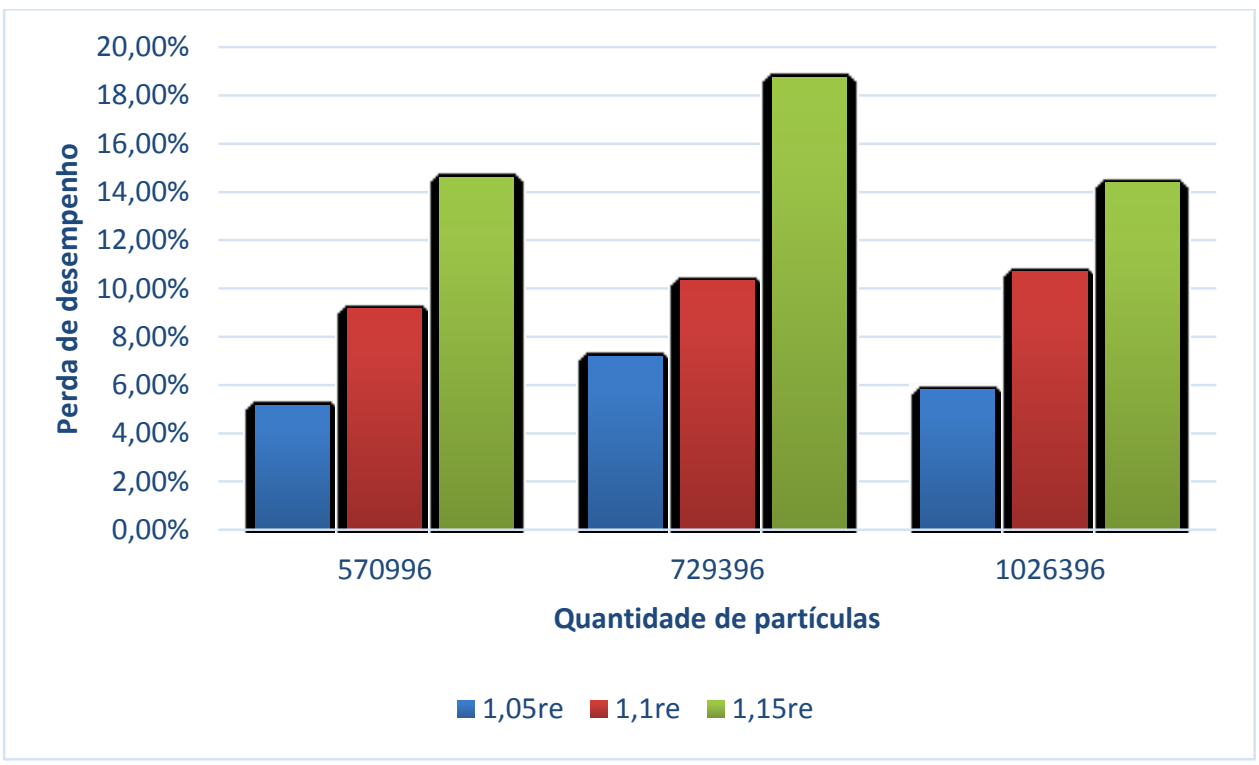

Figura 46 - Perda de desempenho em OpenMP no cálculo das variáveis ponderadas pela função peso com diferentes tamanhos de célula.

Nota-se que os tempos necessários para o processamento de um passo temporal são significativamente maiores se comparados aos resultados obtidos utilizando-se dispositivos GPU.

O ganho de desempenho absoluto e na ordenação para os casos OpenMP são apresentados nos gráficos das Figuras 44 e 45, sendo as porcentagens calculadas em relação ao caso em que $h=r_{e}$. Em todos os casos o melhor desempenho foi obtido com $h=1,1 r_{e}$, como evidenciado pela Figura 44, ponto em que o ganho com a 
ordenação e a perda no cálculo das variáveis ponderadas pela função peso tem a melhor relação que beneficia o desempenho absoluto.

A perda de desempenho em OpenMP no cálculo das variáveis ponderadas pela função peso é mostrada na Figura 46.

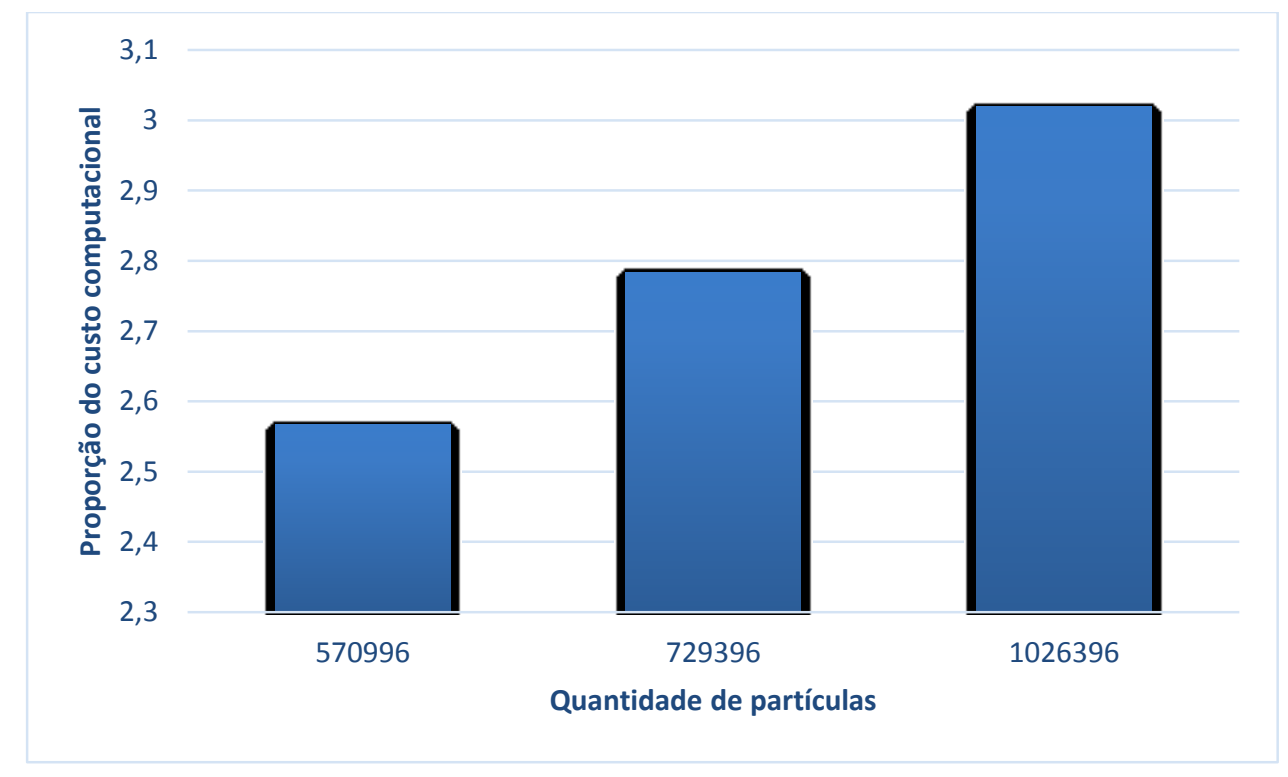

Figura 47 - Proporção entre os custos computacionais de ordenação e cálculo das variáveis ponderadas pela função peso para o caso OpenMP.

Diferentemente do processamento feito em dispositivo GPU, a computação em processadores multicore não apresenta muita diferença de custo computacional entre a ordenação e o cálculo das variáveis ponderadas pela função peso, como mostra a Figura 47. Por isso houve ganho de desempenho em relação ao caso em que $h=r_{e}$ em todos os casos simulados. 


\section{CONCLUSÃO}

O uso da decomposição de domínio espacial para possibilitar o processamento em memória distribuída, aliado ao uso de paralelismo em arquitetura de memória compartilhada para aceleração da computação do método E-MPS, se mostrou um método eficiente para se acelerar o processamento da simulação, podendo ser dezenas de vezes mais rápido do que um processamento serial.

A utilização de dispositivos GPU também se mostrou viável, sendo mais eficiente do que processadores multicore, embora encontre gargalos pelo intensivo uso de registradores devido à complexidade das operações que devem ser executadas por cada thread.

Para se diminuir essa complexidade a granularidade do paralelismo deve ser maior, passando a ser no nível dos pares de partículas interagentes, e não no nível das partículas. Isso, no entanto, consome uma quantidade consideravelmente maior de memória.

Assim como realizado no trabalho de Domínguez (DOMÍNGUEZ; CRESPO; GÓMEZ-GESTEIRA, 2013), possíveis otimizações para processamento em CPUs multicore devem ser investigadas, de modo que a discrepância de desempenho em relação aos dispositivos GPU seja reduzida.

O método de comunicação entre subdomínios proposto neste trabalho se mostrou eficiente, e garantiu uma boa escalabilidade ao se aumentar o número de processos. Ele também se mostrou genérico para aplicação em todos os método de decomposição investigados neste trabalho.

O método estático de decomposição de domínio, embora limitado a casos em que se tem um elevado nível de simetria geométrica durante toda a simulação, se mostra eficiente e escalável, tendo atualmente como gargalo o processamento das interações entre partículas do método MPS.

Tarefas de ordenação e comunicação não representam grande carga de processamento para os casos testados, podendo-se afirmar que o uso de dispositivos mais modernos teria grande impacto no desempenho do sistema.

O método ortogonal se mostrou atrativo pela simplicidade de implementação e pela capacidade de controlar o nível de desbalanceamento. 
Não se encontrou na literatura um método de decomposição de domínio espacial adaptativo que se adequasse totalmente às necessidades do método MPS, que não possua imposições geométricas que o inviabilize, e que seja flexível o suficiente para trabalhar com os deslocamentos das partículas. O padrão de consulta à região esférica do método MPS, que impõem a comunicação das partículas de interface entre subdomínios, motiva a criação de um método que seja capaz de tomar contramedidas de balanceamento de carga apenas pela interação por meio dessas interfaces, sem necessitar de passos adicionais de comunicação. O cell transfer é uma tentativa de criação de um método com essas características.

A variação do tamanho das células da grade impactou fortemente 0 desempenho computacional. Isso devido à redução no número de execuções da busca de vizinhos, e ao aumento do número de partículas vizinhas. Foi mostrado que quanto maior a carga computacional das variáveis ponderadas pela função peso em relação à busca de vizinhos, menor deve ser o incremento dado ao tamanho das células.

\subsection{CONTRIBUIÇÕES}

De modo geral, são poucos os trabalhos na literatura que utilizam métodos de partículas e apresentam os dois níveis de paralelismo existentes neste trabalho.

Baseando-se na revisão bibliográfica efetuada neste trabalho, o trabalho de (OVAYSI; PIRI, 2012) é o único que possui o mesmo nível de paralelismo para o método MPS. No entanto, ele emprega o método SI-MPS e não possui balanceamento dinâmico, pois seu campo de aplicação foca nos fluxos em meios porosos, sendo suficiente a utilização de uma decomposição estática.

O trabalho de Domínguez e Valdez-Balderas (DOMíNGUEZ et al., 2013; VALDEZ-BALDERAS et al., 2013), embora utilize o método SPH, se assemelha muito a este. Uma das grandes diferenças para o trabalho de Valdez-Balderas é o método de comunicação entre subdomínios, que não exige uma reordenação das partículas. No entanto, para se evitar uma do total de duas reordenações empregadas por Valdez-Balderas, deve-se comunicar dados adicionais. 
Considera-se que essa carga adicional de comunicação não signifique uma pior escalabilidade do método frente ao de Valdez-Balderas, visto que sua carga é proporcional ao número de células e comunicantes, e não à quantidade de partículas de interface. A comparação dos dois métodos é dificultada pelo fato de empregarem diferentes métodos de partículas, mas deve ser alvo de trabalhos futuros.

Outra diferença quanto ao método de comunicação, é que ele pode ser empregado para qualquer método de decomposição investigados neste trabalho, fato que não é deixado claro no trabalho de Valdez-Balderas, visto que apenas o método ortogonal é empregado.

A clara separação entre as partículas pertencentes ao subdomínio e aquelas recebidas dos subdomínios vizinhos é uma clara vantagem do método de comunicação apresentado neste trabalho, e não evidenciado nos outros trabalhos investigados.

Para o método ORB, adotou-se o algoritmo de Weiszfeld para cálculo da mediana que não é comumente utilizado na literatura, que evita o problema de sobrecarregar apenas um processo no decorrer das iterações como ocorre com os métodos mais tradicionais, além de ser bem adaptado à computação paralela.

Embora não tenha sido implementado neste trabalho, o método cell transfer é um método totalmente novo de decomposição, e caso confirme a sua eficácia ainda teórica, se tornará uma das grandes contribuições deste trabalho.

Por último, não se tem conhecimento, até o momento, de outro trabalho que tenha feito uma investigação quanto à escolha do tamanho das células com a mesma profundidade realizada neste trabalho.

\subsection{TRABALHOS FUTUROS}

Abaixo encontram-se relacionados sugestões de trabalhos para futuros desenvolvimentos:

1. Resolver as pendências em termos de metodologia do método cell transfer levantadas na subseção 4.1.7.

2. Implementar o método cell transfer e comparar o desempenho de balanceamento com os outros métodos. 
3. Investigar a viabilidade de se reduzir a granularidade do paralelismo em memória compartilhada, fazendo com que cada thread processe pares de partículas interagentes.

4. Testar outras funções de linearização dos índices da célula e verificar o seu impacto no desempenho computacional.

5. Estudar possíveis otimizações específicas para o caso de processamento em GPU, pela viabilização de se utilizar outros tipos de memória como a shared ou de textura.

6. Pesquisar métodos que garantam a consistência dos operadores diferenciais, como o LSMPS, e verificar os impactos no desempenho computacional.

7. Propor uma linguagem de programação para métodos de partículas. A partir dela poderia se descrever o método abstraindo-se o esquema de decomposição e o paralelismo. O C++ provê a capacidade de se definir Domain Specific Embedded Languages (DSEL) que se adequa muito bem a essa finalidade.

8. Melhorar a capacidade de pré-processamento dos métodos de partículas em geral. Isso possibilitaria a simulação de problemas com geometrias complexas, como hélices e cascos.

9. Comparar o método de comunicação entre subdomínios apresentado neste trabalho com o método apresentado por Valdez-Balderas (VALDEZBALDERAS et al., 2013). 


\section{REFERÊNCIAS}

ANDREA COLAGROSSI. A Meshless Lagrangian Method for Free - Surface and Interface Flows with Fragmentation. [s.l: s.n.].

BARNES, J.; HUT, P. A hierarchical O(N $\log N)$ force-calculation algorithm. Nature, v. 324, n. 6096, p. 446-449, 4 dez. 1986.

BELYTSCHKO, T. et al. On the completeness of meshfree particle methods. International Journal for Numerical Methods in Engineering, v. 43, n. 5, p. 785-819, 15 nov. 1998.

COLE, R. H. Underwater explosions. [s.I.] Princeton Univ. Press, 1948. p. 437

CRESPO, A. C. et al. GPUs, a new tool of acceleration in CFD: efficiency and reliability on smoothed particle hydrodynamics methods. PloS one, v. 6, n. 6, p. e20685, jan. 2011.

DOMÍNGUEZ, J. M. et al. New multi-GPU implementation for smoothed particle hydrodynamics on heterogeneous clusters. Computer Physics Communications, v. 184, n. 8, p. 1848-1860, ago. 2013.

DOMÍNGUEZ, J. M.; CRESPO, A. J. C.; GÓMEZ-GESTEIRA, M. Optimization strategies for CPU and GPU implementations of a smoothed particle hydrodynamics method. Computer Physics Communications, v. 184, n. 3, p. 617-627, mar. 2013.

DOMÍNGUEZ, J. M.; CRESPO, A. J. C.; MARONGIU, J. C. Neighbour lists in smoothed particle hydrodynamics. n. November 2010, p. 2026-2042, 2011.

FERRARI, A. et al. A new 3D parallel SPH scheme for free surface flows. Computers \& Fluids, v. 38, n. 6, p. 1203-1217, 2009.

FLOYD, R. W.; RIVEST, R. L. Expected time bounds for selection. Communications of the ACM, v. 18, n. 3, p. 165-172, 1 mar. 1975.

GAO, X. et al. Accelerate Smoothed Particle Hydrodynamics using GPU. 2010 IEEE Youth Conference on Information, Computing and Telecommunications. Anais...IEEE, nov. 2010

GINGOLD, R. A.; MONAGHAN, J. J. Smoothed particle hydrodynamics-theory and application to non-spherical stars. Monthly Notices of the Royal Astronomical Society, v. 181, n. 2, p. 375-389, 1977.

GOMEZ, M. Compressed Axis-Aligned Bounding Box Trees. In: Game Programming: Gems 2. [s.l.] Cengage Learning, 2001. p. 388-393.

GOTOH, H. et al. 3D-CMPS METHOD FOR IMPROVEMENT OF WATER SURFACE TRACKING IN BREAKING WAVES. [s.I.] World Scientific Publishing Co. Pte. Ltd., 2009. p. 1-11 
HARADA, T.; KOSHIZUKA, S.; KAWAGUCHI, Y. Smoothed particle hydrodynamics on GPUs. Proceedings of Computer Graphics International. Anais...2007

HARLOW, F. H. The Particle-in-Cell Computing Method for Fluid Dynamics. Methods in Computational Physics, v. 3, 1964.

HOFMANN, M.; RUNGER, G. A Partitioning Algorithm for Parallel Sorting on Distributed Memory Systems. 2011 IEEE International Conference on High Performance Computing and Communications, p. 402-411, set. 2011.

HORI, C. et al. GPU-acceleration for Moving Particle Semi-Implicit method. Computers \& Fluids, v. 51, n. 1, p. 174-183, dez. 2011.

ISSHIKI, H. Discrete differential operators on irregular nodes (DDIN). International Journal for Numerical Methods in Engineering, v. 88, n. 12, p. 1323-1343, 23 dez. 2011.

KONDO, M. et al. Surface Tension Model Using Inter-Particle Force in Particle Method. ASME/JSME 2007 5th Joint Fluids Engineering Conference. Anais...ASME, 2007

KONDO, M.; KOSHIZUKA, S. Improvement of stability in moving particle semi-implicit method. International Journal for Numerical Methods in Fluids, v. 65, n. 6, p. 638-654, 28 fev. 2011.

KOSHIZUKA, S.; OKA, Y. Moving-particle semi-implicit method for fragmentation of incompressible fluid. Nuclear science and engineering, v. 123, n. 3, p. 421-434, 1996.

LE GRAND, S. Broad-phase collision detection with CUDA. In: GPU Gems 3. [s.I: s.n.]. p. 697721.

LIU, G. R.; LIU, M. B. Smoothed Particle Hydrodynamics: A Meshfree Particle Method. [s.I.] World Scientific Publishing Company, 2003. p. 449

LUCY, L. B. A numerical approach to the testing of the fission hypothesis. The Astronomical Journal, v. 82, n. 12, p. 1013, dez. 1977.

MONAGHAN, J. Simulating Free Surface Flows with SPH. Journal of Computational Physics, v. 110, n. 2, p. 399-406, 1994.

MONAGHAN, J. J. SPH without a Tensile Instability. Journal of Computational Physics, v. 159, n. 2, p. 290-311, abr. 2000.

MOUSSA, B. BEN. ON THE CONVERGENCE OF SPH METHOD FOR SCALAR CONSERVATION LAWS WITH BOUNDARY CONDITIONS. Methods and Applications of Analysis, v. 13, n. 1, p. 29-62, 2006.

MOUSSA, B. BEN; VILA, J. P. Convergence of SPH Method for Scalar Nonlinear Conservation Laws. SIAM Journal on Numerical Analysis, v. 37, n. 3, p. 863-887, 2000. 
OOCHI, M.; KOSHIZUKA, S.; SAKAI, M. Explicit MPS Algorithm for Free Surface Flow Analysis. Transactions of JSCES. Anais...Fukuoka: JSCES, 2010

OVAYSI, S.; PIRI, M. Multi-GPU acceleration of direct pore-scale modeling of fluid flow in natural porous media. Computer Physics Communications, p. 1-9, abr. 2012.

RAJASEKARAN, S.; CHEN, W.; YOOSEPH, S. Unifying Themes for Selection on Any Network. Journal of Parallel and Distributed Computing, v. 46, n. 1, p. 105-111, out. 1997.

RUSTICO, E. et al. Smoothed Particle Hydrodynamics Simulations on Multi-GPU Systems. 2012 20th Euromicro International Conference on Parallel, Distributed and Network-based Processing. Anais...IEEE, fev. 2012

SEAL, S.; ALURU, S. Spatial Domain Decomposition Methods for Parallel Scientific Computing. In: RAJASEKARAN, S.; REIF, J. (Eds.). Handbook of Parallel Computing: Models, Algorithms and Applications. Boca Raton: Chapman and Hall/CRC, 2007. p. 44-1-44-27.

SHAKIBAEINIA, A.; JIN, Y. A weakly compressible MPS method for modeling of openboundary free-surface flow. Online, n. August 2009, p. 1208-1232, 2010.

SHAKIBAEINIA, A.; JIN, Y.-C. A weakly compressible MPS method for modeling of openboundary free-surface flow. International Journal for Numerical Methods in Fluids, p. n/an/a, 2009.

TANAKA, M.; MASUNAGA, T. Stabilization and smoothing of pressure in MPS method by Quasi-Compressibility. Journal of Computational Physics, v. 229, n. 11, p. 4279-4290, jun. 2010.

TANIGUCHI, D.; SATO, L. M.; CHENG, L. Y. EXPLICIT MOVING PARTICLE SIMULATION METHOD ON GPU CLUSTERS. 10th World Congress on Computational Mechanics. Anais...São Paulo: 2012

VALDEZ-BALDERAS, D. et al. Towards accelerating smoothed particle hydrodynamics simulations for free-surface flows on multi-GPU clusters. Journal of Parallel and Distributed Computing, v. 73, n. 11, p. 1483-1493, nov. 2013.

YAMADA, Y. et al. Numerical Simulation of Three-Dimensional Free-Surface Flows with Explicit Moving Particle Simulation Method. Transactions of the Atomic Energy Society of Japan, v. 10, n. 3, p. 185-193, 2011.

ZHU, X. et al. Implementation of the moving particle semi-implicit method on GPU. Science China Physics, Mechanics and Astronomy, v. 54, n. 3, p. 523-532, 22 jan. 2011. 


\section{APÊNDICE A - EXEMPLO DE UM ARQUIVO DE DESCRIÇÃO DE CASO (DAM BREAK BIDIMENSIONAL)}

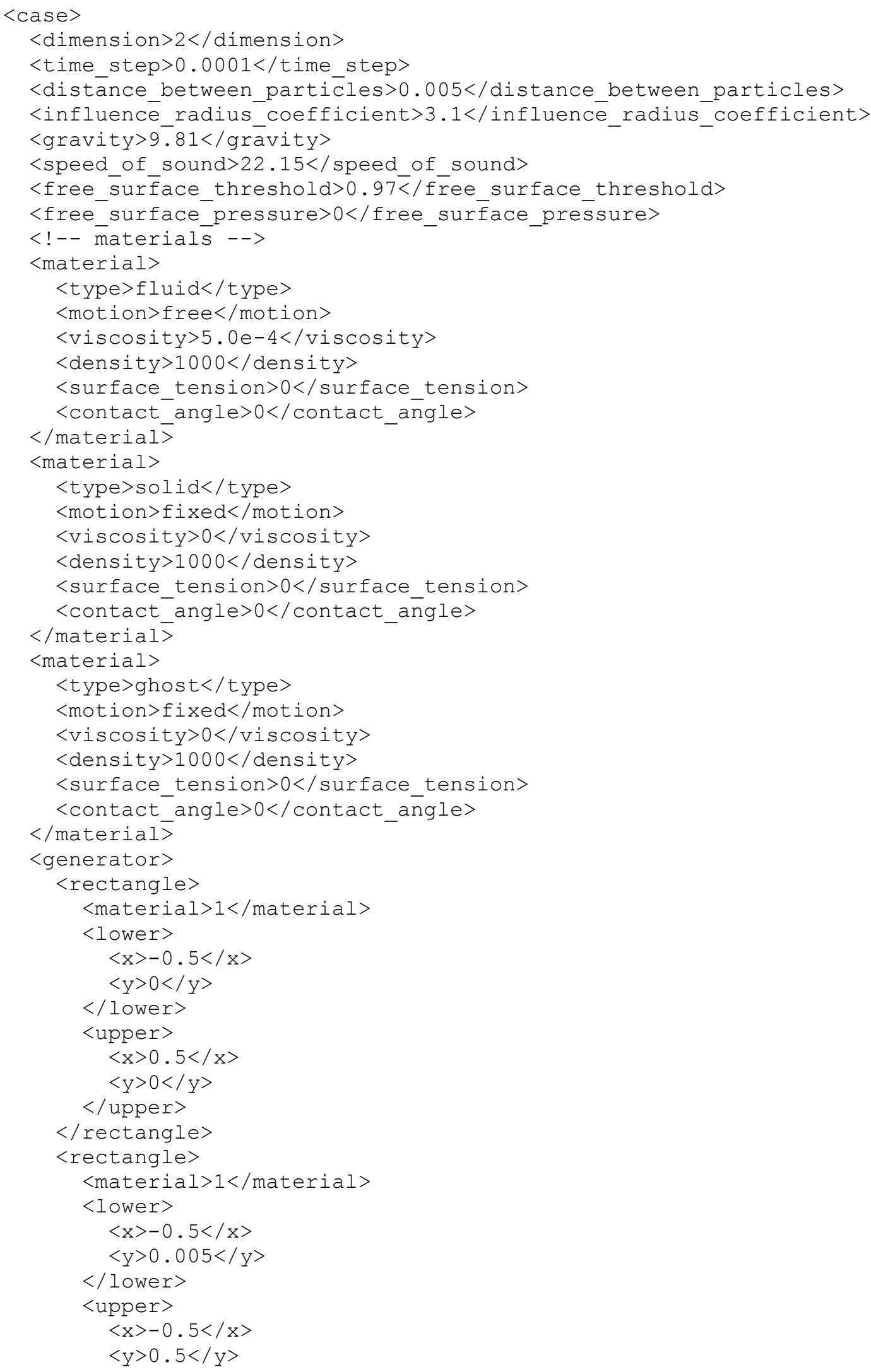




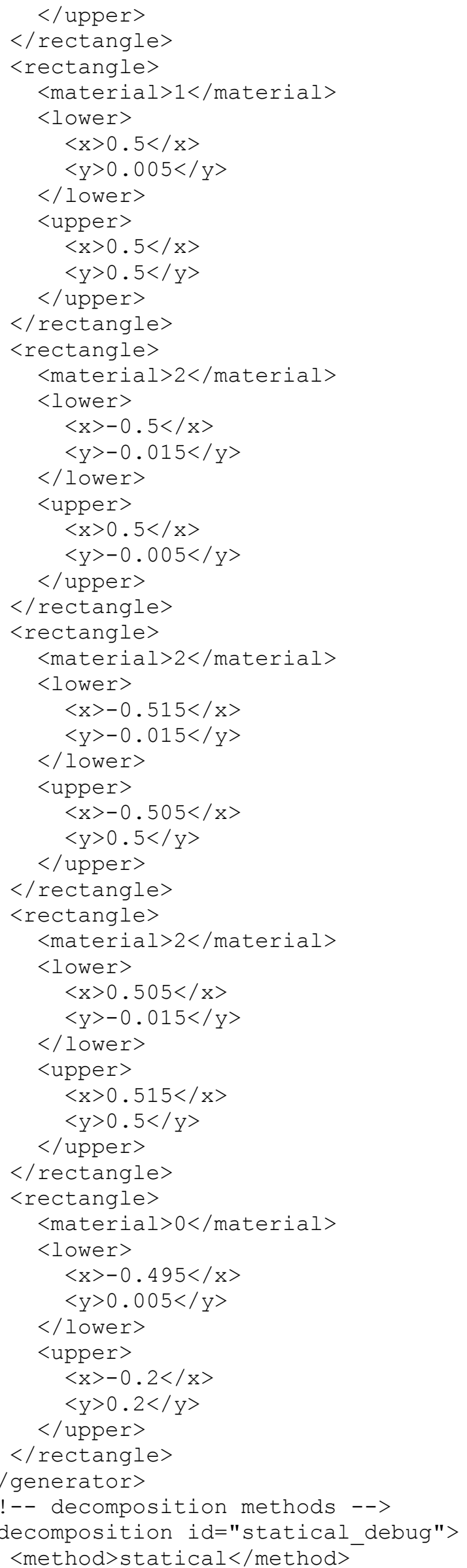




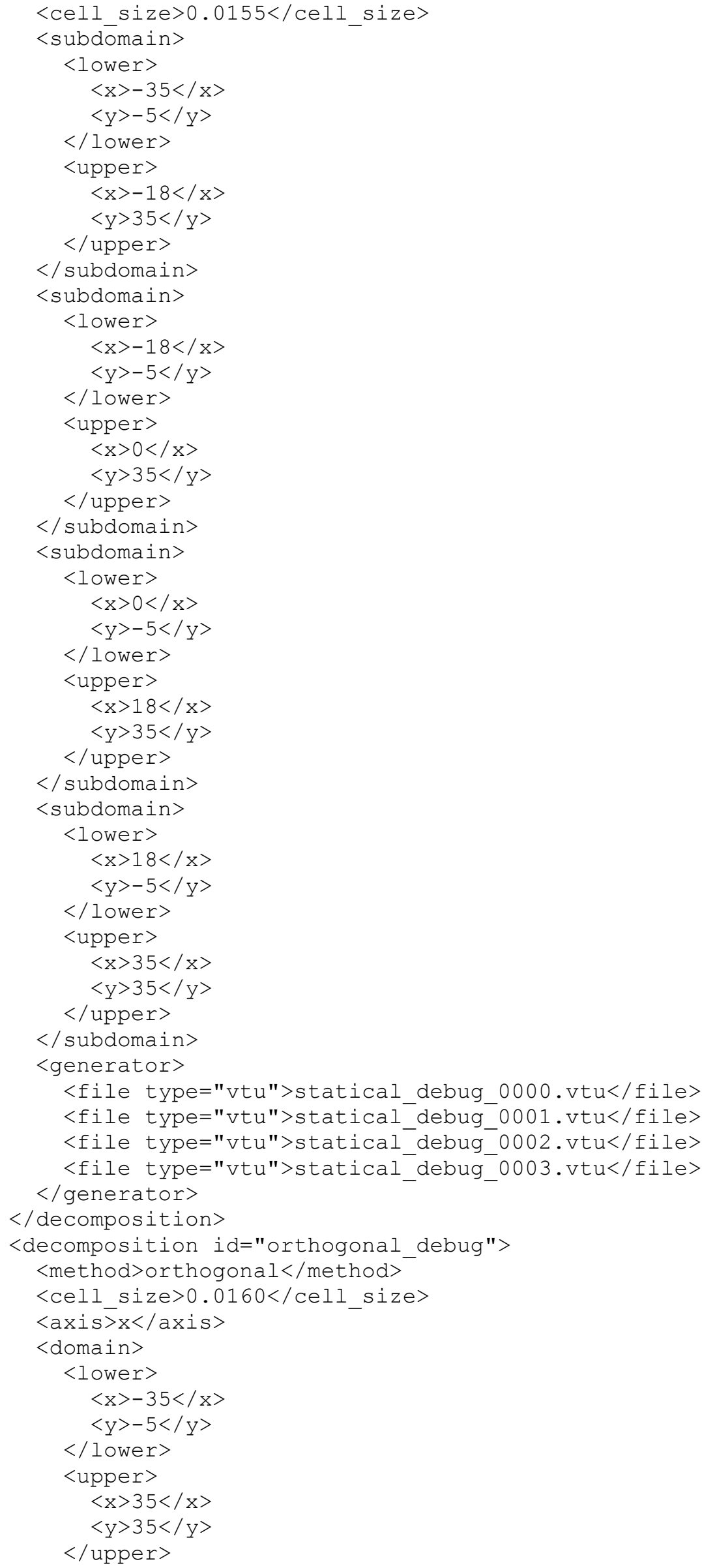




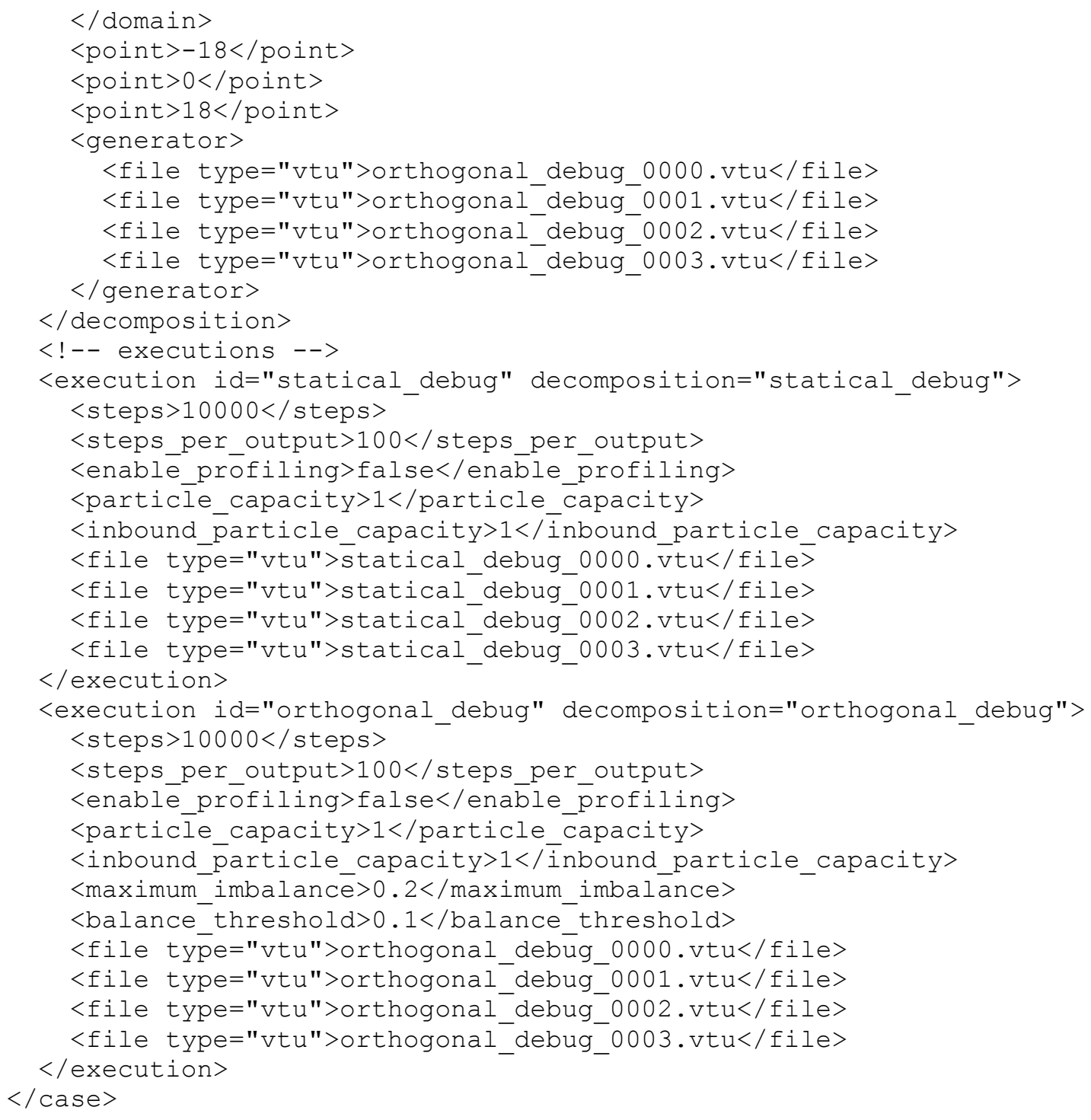




\section{APÊNDICE B - GEOMETRIA DOS CASOS PARA AVERIGUAÇÃO DO IMPACTO DO TAMANHO DAS CÉLULAS}

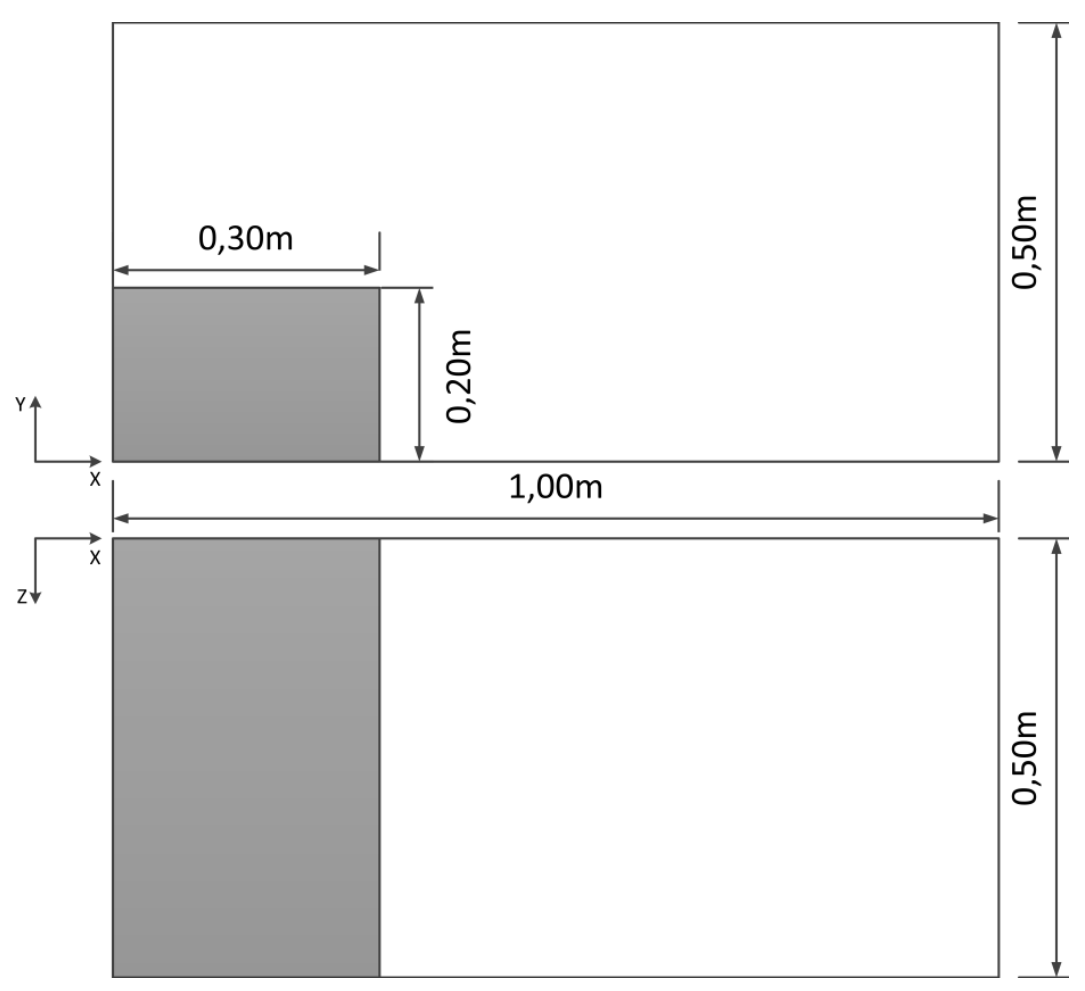

Figura 48 - Geometria do caso com 500 mil partículas.

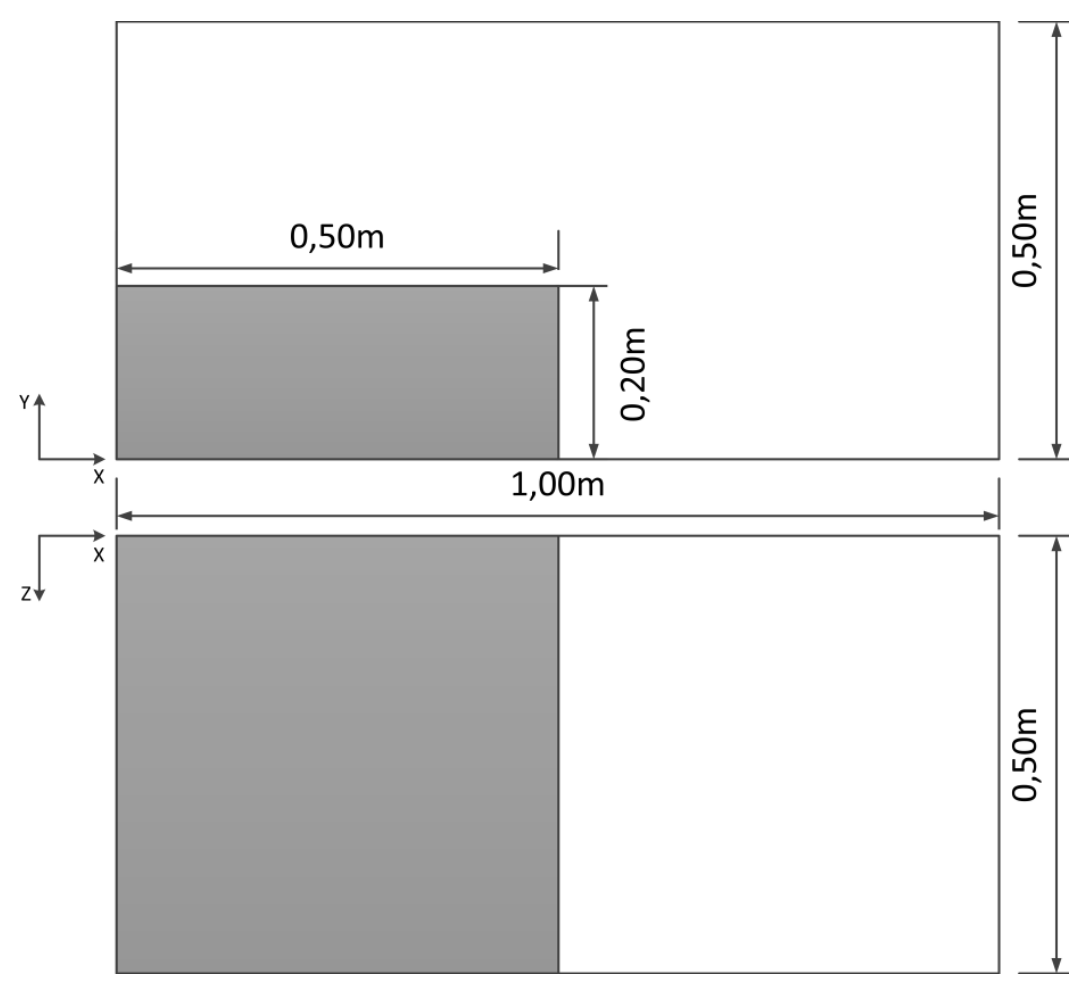

Figura 49 - Geometria do caso com 700 mil partículas. 


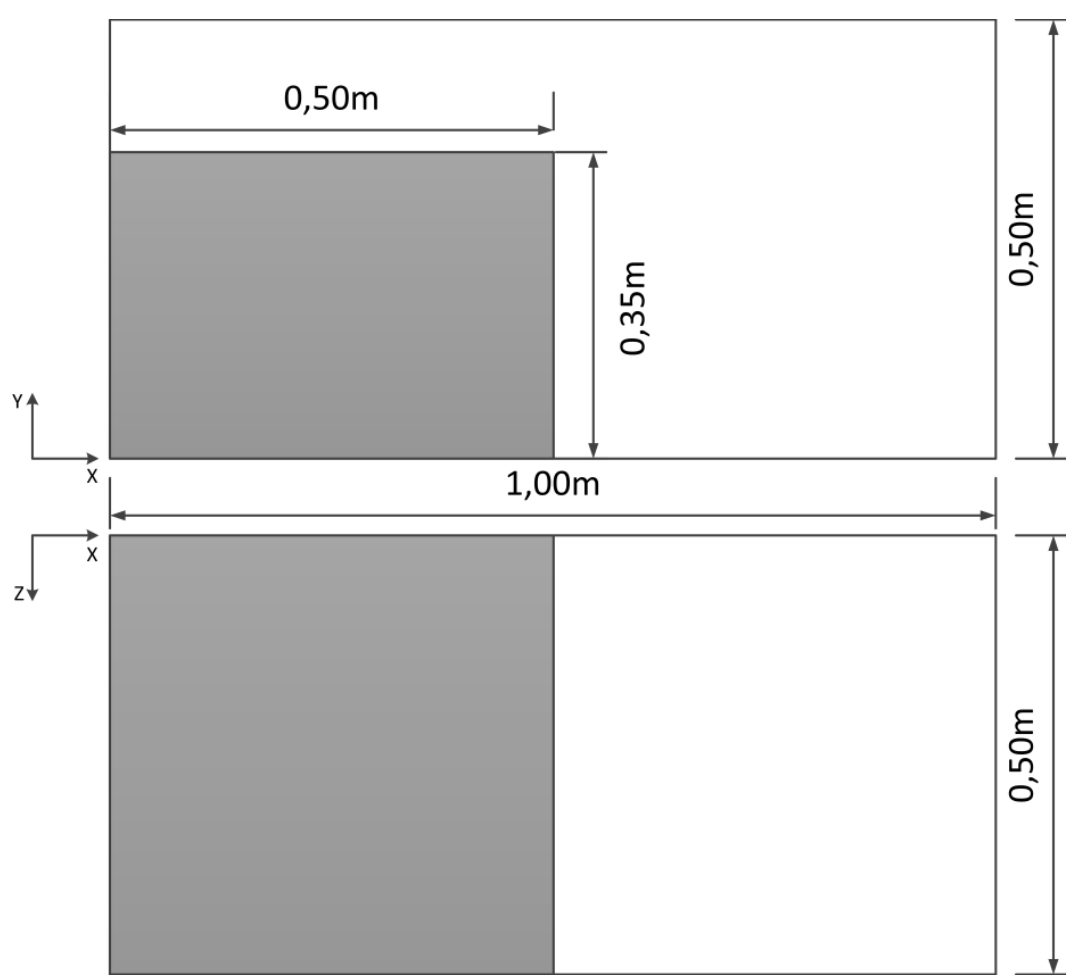

Figura 50 - Geometria do caso com 1 milhão de partículas. 